\title{
Anticipating Corporate Takeovers and the Method of Payment: A Variance-Covariance Non-Stationarity Approach
}

\author{
Mohammad Irani ${ }^{1}$ \\ First version: September 08, 2013 \\ This version: April 3, 2014
}

\begin{abstract}
The previous literature mainly assumes that the mergers and acquisitions (M\&As) and their payment-forms are unpredictable prior to the first bid announcement day. Using a sample of 125 completed acquisitions between U.S. public firms from 2003 to 2006, I find that a bid offer is anticipated on average 187 trading days before the announcement day in $86 \%$ of deals. The market also anticipates the payment-form in $62 \%$ of deals. It takes on average three months for the market to pinpoint the most likely payment-form of the anticipated deals. Moreover, the announcement of Cash (Mixed and Equity) offers contains the least (most) unexpected information for the market. This paper introduces an empirical time series solution to identify the anticipation dates, i.e. non-stationarity in the variance-covariance structure of the joint target and acquirer daily return series. I hypothesize that the variancecovariance of the joint price process can shift during the pre-announcement period in response to anticipating a potential M\&A deal and its payment-form. The empirical identification of the proposed solution is also investigated by testing for existence of similar anticipation shifts in a benchmark sample, i.e., a random sample of non-M\&A firms. Similar shifts occur much less frequent in the benchmark sample compared to the M\&A sample, indicating that the likely mechanism for observing those shifts is the M\&A and paymentform anticipations.
\end{abstract}

Key words: Mergers and Acquisitions; method of payment; forecasting; change points; variance; covariance; correlation; merger arbitrage

JEL codes: G14 - G17- G34

\footnotetext{
${ }^{1}$ The author is a PhD candidate in Finance at Stockholm Business School, Stockholm University, SE-106 91 Stockholm, E-mail: mir@sbs.su.se, http://www.sbs.su.se/en/About-us/Contact-us/PhD-Candidates/Mohammad-Irani/ I would like to thank Lars Nordén, Rickard Sandberg, Martin Holmén, Johan Stennek, Joakim Westerlund, Mariassunta Giannetti, Catalin Starica, and Chris Adcock for comments and discussions. I also thank seminar discussants and participants at: the second National PhD Workshop in Finance (Stockholm, 2013), the 3rd PhD Conference (Stockholm University, 2014), and the 63rd Annual Meeting of Midwest Finance Association (Orlando, 2014).
} 


\section{Introduction}

It is well documented that the target shareholders gain large abnormal returns while returns to the acquiring firms are negligible in the mergers and acquisitions (M\&As). ${ }^{2}$ Schwert (1996), for example, finds that the cumulative average abnormal returns (CAARs) to the target shareholders starts to run up 42 trading days before the first public bid announcement day. This result indicates that the market anticipates the target firms during the pre-announcement period. The CAARs to the acquiring firms, on the other hand, is not trending in this period, indicating that they are unpredictable. ${ }^{3}$ Since the mean of acquirer return series is rather stable, extending the analysis to the joint return distribution for the target and acquirer firms might reveal relevant information for predicting the pair of merging firms. I postulate that both the target and acquirer firms can be anticipated by studying the behavior of the second-order moments of the joint return distribution around the announcement day.

If the market can anticipate both the acquirer and target firms, expectations can be formed about characteristics of potential takeover transactions, and the method of payment in particular. The M\&A literature suggests that abnormal returns to both target and acquirer shareholders of Cash-financed offers generally exceed those of Equity- or Mixed-financed deals around the bid announcement (e.g., Travlos, 1987 and Schwert, 1996). ${ }^{4}$ The differential returns between the target and acquirer shareholders and across the payment-forms motivate the anticipation of both takeover transactions and the method of payment in practice. Empirical studies on this subject are, however, sparse. The extant studies provide mainly partial and cross-sectional predictions. ${ }^{5}$ The partial prediction denotes that these studies focus only on one of the pair-firms at a time (i.e. either the target or acquirer firm) and neglect the additional information may contain in the joint return distribution. The cross-sectional prediction overlooks the time dimension of data. This time series variations can be used to distinguish anticipated from unanticipated deals and to pinpoint the anticipation dates. Thus, there is a significant gap in the literature that this paper is designed to fill. This paper, hence, investigates whether the market can anticipate the M\&As and their method of payment.

This paper introduces an empirical time series solution to identify the deal and payment-form anticipation dates, i.e. non-stationarity in the variance-covariance structure (henceforward, VCS) of the joint target and acquirer daily return series. When the market anticipates a potential deal for the first time during the pre-announcement period, the likelihood of merging increases significantly. The market also expects simultaneously the synergy value of this merger and its division between the shareholders. The merging likelihood, the expected synergy and its division can shift the price process of target, acquirer or both firms, and so the VCS of the joint return distribution. While those parameters are generally unobservable, shifts in the second-order moments can be estimated. Shifts in the variance of either target or acquirer return series might suggest reactions to some firm-

\footnotetext{
${ }^{2}$ Jensen and Ruback (1983) and Martynova and Renneboog (2008) review many M\&A studies and report similar returns to the target and acquirer shareholders.

${ }^{3}$ Similarly, Smith and Kim (1994) find for their sample that CAARs of target firms is accruing starting 60 days before the announcement day; however, the returns to the acquiring firms do not deviate from zero in this period. Comparable CAARs are also found for the target and acquirer firms in the sample of this paper.

${ }^{4}$ There are various competing hypotheses (e.g., asymmetric information, tax considerations and managerial control, among others) that justify why acquirers' managers choose different payment methods to finance takeover transactions. See, for instance, Eckbo, Giammarino, and Heinkel (1990) and Martin (1996), Ismail and Krause (2010) and references therein.

${ }^{5}$ For example, the binary discrimination literature examines investors' prediction of acquirer and target merger candidacy and of medium of payment via a cross-sectional approach. See, e.g., Amihud, Lev, and Travlos (1990), Hasbrouck (1985), Martin (1996), among others.
} 
specific (non-M\&A) news but those in the VCS can indicate responses to the pair-firms related information (e.g., M\&A). Every shift in the VCS during the pre-announcement period, however, cannot be associated with the takeover anticipations. Restrictions are imposed on the sign of those shifts to disentangle consistent from inconsistent shifts for the takeover anticipations. The hypothesized sign of consistent shifts for Deal- and PaymentForm-anticipation dates are mainly from the merger arbitrage literature. A break date in the pre-announcement period is interpreted as the anticipation date if shifts in those moments are consistent with those hypothesized signs. Furthermore, there might be non-M\&A mechanisms that causes those consistent shifts in the M\&A sample. The empirical identification strategy for the proposed solution is thus investigated by testing existence of similar consistent shifts in a benchmark sample (i.e., a random sample of non-M\&A firms).

Moreover, the proposed solution extends the merger arbitrage literature. First, this literature usually compares the cross-sectional average pre- and post-announcement secondorder-moments by assuming the announcement day as the only break date. To the best of my knowledge, Jayaraman, Mandelker, and Shastri (1991) is the only study that documents predictability of the target firms by assuming three uniform break dates in their implied volatility during the pre-announcement period. This solution, however, relaxes any assumptions about the number and location of break dates in those moments. Second, the behavior of the acquirer-target return correlation in Cash and Mixed subsamples and the covariance has not been studied yet. This paper documents the behavior of these moments around the announcement of Cash, Equity and Mixed offers.

Using a sample of 125 completed acquisitions of U.S. public companies between 2003 and 2006 and the VCS of targets and acquirer return series, this paper finds that that a bid offer is anticipated on average 187 trading days before the announcement day in $86 \%$ of deals. The market anticipates the payment-form in $62 \%$ of deals on average 123 trading days before the announcement day. Both of these results provide further insights into how early those anticipations are formed. This early anticipation is in contrast to the usual assumption in event studies in which any anticipation effects can be captured by a short interval (i.e., a few days) prior to the announcement day. The market anticipates the Cash offers almost at the same date as their deal-anticipation dates. However, there is a lag of 90 trading days on average between deal- and payment-form-anticipation dates in Equity and Mixed offers. Studying the behavior of second-order moments reveals that the announcement of Cash (Equity and Mixed) offers contains the least (most) unexpected information for the market investors. The lowest portion of anticipated Mixed offers indicates that the market is less successful in anticipating the Mixed bids. Furthermore, the consistent shifts occur much less frequent in the benchmark sample compared to the M\&A sample, indicating that the likely mechanism is the anticipation of takeover transactions.

The rest of paper is organized as follows: Section 2 reviews the merger arbitrage literature to identify consistent shifts in the second-order moments for the takeover anticipations. Section 3 presents the methodology and the anticipation hypotheses. Section 4 provides data and descriptive statistics. Section 5 and 6 documents the anticipation results for the individual and average bivariate return series. Section 7 discusses robustness checks and finally Section 8 concludes.

\section{Consistent Shifts in the Second-Order Moments}

\subsection{Target Volatility}

Bhagat, Brickley, and Loewenstein (1987) figure out an anomaly in the relation between risk and return in the target's stocks during the post-announcement period. That 
anomaly cannot be explained with the standard Capital Asset Pricing Model (e.g., Sharpe, 1964). In particular, they report significant declines in both beta and sample unconditional volatility of target of Cash bids in the post-announcement period while the returns are rising. Consistent with synergy theory in the takeover transactions, Bhagat et al. (1987) propose that the price of a target share during the post-announcement period is the sum of the value of common stock and the value of put option. The target shareholders have options to sell their shares to acquirer firm in the post-announcement period. They then show via option theory that a portfolio of a stock and a put option has a lower standard deviation than for the stock itself. This conjecture explains the observed decline in the target volatility.

Hutson and Kearney (2001 and 2005) extend the analysis of risk-return relation to the targets of other payment subsamples and to the completed and failed offers. They document that regardless of the payment-form and the final outcome of the pending bid-offer, conditional volatility of target shares decline significantly in the post announcement period. The greatest (smallest) decline is in Cash (Equity) subsample. The drop in the conditional volatility of completed bids is larger than that of failed offers. This suggests that the merger arbitrage market can anticipate which pending offer will be finally consummated via using the target's volatility. Hutson and Kearney (2001) claim that this observation is due to a fundamental change in the price formation process, i.e. trader opinions about the value of target stock converges during the post-announcement period.

Overall, the decline in the target volatility regardless of payment-form and the offer outcome indicates increase in the likelihood of being target of an acquisition. A significant decline in the target volatility during the pre-announcement period is hence interpreted in this paper as the indicator of anticipating the target firm.

\subsection{Acquirer Volatility}

Various competing hypotheses have been developed about the post-acquisition (i.e., long-run) risk profile of the acquirers. First, "portfolio effect" predicts that the risk of the acquiring firm in the post-acquisition period is nothing more than the risk of a market value weighted portfolio formed from the shares of two firms in the pre-announcement period (e.g., Langetieg, Haugen, and Wichern, 1980). Since the cash flows of pair-firms are imperfectly correlated in the pre-announcement period, the portfolio diversification hypothesis suggests a decline in the risk of acquirer after acquisition. Second, "leverage effect" predicts acquisitions that worsen the leverage (debt-to-equity ratios) of acquirer firm induce an increase in risk of the consolidated firm (Hamada, 1972). Third, "integration risk" predicts a raise in the risk of consolidated firm if the acquirer management is inefficient in merging the pair-firms into a single corporation in the post-acquisition period (Bharath and $\mathrm{Wu}, 2006$ ). Fourth, "merger wave effect" predicts to observe inter-industry acquisitions in response to industry shocks faced by firms within that industry (Mitchell and Mulherin, 1996, and Harford, 2005). Since completed inter-industry acquisitions have stabilizing effects, this hypothesis predicts a decline in the risk of those consolidated firms in the post-acquisition period. Finally, "synergy effect" predicts a decline in the risk of acquiring firm in the postacquisition period since the takeover synergistic gains increase the value of consolidated firm. Synergistic gains are considered as one of the main motives for corporate acquisitions. Bradley Desai, and Kim (1988) argue that the acquirer can redeploy the combined assets of both firms in such a way that enhance its value in the post-acquisition period. Moreover, strategic management studies consider product market motives to expect synergistic gains to the acquirer firms (see, e.g., Chatterjee and Lubatkin, 1990, and reference therein). For example, cost reductions due to the economics of scale, the economics of scope, more diverse corporate skills and enhanced market power, among others. 
Given the opposing predictions, the net impact of acquisitions on the risk of acquirer firm is an empirical question. The empirical findings are indeed mixed. For example, Langetieg et al. (1980) show an increase in the various unconditional risk measures (i.e., total, systematic, and idiosyncratic risks) of the acquirer in the post-acquisition period. They conclude that an aggressive management together with an increase in the leverage can explain this exacerbated risk. Geppert and Kamerschen (2008) study the implied volatility of the acquirer firms, i.e. compare its pre- to post-announcement values. They find a statistically greater implied volatility than the value predicted by the portfolio hypothesis in the postannouncement period. Geppert and Kamerschen argue that the integration risk and uncertainty about potential efficiency gains make the acquirer firms more risky after the bid announcements. However, after controlling the systematic risk of target firms, Chatterjee and M. Lubatkin (1990) find that acquirers' systematic risk decline both in short and long horizons after the acquisitions. They argue that the takeover acquisitions generate synergistic value and can hence reduce systematic risk. Hutson and Kearney (2005) find that the average unconditional volatility of the acquiring firms declines significantly after the bid announcement. However, when they distinguish by payment subsamples, the reduction is only significant for the acquirers of Cash offers.

Declining shifts are more consistent with the proposed anticipation mechanism. When the market anticipates the bid in the pre-announcement period, it expects synergistic gains to the consolidated firm. Accordingly, the synergy hypothesis predicts a decline in the acquirer risk. A decline in the acquirer risk during the pre-announcement period suggests that the diversification and the synergy effects dominate any leverage and integration impacts.

Overall, those opposing hypotheses and mixed evidence predict changes in the acquirer risk in different directions. Thus, any significant shift in the acquirer's variance in the preannouncement period in this paper is interpreted as the indicator of anticipating the acquirer firm.

\subsection{Acquirer-Target Return Correlation}

Ismail and Krause (2010) and Bhagwat and Dam (2012) find that the preannouncement correlation is one of the significant cross-sectional predictors of the method of payment in M\&As. Ismail and Krause (2010) report a positive relation between the fraction of acquirer's equity in the bid payment and the correlation. Bhagwat et al. (2012) propose that the risk of over-payment is reduced by an Equity offer if the acquirer and target returns are highly correlated but that risk increases with a weak correlation.

These results suggest that the shifts in the correlations can be used to anticipate the method of payment in M\&As. To the best of my knowledge, only Subramanian (2004) analyses the effect of merger announcements on the correlations. He constructs a theoretical model and provides empirical evidence in which the announcement of Equity offers cause the correlations shifts towards perfect correlation. Subramanian (2004) argues that if the market investors assign a high likelihood for the success of a merger attempt, the two stock price processes must be perfectly correlated after the bid announcement. The reason is that the acquirer offers a constant equity-exchange ratio to acquire each share of the target firm in Equity bids. Moreover, if the market investors assign a high chance for the success of a Cash offer, the volatility of Cash targets should drop significantly after the bid announcement. The stock price process of the target shares is almost a constant in this case due to the offered bid premium. Thus, if the likelihood of merging is high, the return processes will be uncorrelated after the Cash bid announcement. The portion of cash in a mixed payment determines whether the correlations should shift towards zero or one. If the cash portion is the dominant payment-form in a Mixed offer, the above argument predicts that the correlations should 
converge to zero after the bid announcement. Otherwise, acquirer-target return process should be shifted towards the perfect correlation.

Overall, anticipating payment-form during the pre-announcement period should shift the correlations toward its hypothesized level (i.e. perfect correlation in Equity offers and zero correlation in Cash offers).

\subsection{Acquirer-Target Return Covariance}

Both the covariance and the correlation measure the degree of co-variation between the target and acquirer returns. However, standardization via individual volatilities in the correlation can discard useful variations necessary for anticipating the payment-form. Put differently, while the correlation is stable, the covariance can shift in response to the market's anticipation of the payment-form. This suggests that the changes in the covariance complement the changes in the correlation for detecting the payment-form anticipation dates.

Since the acquirer-target return process converges to perfect (zero) correlation in Equity (Cash) offers, it is hypothesized that if the market anticipates Equity (Cash) offers, the covariance should increase (converge to zero) in the pre-announcement period. The hypothesized direction for the covariance of a Mixed offer depends on the portion of cash offered in the payment form. If cash portion is dominant, then the market anticipates if the covariance converges to zero. Otherwise, it should increase.

On the one hand, existence of any consistent breaks in the covariance or correlation after the bid announcement can be interpreted as the increased likelihood of success of those pending bid offers. On the other hand, their consistent shifts during the pre-announcement period can lead to conclude that market anticipates both the bid-offer and its payment-form.

\section{Methodology and Anticipation Hypotheses}

To investigate whether a Deal and its Payment-form is anticipated or not, first, each return series is prepared before applying the structural break test. Second, if that test detects break(s) in the variance-covariance structure of a bivariate return series, the significance of shifts in its second-order moments are examined individually around each break date. Finally, inference about existence of the anticipation dates is made based on the sign of the significant shifts.

\subsection{Data Preparation}

Daily log returns (henceforth, the returns) of acquirer and target stocks are used in all tests of this paper and computed in the following way:

$r_{i, n, t}=\ln \left(\frac{P_{i, n, t}}{P_{i, n, t-1}}\right)$

Where $i=A c q, \operatorname{Trg} ; n$ is the index for deals in the sample; $t(=-379, \ldots, 0,1, \ldots, \mathrm{C})$ is the daily subscript; $r_{A c q, n, t}$ and $r_{T r g, n, t}$ represent the realized returns to acquirer and target shareholders involved in deal $n$ at day $t$; and $P_{A c q, n, t}$ and $P_{T r g, n, t}$ is their adjusted closing prices at day $t$. Similar to Schwert (1996), the sample observation period for each of target and acquirer daily return series starts -379 days prior to the first public bid announcement day $(\mathrm{t}=$ 
0 ) and ends at the delisting date of the target shares, which is $C$ days after the announcement date. ${ }^{6}$ The pre (post)-announcement period is from Day-379 (Day 0) to Day-1 (Day C).

The largest absolute daily-log-returns of each acquirer and target return series are identified and winsorized at $99 \%$. The mean of return series should be stable during the whole observation period in order to identify breaks in its second-order moments. The structural breaks methodology developed by Bai and Perron (1998, 2003 and 2006) is thus used to detect shifts in the mean of each return series. The return series are then adjusted for the detected shifts. See Data Preparation in the Appendix for further details about adjustments of outliers and the structural breaks. All tests used in this paper assume the sample mean of each return series is zero. The following transformation is therefore applied to each target and acquirer return series: $\tilde{r}_{i, n, t}=r_{i, n, t}-\bar{r}_{i, n}$,

Where $\bar{r}_{i, n}=\frac{1}{(380+C)} \sum_{t=-379}^{T=C} r_{i, n, t}$ is the sample mean of the observed return series and $\tilde{r}_{i, n, t}$ is the mean-adjusted return series.

\subsection{Detecting Breaks in the Variance-Covariance Structure of the Bivariate Return Series}

I use a cumulative sum (CUSUM) type test proposed by Aue, Hörmann, Horváth, and Reimherr (2009). This test is suitable in this paper since it does not impose any normality or parametric assumptions, which are usually assumed in the parametric and cross-sectional models. This test is a non-parametric test since it only uses the realized returns, i.e. $\tilde{r}_{i, n, t}$, in modeling the second-order moments and in computing the test statistic. However, it requires the finiteness of the fourth sample moment of the multivariate series. The $99 \%$ winsorization is thus necessary and used to fulfill the existence of fourth-order moment condition.

Financial time series are generally characterized by conditional heteroskedasticity patterns of unknown form. The appealing feature of CUSUM-type tests is their ability to use a non-parametric HAC type estimator to capture the dependence structure in the data. As recommended by Aue et al. (2009), the Bartlett estimator is used as a proxy for the asymptotic covariance matrix in the testing procedure. ${ }^{7}$

Since shifts in the VCS of the bivariate return series can occur in the both of pre- and post-announcement periods, the multiple break detection version of Aue et al. (2009) test is applied in this paper. The binary segmentation approach tests for existence of multiple breaks. When the test detects a significant break date, it is reapplied separately across the two segments, which is obtained from splitting the data into two subsamples around that break date. This binary segmentation procedure is ended whenever the test could not detect any significant breaks in the new segments.

The identity subscript of deals is excluded from notations for simplicity but the following procedure is applied for each deal in the sample. Let $\left(y_{t}\right)$ be a sequence of twodimensional random return vectors with $\mathrm{E}\left[y_{t}\right]=0 .\left(y_{-379}, \ldots, y_{0}, \ldots, y_{C}\right)$ is the bivariate return

\footnotetext{
${ }^{6}$ The binary discrimination regressions usually use predictors from the last year to discriminate merging from non-merging firms. This can also support starting the sample observation period one and a half year before the announcement day.

${ }^{7}$ Moreover, Berkes, Horváth, Kokoszka, and Shao (2005) show that the Bartlett estimator is a consistent estimator of the asymptotic covariance matrix since it converges almost surely. The data-dependent approach of Newey and West (1994) is also applied to determine an optimal truncation lag in the Bartlett estimator. Rodrigues and Rubia (2007) show that this truncation lag can improve the finite-sample performance of the CUSUM-type tests.
} 
vectors over the sample observation period of a deal. For example,

$y_{-379}=\left(\begin{array}{l}\tilde{r}_{T r g,-379} \\ \tilde{r}_{A c q,-379}\end{array}\right)$

is the bivariate vector of mean-adjusted realized returns for the target and acquirer shareholders at Day-379.

$\operatorname{Cov}\left(y_{-379}\right)=\left(\begin{array}{ll}\sigma_{T r g,-379}^{2} & \\ \sigma_{T r g-A c q,-379} & \sigma_{A c q,-379}^{2}\end{array}\right)=\left(\begin{array}{ll}\tilde{r}_{T r g,-379}^{2} & \\ \tilde{r}_{T r g,-379} \tilde{r}_{A c q,-379} & \tilde{r}_{A c q,-379}^{2}\end{array}\right)$

is the realized variance-covariance matrix of the bivariate returns at Day-379. The $\tilde{\Omega}_{n}$ test statistic of Aue et al. (2009, page 4050) is used to detect structural breaks in the VCS of the bivariate return process $\left(y_{t}\right)$ by examining the following hypothesis:

$$
\begin{aligned}
& \mathrm{H}_{0}: \operatorname{Cov}\left(y_{-379}\right)=\cdots=\operatorname{Cov}\left(y_{C}\right) \\
& \mathrm{H}_{A}: \operatorname{Cov}\left(y_{-379}\right)=\cdots \operatorname{Cov}\left(y_{k_{1}}\right) \neq \operatorname{Cov}\left(y_{k_{1}+1}\right)=\cdots=\operatorname{Cov}\left(y_{k_{2}}\right) \neq \cdots \neq \operatorname{Cov}\left(y_{k_{m}+1}\right)=\cdots=\operatorname{Cov}\left(y_{C}\right),
\end{aligned}
$$

Where $m$ is the unknown number of change-points in the VCS of the bivariate return series and $-379<k_{1}<\cdots<k_{m}<C$ are unknown positions of the change-points in the sample observation period. The test itself identifies the number of breaks (i.e. $m$ ) and their locations $\left(k_{1}\right.$ to $\left.k_{m}\right)$ in each bivariate return series. I do not impose any restrictions on the number and location of breaks of each bivariate series to capture all informational events during its sample observation period. Detecting multiple breaks is also likely; however, the binary segmentation approach usually ends at the third round, indicating that up to seven breaks can be detected in a given bivariate series.

\subsection{Tests for Equality of Second-Order Moments around the Estimated Break Dates}

Since Aue et al. (2009) test is a joint test, it does not identify which of those secondorder moments changes significantly after each break date in the VCS. One may expect that all or the majority of those second-order moments shifts after each break date but there is a positive chance that shift only in one moment drives shift(s) in the VCS. Moreover, there might be instances that none of the moments change significantly but there is a break in the VCS. Identifying the size and sign of significant changes in those moments is also necessary to examine the deal and payment-form anticipation hypotheses. Since the sample secondorder moments are locally stationary at each segment, the sample moments can be estimates for the population moments across the detected segments. Tests for equality of the sample second-order moment are then performed to identify which moments shift significantly after each break date. Suppose, e.g., that Aue et al. test finds only a break in the VCS of a bivariate return series at time lag $k_{1}$. The target variance in the pre- and post-break segment is:

$$
\begin{aligned}
& \sigma_{T r g, p r e}^{2}=\frac{1}{\left(379-k_{1}\right)} \sum_{t=-379}^{T=k_{1}}\left(\tilde{r}_{T r g, t}^{2}\right) \\
& \sigma_{T r g, p o s t}^{2}=\frac{1}{\left(C-k_{1}\right)} \sum_{t=k_{1}+1}^{T=C}\left(\tilde{r}_{T r g, t}^{2}\right)
\end{aligned}
$$


Other sample second-order moments (i.e., acquirer variance, the covariance and correlation) in the pre- and post-break segment are computed in the similar way.

The cross-sectional mean test is usually used in the merger arbitrage studies to compare the average of two sample distributions (e.g., pre- vs. post-announcement target volatility) to infer whether their distributions are significantly different from each other. However, this test might generate questionable results: first, if there are some extreme outliers, second, if both increasing and declining changes are equally likely. In the latter case averaging can cancel out useful variations and makes the inference invalid. The median test can resolve some of the above problems but it also compares only one point across two sample distributions. A proper test should therefore consider each cross-section to provide information how the whole distribution across two samples is different. Then one can document not only the portion of total cross-sections at which the change is significant but also distinguish declining from increasing changes. Therefore, in addition to the mean and median test, this paper considers the cross-sectional tests by applying the equality tests that examine pre- vs. postannouncement moments (and pre- vs. post-break segment) across each return series.

The modified version of Levene (1960) test, proposed by Brown and Forsythe (1974), is used in this paper to test whether the sample variances is homogenous across two subsequent segments. This test is proper since it uses the median instead of the mean in computing the absolute deviations, and so robust against non-normality. ${ }^{8}$ For example, this test examines whether the target variance is homogenous around a break date:

$$
\begin{array}{ll}
H_{0}: & \sigma_{T r g, p r e}^{2}=\sigma_{T r g, p o s t}^{2} \\
H_{A}: & \sigma_{T r g, p r e}^{2} \neq \sigma_{T r g, p o s t}^{2}
\end{array}
$$

Given that the F-test for the homogeneity of variances follows the F-distribution, so the statistic should be always positive. In contrast to the variance, the covariance can be negative. The absolute value of the covariance is used here in computing the common $F$ test for the equality of sample covariance across two subsequent segments. However, using absolute value can lead to a more conservative test in detecting heterogeneity when the sign of sample covariance is different across two subsequent segments (i.e. one is positive and another one is negative). The number of significant changes in the covariance might hence be underestimated if the absolute values of change are small.

Detecting break dates in the VCS enables also to test whether the sample correlation changes significantly after those break dates. If so, the anticipations can be concluded based on significant changes in the correlations. Jennrich's (1970) test is used here to test for equality of sample correlations across two subsequent segments, as follows:

$$
\begin{array}{ll}
H_{0}: & \rho_{\text {Acq-Trg,pre }}=\rho_{\text {Acq-Trg,Post }} \\
H_{A}: & \rho_{\text {Acq-Trg, pre }} \neq \rho_{\text {Acq-Trg,Post }},
\end{array}
$$

Where $\rho_{\text {Acq-Trg,pre }}$ and $\rho_{\text {Acq-Trg,post }}$ is the sample acquirer-target return correlation in preand post-break segment.

\subsection{Daily Average Bivariate Return Series}

There are two approaches to compute the average anticipation date for a sample. First, given that some deals can be unpredictable, the average date can be computed from the subsample

\footnotetext{
${ }^{8}$ Lim and Loh (1996) compare seven existent tests for the equality of variances in a simulation exercise and find that the modified Levene test is the most powerful one.
} 
of anticipated deals. Another approach is to use the full sample to find that average date. In this case, the daily average bivariate return series can be constructed by cross-sectional aggregation of daily target and acquirer returns. Then, Aue et al. (2009) test can be performed on this average bivariate series to identify the average anticipation date. The latter approach is computationally less burdensome, and its anticipation date is to some extent comparable with those of previous cross-sectional studies (e.g., the usual event studies). However, its cross-sectional aggregation might remove some relevant information. Therefore, the main conclusions in this paper are based on the results of the individual bivariate series (and not the aggregate one). Nevertheless, any similarity between these two average dates can further support the evidence that the anticipation is the key feature of the sample in question, since the aggregation is unable to remove this predictability.

The daily average return series are returns to an equally weighted portfolio of merging firms and constructed for the total and each payment subsample in the following way:

$\bar{r}_{i, j, t}=\frac{1}{N_{j}} \sum_{n=1}^{N_{j}} r_{i, n, t}$,

where $r_{i, n, t}$ is the realized return, $i$ is the subscript for the acquirer and target series; $j$ is the subscript for the total sample and for Cash, Equity and Mixed subsamples; $t$ is the subscript for Day $t$ and runs from trading day -379 to +78 ; and $N_{j}$ is the subscript for the number of stocks in the subsample $j$ that have return observation at Day $t$. For example,

$\bar{r}_{\text {Acq,Cash }, t}$ represents the daily average returns to the acquiring firms in the cash subsample at day t. Each daily average return series is then adjusted for outliers, breaks in mean and nonzero mean before applying Aue et al. (2009) test.

\subsection{Anticipation Hypotheses}

As documented in the binary state studies, the market uses information of the pair-firms (e.g., relative size of target and acquirer firm) to predict the likely payment-form. Therefore, the market first needs to anticipate a pair of target and acquirer firms and then predict which payment-form is the most likely one for that acquirer to finance its bid. This indicates that first the deal-anticipation should be examined and then the payment-form. If the deal is not anticipated, the prediction of payment-form should be abandoned. Anticipation of paymentfrom indicates that the market either has already anticipated the deal in an earlier date or anticipates simultaneously the deal and its payment-form in one break date.

This paper makes assumptions to interpret the results of the structural break test. First, existence of multiple consistent breaks indicates that the market updates its assessments about the likelihood of merging. These updating shifts are observed since the market may receive new information about the deal or reinterpret the existent information differently. Multiple breaks can also be observed due to updates about the perceived synergy and its division though those values are expected to be time invariant. Second, a threshold is needed to conclude whether a Mixed offer is anticipated or not. The threshold is assumed to be $50 \%$. If more than $50 \%$ of a deal value is paid in cash, then Cash is the dominant payment-form in that Mixed offer. Finally, the testing procedure presumes that a true anticipation of the payment-form of a Mixed offer should shift the covariance and the correlation during the preannouncement period towards those of the dominant payment-form. Let's assume, e.g., a Mixed offer in which $60 \%$ of the deal value is offered in cash. The market anticipates its payment-form if the covariance, correlation or both shifts towards zero during the preannouncement period. 
The following two procedures examine existence of consistent break(s) in the variancecovariance structure of a bivariate return series for identifying as the Deal- and PaymentForm-Anticipation dates.

\subsubsection{Anticipating the Deal}

1. There should be at least one break in the pre-announcement period; otherwise the deal is not anticipated.

2. If there is only one break, it is selected as the candidate break date. In the case of multiple breaks in the pre-announcement period, the very distant break date from the announcement day is considered as the first candidate date.

3. If at least one of the sample second order-moments (except the target variance) changes significantly after the candidate date, that date is considered as the DealAnticipation date. Otherwise, step 4 is followed.

Decline in the target variance may only indicate that the market anticipates the target firm and not the deal. Therefore, observing at least one significant shift in other moments is also required in addition to a declining target variance.

4. If there is at least one more break date in the pre-announcement period, the next one is considered as the new candidate date and step 3 is re-assessed. Otherwise, the deal is not anticipated.

\subsubsection{Anticipating the Payment-Form}

1. The deal should be anticipated. Otherwise, the payment-form is not anticipated.

2. The Deal-anticipation date is chosen as the first candidate date.

3. If at least one of the covariance or correlation shifts significantly towards its hypothesized level after the candidate date, that date is the first candidate for the payment-form anticipation date. Then, step 4 is followed. However, if the shifts are inconsistent with the hypothesized directions, step 5 is followed.

A consistent shift is a rising change in the case of Equity offers, shift towards zero in the case of Cash offers. A Mixed offer follows the rule for Equity (Cash) offers if the equity (cash) is the dominant portion in its payment-form.

4. If there is no more break dates after the candidate date during the pre-announcement period, that date is considered as the Payment-Form-Anticipation date. However, if there is at least one more break date in the pre-announcement period, the next one is considered as the new candidate date and step 3 is re-assessed.

5. If there is no more break dates after the candidate date during the pre-announcement period, the payment-form is not anticipated. However, if there is at least one more break date in the pre-announcement period, the next one is considered as the new candidate date and step 3 is re-assessed.

\section{Data and Descriptive Statistics}

\subsection{Sample Selection}

Martinova and Renneboog (2008) demonstrate that the beginning of the sixth M\&A wave in mid-2003 coincides with the gradual recovery of economic and financial markets after the IT bubble. The takeover market, however, slows down after the 2007 financial crisis. The period between 1 July 2003 and 30 June 2006 is selected as the sample period in this paper, which corresponds to the sixth M\&A wave. 
When an acquirer has multiple bid records in the sample period, some of its returns overlap in more than one deal. This can lead to potential error in identifying a break date as an anticipation date of a specific bid while that break might be induced by other bids of the acquirer. All acquirers with multiple bids over the period of Jan. 2003 to Dec. 2006 are dropped to avoid this problem. The main sample is then extracted by excluding all offers that are announced during the first half of 2003 and second half of 2006. This exclusion can reduce potential biases due to existence of acquirer with multiple bids before 2003 and after 2006.

The Bureau Van Dijk Zephyr database is used to collect data of takeover transactions. The sample consists all completed acquisitions between U.S. publicly listed firms. Adjusted daily-closed prices of securities (adjusted for the splits and dividend distributions) are from Thomson Financial DataStream. All financial institutions as acquirer and target firms and any deals with a value less than $\$ 50$ million were excluded from this sample. The financial institutions are highly leveraged and are subject to different regulations. The method of payment is restricted to the all-Cash, all-Equity and the Mixed offers (i.e., a combination of cash and equity payments). Partial or cleanup offers are excluded in the sample deals, and so an acquirer gains entire control of the target firm by acquiring $100 \%$ of the target's shares. Furthermore, all deals that took longer than one year or shorter than 19 trading days to consummate and any deals in which the target's pre-announcement (roughly, two months before the announcement day) stock price is remarkably low (below $2 \$$ per share) were dropped. Schwert (1996) argues that the returns to these low-priced stocks could be imprecise as they are probably more exposed to frictions in the market microstructure. Existence of at least 19 trading days during the post-announcement period raises the likelihood of observing breaks in the post-announcemnt period. If there are fewer observations, it is highly likely that breaks are pushed to the pre-announcement period. After these restrictions, the final sample contains 125 deals with enough return data to perform univariate and multivariate tests. The sample splits to 54 all-Cash, 33 all-Equity and 38 Mixed-payment deals.

The Appendix provides further data analysis including: descriptive statistics for the acquisitions, the sample higher-order moments before and after the winsorization the return series, and structural breaks in the mean of return series.

\subsection{Sample Second-Order Moments in the Pre- and Post-Announcement Period}

Table 1 summarizes the sample unconditional second-order moments of the acquirer and target returns series during the pre- and post-announcement period. If the bid offer is completely unanticipated or if the market revises its anticipations after the bid announcement, one can expect shifts in those moments. Those comparisons hence provide first insights about the reliability of hypothesized changes in those moments to identify the deal and paymentform anticipations.

The variances and covariance are reported in the basis points (bps) throughout the paper to enhance readability of the numbers. ${ }^{9}$ However, all tests are based on the original numbers.

Insert Table 1 here

\footnotetext{
${ }^{9}$ Since the daily realized variance and covariance are very small in magnitude, the original numbers are multiplied by 10000 .
} 
The cross-sectional average (median) unconditional daily target variance for the full sample declines by a highly significant $66.3 \%$ (71.7\%), from $10.7 \mathrm{bps}(8.5 \mathrm{bps})$ to $3.6 \mathrm{bps}$ (2.4 bps) from the pre-to the post-announcement period. This average decline (which is around $42 \%$ decline in the average volatility) is similar to the result in Hutson and Kearney (2001) who documents that the average unconditional target volatility declined by $46 \%$ after the bid announcement.

The result of the modified Levene test of Brown and Forsythe (1974) is reported in the column called "Portion of Significant Changes" in Table 1. The Relative Change quantifies the change in a post-announcement sample moment of a series relative to its preannouncement value. Therefore, the "Relative Change (Post vs. Pre)" raw in Table 1 represents the descriptive statistics of this measure for the whole and the payment subsamples. The homogeneity test indicates that the post-announcement variance is significantly different from its pre-announcement value in $88.8 \%$ of target firms (111 out of 125 firms). Target variance decline significantly in 109 out of 111 series after the bid announcement.

Furthermore, when the sample is split based on the payment form, the average relative change is significantly negative across all subsamples. The large F-value of ANOVA analysis (32.92) in Table 1 indicates that the average relative change is statistically different across payment subsamples. Consistent with the Hutson and Kearney (2001), the largest (smallest) risk reduction is in target of Cash (Equity) offers. However, the ANOVA result (F-value of 0.99 ) indicates that the target variance is comparable across payment subsamples during the pre-announcement period.

Overall, announcing the bid offer drops significantly the target variance regardless of the offered payment-form. This is consistent with that part of the deal anticipation hypothesis that anticipates partially a bid offer due to a significant decline in the target variance.

Table 1 shows a highly significant decline on the cross-sectional average (median) acquirer variance for the full sample, from $7.2 \mathrm{bps}(4.3 \mathrm{bps})$ to $4.8 \mathrm{bps}(3.5 \mathrm{bps})$ from the preto the post-announcement period. This cross-sectional average decline $(33.3 \%)$ is to some extent consistent with Hutson and Kearney (2005) who find that the average acquirer volatility declines by $21 \%$ after the bid announcement.

The results of individual variance homogeneity tests in Table 1 indicate that the relative change is significant in $55.2 \%$ of acquirer firms. First, this lower portion of significant change relative to that of the target firms $(88.8 \%)$ suggests that the risk profile of acquirer firms remains more constant after the bid announcement. Second, the dominancy of declining shifts (60 of those 69 significant shifts) can imply that the market investors perceive that the synergy and diversification effects of bids dominate the leverage and integration risks. However, a rise in the acquirer variance is also observed in 9 series. This is also likely when the leverage and integration risks dominate the synergy and diversification effects.

The highest (lowest) average acquirer variance during the pre-announcement period is observed for the Equity (Cash) subsample. The ANOVA results (i.e., the F-value of 4.66) indicate that acquirers with more volatile stocks during the pre-announcement period prefer on average to use their equity as part of payment to the target shareholders.

Hutson and Kearney (2005) reports only a significant decline (27\%) in the volatility of acquirers when they offer Cash payment. However, the average relative reduction in the acquirer variance is significant at $1 \%$ across all payment subsamples and ranges from $20 \%$ to $23 \%$ in this paper.

The difference between the cross-sectional average (median) post- and preannouncement covariance is unexpectedly insignificant (moderately significant). This is due to the above-mentioned problems in the joint cross-sectional tests. The covariance either decreases or increases after the bid-announcement without a significant tendency in one 
direction. Thus, averaging across cross-sections can remove part of useful information essential for the inference. The main inference should hence be based on the individual homogeneity tests that performed on the covariance of each bivariate return series. The summarized results of individual homogeneity tests show that the covariance changes significantly in 110 out of 125 ( $88 \%$ of) bivariate return series after the bid announcement.

The significant ANOVA results (F-values of 5.73 and 23.03) indicate that both the average pre- and post-announcement sample covariance is significantly different across payment subsamples. It is observed on average that the more linearly dependent pair-firms during the pre-announcement period use more equity in financing their bids. Consistent with the payment-form anticipation hypothesis, announcing an Equity (Cash) offer raises (declines) significantly the cross-sectional average covariance by $65.3 \%(99.8 \%)$ from 2.6 bps ( $1.1 \mathrm{bps})$ to $4.3 \mathrm{bps}(0.002 \mathrm{bps})$ from the pre-to the post-announcement period.

Overall, the covariance changes significantly after the bid announcement based on the offered payment-form. This is also consistent with the deal anticipation hypothesis since it changes in a very significant portion of deals $(88 \%)$. Detecting break(s) in the covariance during the pre-announcement period can therefore anticipate the takeover transaction and its payment-form.

Table 1 illustrates that both the cross-sectional average and median of correlation in the full sample increase significantly after the bid announcement. The results of individual correlation equality tests show that the correlation changes significantly in 78 out of 125 series $(62.4 \%)$ after the bid announcement. This portion is significantly lower than the portion of significant changes in the covariance $(88 \%)$. This simple observation verifies the claim that the standardization in constructing the correlations can remove part of useful variations in the covariance.

The large F-value of ANOVA model (8.28) indicates that the average sample correlation during the pre-announcement period is significantly different across payment subsamples. On average, the more correlated is the pair-firms, the more shares used by acquirer to finance the bid. This univariate result is consistent with Ismail et al. (2010) who find a significant positive relation between the correlations and the fraction of acquirer shares used in the bid payment. Furthermore, Bhagwat et al. (2012) report similar result since they find that the probability of an Equity offer is rising with the correlations.

The very large F-value of ANOVA model (62.69) implies that the cross-sectional average sample correlation diverge significantly across all payment subsamples after the bidannouncement. Announcing of Equity offers upsurge the cross-sectional average correlation by a highly significant $122.6 \%$ from $31 \%$ to $69 \%$ from pre- to post-announcement period. This is consistent with Subramanian (2004), who finds that the sample correlation of pairfirms involved in an equity-exchange deal converges to perfect correlation after the bid announcement. The cross-sectional average correlations decline significantly by $82.4 \%$ (from $17 \%$ to $3 \%$ ) after the Cash announcements. Overall, similar to the covariance case, the results here are consistent with the hypothesized shifts for anticipating payment-form. ${ }^{10}$

\footnotetext{
${ }^{10}$ The Min and Max of the Relative Change for the covariance and the correlation in Table 1 might seem odd; however, they are based on the pre- and post-announcement moment of a deal in the sample. For example, the maximum Relative Change of the correlation (14194\%) is computed for a deal in which the correlation upsurges significantly from $-0.615 \%$ to $86.7 \%$ from pre- to post-announcement period.
} 


\section{Anticipation Results Via Individual Bivariate Return Series}

The results of performing Aue et al. (2009) test on each 125 bivariate return series are summarized in Table 2, Table 3 and Figure 1. Table 2 illustrates the frequency distribution of number of breaks per deal. There is at least one significant break in the VCS in $87.2 \%$ of deals (i.e. 109 out of 125 deals) and multiple breaks in $60 \%$ of them. A break is detected at $1 \%(10 \%)$ significant level in 88 (3) out of 109 deals. The rest of those deals have significant breaks at 5\% significant level. The common characteristic of the bivariate return series is that they are returns to the firms involved in the successful takeover transactions. Therefore, the observed large portion of series with break(s) suggests that some relevant information about the takeover transactions should be revealed to the market through those shifts.

\section{Insert Table 2 here}

There is no significant break in 16 out of 125 deals ( $12.8 \%$ of deals). This observation may suggest that announcement of these 16 deals are completely surprising for the market. If the market believes a substantial synergy in a given pair-firm, one can expect to observe shifts in the VCS at least after the announcement day. However, this argument is invalid if the second-order moments are stable around the hypothesized level during the preannouncement period, and so the announcement cannot change them.

Moreover, existence of non-trivial portion of deals without any breaks can be empirically interpreted as the reliability of Aue et al. (2009) test. This means that this test does not always detect break(s) in every bivariate return series. Although there is not any restriction about the maximum number of breaks per deal in Aue et al. (2009) test, the majority of deals (102) have between one and three significant breaks per deal. This observation may also indicate that this test estimates a reasonable number of breaks.

Table 2 also groups deals based on the location of their break(s). The sample observation period is designed in a way that it is likely to observe breaks during both pre-and post-announcement periods. The general knowledge suggests that the deal may not be anticipated before the bid announcement. If this is the case, any shifts in the sample secondorder moments, if any, should be observed only after the announcement day. However, the results here indicate that 108 out of 109 deals with significant breaks have shifts during the pre-announcement period. This implies a significant skewed location of breaks towards the pre-announcement period. The number of deals with significant break(s) only during the preannouncement periods is 81 (64.8\% of total deals). Deals with significant break(s) during the post-announcement period are 28 (21.6\% of total deals). However, 27 out of those 28 deals also have break(s) during the pre-announcement period. Existence of these additional postannouncement breaks indicates that the market only revise its pre-announcement predictions about the takeover transaction after the bid announcement. If we assume that the VCS reveals some information about the takeover transactions, the majority of those information is hence revealed to the market during the pre-announcement period.

\section{Insert Figure 1 here}

Aue et al. (2009) test detects a total of 235 breaks in the VCS of 125 bivariate return series. Panel A of Figure 1 illustrates the distribution of these 235 break dates relative to the announcement day (Day 0). This Figure shows marked variations in the break dates with one substantial spike around the announcement date. This spike is consistent with the previous studies (e.g., the merger arbitrage literature) that assume implicitly a break in the samplesecond order moments around the announcement day. Apart from this spike, Panel A of 
Figure 1 demonstrates that break dates are almost uniformly distributed during the sample observation period, in particular between Day-260 and Day-10. Table 3 indicates that the inter-quartile for these 235 break dates ranges from Day-208 to Day-1. In contrast to the assumption in the previous studies, these findings imply that the mass of distribution of break dates is located significantly prior to the announcement day.

Similar skewed location of breaks is observed when the number of break dates is considered. Table 3 denotes that 196 out of 235 significant breaks ( $83.4 \%$ of total) are located during the pre-announcement period. Only 39 out of 235 (16.6\% of total) breaks are detected after the announcement date.

\section{Insert Table 3 here}

The first break after the bid announcement day is of interest. This updating break is called Reaction-Break since it shows the earliest time that the market reacts to the first public bid announcement. The results in Table 3 indicate that the Reaction-Break is detected in 28 out of 125 deals $(22.4 \%)$. The market reacts on average 9 days after the bid announcement. The median reaction time is only one day. The fraction of deals with Reaction-Breaks is larger in the Equity subsample (i.e., 39.4\%) compared to Cash and Mixed subsamples. This proposes that the announcement of Equity offers reveals unanticipated information that the market incorporates them in the VCS of the joint return distribution. This information might be minor issues about the deal that are difficult to predict during the pre-announcement period (e.g., the exact equity-exchange ratio).

\subsection{Deal-Anticipation}

Results for identifying Deal-Anticipation breaks are summarized in Table 3. The deal is not anticipated in 17 bids since 16 bivariate series do not have any break during the preannouncement period and one series has only one break during the post-announcement period. The Deal-Anticipation procedure examines every 108 deals with significant break(s) during the pre-announcement period. This leads to recognize 108 consistent breaks as the Deal-Anticipation dates. Existence of consistent shifts in a significant fraction of deals $(86.4 \%)$ may verify the proposed anticipation mechanism. These 108 anticipated deals consists of 46 Cash, 30 Equity and 32 Mixed payment deals. Table 3 shows that the fraction of anticipated deals is similar across the payment subsamples.

\subsubsection{Deal-Anticipation Dates}

All statistics in this subsection are based on the subsample of anticipated deals (i.e. those 108 deals). Table 3 shows that the Deal-Anticipation break is detected on average 187 trading days prior to the announcement day for the total sample. The median anticipation date is 190 trading days prior to the announcement day. The interquartile range for the DealAnticipation date is between Day-252 and Day-133. That indicates that $75 \%$ of deals are anticipated at least 6 months prior to the announcement day. The box plot of the distribution of Deal-Anticipation date in Panel B of Figure 1 demonstrates relatively similar distributions across Cash, Equity and Mixed subsamples. A very small F-Value of ANOVA test (0.05) also indicates that the average anticipation date is similar across payment subsamples. This leads to conclude that the market can start to anticipate a likely takeover transaction on average almost 9 months prior to the bid announcement day.

Only 3 deals are anticipated between Day-24 and Day-8. The number of deals that are anticipated before the announcement day (i.e. Day-1) is only 3 deals. The number of anticipated deals can be modified to 105 deals if those 3 deals are excluded. Aue et al. (2009) 
test does not provide confidence interval for detected break dates. Therefore, any consistent break prior (subsequent) to the announcement day is considered as the Deal-Anticipation (Reaction) breaks. Only 9 out of 108 deals are anticipated before Day-300. One may find this anticipation dates are questionable since they are located rather far from the announcement date. Other closer consistent break dates are also detected in all of those 9 deals during the pre-announcement period. Thus, the fraction of total anticipated deals does not change with the use of far or close breaks relative to the announcement date in those deals.

\subsubsection{Size of Shift in the Sample Moments around Deal-Anticipation Dates}

Table 4 summarizes the magnitude of shift in the second-order moments around those 108 Deal-Anticipation dates and across the payment subsamples. The Deal-Anticipation procedure recognizes that 5 deals $(1$ deal) are anticipated due to significant decline in the acquirers' variance (a significant change in the correlation) after the candidate break dates. The rest of deals (102 out of 108) are anticipated due to significant shifts at least in two of the second-order moments after the candidate break dates.

Insert Table 4 here

\subsubsection{Target Variance}

The summarized result of the variance homogeneity test in Table 4 indicates that the number of deals in which the target variance change significantly after the deal-anticipation dates is 78. The target variance declines in 68 out of those 78 deals while it rises in the rest (10). Existence of those increasing shifts may be contrary to the Deal-Anticipation procedure, which requires a decline in the target variance after a candidate break date as an indictor of the deal anticipation break. However, in addition to that raise, at least one of the other second-order moments shifts significantly after each of those 10 break dates. Since consistent shift in other moments have priority to a consistent change in the target variance, those breaks are recognized as the Deal-Anticipation dates.

The average (median) unconditional daily target variance for the total sample of anticipated deals declines by a highly significant $31.4 \%$ (36.9\%), from $14.3 \mathrm{bps}(10.3 \mathrm{bps})$ to $9.8 \mathrm{bps}(6.5 \mathrm{bps})$ from pre- to post-anticipation segment. However, the average relative size of shift and the fraction of deals with significant changes are smaller here compared to the pre- vs. post-announcement results. The average (the fraction) is $26 \%(72.2 \%)$ here compared to $62 \%(88.8 \%)$ in the previous section. These differences can be explained by existence of multiple breaks per deal in the majority of deals ( 75 out of 125 deals). If the target variance declines constantly across subsequent segments, assuming only one break at the announcement date can overestimate the size of shift in the target variance. This accordingly leads the fraction of deals with significant changes to be overestimated. This is the case in the sample of this paper.

The level of the second-order moments across payment subsamples in the preanticipation segment is of particular interest since the deal is almost completely unexpected to the market in this interval. Very small F-value of ANOVA analysis (0.12) indicates that the average target variance in the pre-anticipation segment is similar across payment subsamples. However, anticipating deals leads to different levels of the average target variances in the post-anticipation segments across payment subsamples (see the marginally significant F-value of ANOVA test, 2.61). Similarly, both the mean and median difference tests (Post - Pre) indicate that the average and median of target variances decline significantly in the Cash and Mixed subsample and are unchanged in the Equity subsample. The large F-value of ANOVA analysis (6.73) also implies that the average relative change 
(Post vs. Pre) in the target variance differs significantly across payment subsamples. Overall, similar to the merger arbitrage literature and the descriptive results, the largest (smallest) decline in the target variance is observed in the bids that the medium of payment consists at least some fraction of cash in the payment (in the Equity subsample).

The portion of deals with significant changes in the target variance after the dealanticipation date is similar across payment subsamples $(69.6 \%, 73.3 \%$ and $75 \%$ of anticipated Cash, Equity and Mixed deals, respectively). However, a different view is depicted when the increasing and decreasing significant shifts in the target variance are separated in each payment subsample. There is only one increasing shift in each of Cash and Mixed subsamples while 8 increasing shifts is observed in the Equity subsample. This suggests that expecting some fraction of cash in the bid payment can result in much significant declines in the target variances in the post-deal-anticipation segment.

\subsubsection{Acquirer Variance}

The summarized result of the variance homogeneity test in Table 4 indicates that the number of deals in which the acquirer variances change significantly due to the dealanticipation breaks is 80 . This result is similar to the number of significant changes in the target variance ( 78 deals). Thus, one can conclude that the shifts in the risk profile of acquirers can convey useful information about potential takeover transactions as well. The number of deals with significant changes in the acquirer variance is larger here compared to the pre- vs. post-announcement result (i.e. 80 deals vs. 69). Those 80 shifts are detected in the subsample of anticipated deals (108 deals) while the full sample (125 deals) is used for detecting those 69 shifts. This suggests the importance of relaxing the assumption of only one break at the announcement day to find accurate frequency of significant changes in the second-order moments.

The average (median) acquirer variance for the total sample of anticipated deals declines by a significant $22.6 \%(16.7 \%)$, from $9.9 \mathrm{bps}(5.4 \mathrm{bps})$ to $7.7 \mathrm{bps}(4.5 \mathrm{bps})$ from preto post-anticipation segment. The mean comparison tests (the $t$-test and the ANOVA test) in Table 4 indicate that the average acquirer variance only drops significantly in the Mixed subsample during the post-anticipation segment. However, the median comparison test (Post - Pre) shows that the acquirer variance declines significantly in all payment subsamples. Decline in the median of Relative Change (Post vs. Pre) is 34\% for Cash, 33\% for Equity and $47 \%$ for Mixed subsample. This result is contrary to the previous merger arbitrage studies that report mixed results for change in the acquirer variance across payment subsample after the bid announcement.

Similarly, decomposing significant shifts indicates that the majority of them are decreasing ( 66 out of the 80 shifts) across all payment subsamples (i.e., 27 out of 33, 16 out of 22 and 23 out of 25 significant shifts in the Cash, Equity and Mixed subsamples, respectively). This large portion of significant decreasing shifts in the acquirer variance can be recognized as another verification of the proposed synergy hypothesis. Absence or increasing shifts in the acquirer variance does not necessarily mean that the market does not perceive any synergistic gains when it anticipates the deal. The reduction in the acquirer variance due to those perceived synergistic gains might be rather small to outweigh the raises due to the leverage and integration risks of takeover transactions. This discussion may lead to conclude that the market perceives substantial synergistic gains at least in those 66 anticipated deals.

The ANOVA analysis indicates that the average acquirer variance in the preanticipation segment is statistically different across payment subsamples (i.e. 7 bps for Cash, $11.5 \mathrm{bps}$ for Mixed and $12.7 \mathrm{bps}$ for Equity subsample). Thus, when the market anticipates the deals, expects that the acquirers with more volatile (less volatile) stocks will prefer on 
average their own shares as part of the bid payment (Cash offer) to the target shareholders. This result suggests that the level of acquirer variance during the pre-anticipation segments may have some relevant information for anticipating the payment-form. However, the payment-form anticipation requires also consistent changes in one of the covariance and correlation around the anticipation breaks.

As already reported, the acquirer and target firms are on average about the same size in the Equity subsample. One can hence expect that the Equity bids compared to both of Cash and Mixed bids are largely exposed to the integration and leverage risks. The risk of overpayment is high in Cash offers if the pair-firm is strongly correlated (see Bhagwat and Dam, 2012, for related explanation). This suggests that acquirer might intend to protect itself against the additional risk of overpayment by offering an equity-exchange bid.

\subsubsection{Acquirer-Target Covariance}

The summarized result of the covariance homogeneity test in Table 4 indicates that the number of deals in which the covariance change significantly due to the deal-anticipation breaks is 91 . This number is greater than the number of significant changes in the both target and acquirer variances (78 and 80 deals, respectively). This implies that shifts in the covariance (among the second-order moments) are the main source of recognizing breaks in the VCS as the Deal-Anticipation dates.

The significant F-value of ANOVA test (4.56) shows that the average covariance in the post-anticipation segment differs across payment subsamples. This suggests that that market can form some expectations about the payment-form by shifting the covariance. However, consistency of those shifts with the offered medium of payment needs to be investigated across deals of each payment subsample. If those shifts are consistent, one may interpret that the market anticipates both the deal and its payment-form in one break. However, if there are more breaks between the deal-anticipation date and the announcement, consistent shifts should be detected in all of those breaks for concluding that the payment-form is anticipated in the Deal-Anticipation date.

The results of individual covariance homogeneity tests indicates that the relative change (Post vs. Pre) is significant in 39 out of 46 anticipated Cash deals. Unreported results indicate that 32 out of those 39 significant shifts are consistent with the Payment-Form anticipation procedure. This suggests that the market anticipates Cash offers (i.e., both the deal and its payment-form) in some of those 32 Deal-Anticipation dates. The mean and median tests support these declining shifts in the Cash subsample. The unreported results show that only 8 out of those 23 significant shifts in the Equity subsample are consistent with the Payment-Form anticipation procedure. The insignificance of mean and median tests in Table 4 supports somehow this low portion of consistent shifts. These results indicate that other consistent shifts need to be detected at least in those 15 deals in order to conclude that the Equity offers are anticipated as well. The covariance changes significantly after the Dealanticipation breaks in a large fraction of the Mixed subsample (29 out of 32). Since the Equity portion is dominant payment form in the subsample of Mixed bids, a consistent break should upsurge the covariance after the anticipation date. However, the unreported results show that 21 out of those 29 significant shifts are decreasing. This implies that market anticipate incorrectly that cash would be the dominant payment form when it anticipates those deals. Overall, shifts in the covariance suggest that the market seems to be partially more successful in anticipating the Cash offers when it anticipates the deal for the first time during the preannouncement period. 


\subsubsection{Acquirer-Target Correlation}

The summarized result of the correlation homogeneity tests in Table 4 indicates that the number of deals in which the covariance change significantly due to the deal-anticipation breaks is 40 . This indicates that the correlation is the most stable moment among the secondorder moments since it has the smallest number of significant changes after those 108 DealAnticipation breaks. However, this small number is not odd since the standardization in the correlation can remove some part of useful variations. This finding implies the usefulness of examining shifts in the covariance to identify both types of anticipations.

The results of mean and median tests for the total and the payment subsamples in Table 4 show that the cross-sectional correlations are unaffected by the deal anticipations. However, the individual correlation homogeneity tests indicate that the market can form some expectations about the likely medium of payment. The unreported results below show the number of consistent shifts in the correlation after the deal-anticipation breaks: 11 out of 13, 8 out of 14 and 8 out of 13 significant shifts in the Cash, Equity and Mixed subsamples, respectively.

\subsection{Payment-Form-Anticipation}

Results for identifying Payment-Form-Anticipation break dates are summarized in Table 3. By definition, the Payment-Form Anticipation procedure examines the subsample of anticipated deals, i.e., those 108 deals. It identifies only 77 deals with consistent shifts in their covariance, correlations or both. Only 2 out of 77 the Payment-Form-Anticipation breaks are detected at 10\% significant level while 65 out of them are identified at $1 \%$ significant level. The rest is detected at 5\% significant level. Those 77 anticipated deals consist of 37 Cash, 21 Equity and 19 Mixed-payment bids. The portion of payment-form anticipated deals $(61.6 \%)$ is considerably lower than the anticipated deals $(86.4 \%)$. This result indicates that the Payment-Form-Anticipation procedure cannot detect consistent shifts in either the dealanticipation date or other recent breaks of those 31 anticipated deals. This is expected since this procedure requires more precise changes in the second-order moments over the preannouncement period.

The fraction of anticipated Mixed offers (50\%) is lower than Cash and Equity offers $(68.5 \%$ and $63.6 \%)$. This result indicates that the market is less successful in anticipating the Mixed bids. Moreover, this result can further explain why an average payment-formanticipation date is not detected for the Mixed subsample when the daily average return series is used. This lower portion is not surprising since there are more parameters to anticipate in the Mixed offers, e.g. the exact portion of cash in the total payment. One need also to predict how this anticipated cash portion can shift the moments during the pre-announcement period.

Unreported results show that the market anticipates simultaneously both the deal and its payment-form in 45 out of those 77 deals. Cash offers are anticipatable to a greater extent in simultaneous breaks compared to Equity and Mixed offers: 27 out of 37, 8 out of 21 and 10 out of 19 shifts in the Cash, Equity and Mixed offers, respectively. The signals market receives are hence much stronger when anticipates the Cash offers since the moments shifts more consistently with the anticipation procedures.

\subsubsection{Payment-Form-Anticipation Dates}

All statistics in this subsection are based on the subsample of payment-form-anticipated deals (i.e. those 77 deals). Table 3 shows that the average (median) anticipation date is Day123 (Day-106). This indicates that market anticipates on average the payment-form six months prior to the announcement day. It takes on average 63 trading days (almost three 
months) for the market either to receive more strong signals or to reinterpret available information to pinpoint the payment-form of the anticipated deals. The mean test (with tstatistic of -4.49) in Table 3 indicates that the deal is anticipated on average significantly earlier than the payment-form. This significant difference is solely due to the fact that the deal and payment-form anticipation dates are not coincide in 32 out of those 77 deals. Another recent break date is identified as the payment-form-anticipation date in those 32 deals.

The interquartile range for the Payment-Form Anticipation date is between Day-210 and Day-25. This indicates that the $75 \%$ of deals are anticipated at least one month prior to the announcement day. Only 5 of those 77 deals are anticipated between Day-24 and Day-3. The number of payment-form-anticipated deals before the announcement day is 14 (i.e., 3 Cash, 5 Equity and 6 Mixed offers). This figure is significantly larger than the number for the deal-anticipation case ( 3 deals). This suggests that the stronger signals for anticipating the payment-form of these 14 deals are indeed revealed very late to the market. Excluding those 14 deals reduces the payment-form anticipated subsample to 63 deals $(50.4 \%$ of total). This figure can serve a lower bound for the true number of the payment-form anticipated deals. However, detecting these close dates cannot falsify the fact that the market anticipates the payment-form in a significant portion of deals long before the announcement day.

The solid box plot in Panel B of Figure 1 suggests that the empirical distribution of Payment-Form-Anticipation date varies across Cash, Equity and Mixed offers. In contrast to the deal-anticipation dates, large F-value of ANOVA test (6.11) in Table 3 indicates that the average payment-form-anticipation date significantly differs across payment subsamples. The Cash offers are anticipated on average much earlier than both Equity and Mixed offers (Day162 vs. Day-83 and Day-92). This is qualitatively similar to the result reported for the daily average return series in which the Cash offers are anticipated earlier than Equity offers. Moreover, the comparison of box plot of Deal- and Payment-Anticipation dates in Panel B of Figure 1 illustrates that the distributions of both type of anticipation dates differ significantly in Equity and Mixed subsamples. However, it remains almost unchanged in Cash subsample. The mean tests also indicate that the deals are anticipated on average earlier than paymentform in both Equity and Mixed subsamples (t-statistics of -4.29 and -3.07). A deal is anticipated on average at least four months before the market predicts that its payment-form will be eventually either Equity or Mixed. Nevertheless, the average deal and payment-form anticipation date is almost coincide for Cash subsample. Overall, the above results leads to conclude that the first bid announcement of Cash (Equity and Mixed) offers has the least (most) unexpected information across payment subsamples for the market investors.

\subsubsection{Size of Shift in the Sample Moments around Payment-Form Anticipation Dates}

Table 5 summarizes descriptive statistics for the size of shift in the moments of the bivariate returns series around those 77 Payment-form-Anticipation break dates. These statistics are provided for Total sample, Cash, Equity and Mixed subsamples. The paymentform is anticipated in 44 out of the 77 deals due to consistent shifts in both of the covariance and correlations series, 28 deals due to consistent shifts in the covariance series. The rest (3) of deals are anticipated because of consistent shifts in the correlation series. The majority of payment-form of deals is hence anticipated due to instability in the covariance. This indicates that the covariance is better than the correlation to capture non-stationarity in the co-variation between the target and acquirer return series over time.

Insert Table 5 here 


\subsubsection{Target Variance}

The results of the variance homogeneity test in Table 5 indicate that the number of deals in which the target variance changes significantly due to the payment-form-anticipation breaks is 60 (out of 77 anticipated deals, 78\%). Similar to the deal-anticipation case, both mean and median tests indicate that the target variance declines significantly during the postanticipation segments by $31 \%$ and $42 \%$, respectively. The target variance declines significantly in 55 out of those 60 deals while it rises in the rest. The 4 of those 5 rising shifts is related to the Equity subsample and only one increasing change is observed in the Cash subsample.

Similar to the deal-anticipation case, the mean and median of target variance drops significantly after the payment-anticipation dates for both of Cash and Mixed subsamples. In contrast to that case, the median of target variance declines for the Equity subsample. This suggests that anticipating an Equity offer also reduces the risk of target firms. Moreover, the ANOVA analysis indicates that the largest average relative decline (Post-Pre) is observed for Cash and Mixed subsamples (-39\% and -43\%) and the lowest for the Equity subsample ($6 \%$ ). Overall, anticipating the payment-form of forthcoming bid offers is associated with significant reduction in the risk profile of target firms.

The average target variance over the post-payment-anticipation segment (6.6 bps) is significantly smaller (with a t-statistic of 2.18) than its counterpart over the post-dealanticipation segment $(9.8 \mathrm{bps})$. This indicates that the target variance declines continuously across subsequent regimes during the pre-announcement to approach its average level over the post-announcement period (3.6 bps). Therefore, the market incorporates signals about the deal and payment-from anticipations by reducing the risk of investing in those target stocks.

\subsubsection{Acquirer Variance}

The portion of deals with significant change in their acquirer variance due to the payment-form-anticipation breaks (47 out of 77 deals, 61\%) is significantly lower than portion for the deal-anticipation case (80 out of 108 deals, $74.1 \%$ ). The average relative change (Post vs. Pre) in the acquirer variance of the payment-anticipated deals $(-5 \%)$ is significantly smaller than those of deal-anticipated subsample (-18\%).

Unreported results indicate that the acquirer variance declines significantly in 34 out of those 47 deals while it rises in the rest. The 3, 5 and 6 of those 13 rising shifts is observed in the Cash, Equity and Mixed subsamples, respectively. The largest portion of significant declines in the acquirer risk is observed in the Cash subsample. Moreover, the ANOVA analyses in Table 5 illustrate that the average acquirer variance only differs in the postpayment-anticipation segment. The mean and median tests show that this difference is due to the significant decline in the acquirer variance after anticipating Cash offers. Overall, These results leads to conclude that the market only reduces the risk profile of acquirers when it anticipates that the forthcoming bid will be Cash offer.

\subsubsection{Acquirer-Target Covariance}

Table 5 indicate that the number of deals in which the covariance changes significantly due to the payment-form-anticipation breaks is 72 (out of 77 anticipated deals). Similar to the Deal-Anticipation results, the greatest portion of significant changes $(93.5 \%)$ among moments around those payment-anticipation dates is observed in the covariance series.

The mean and median tests indicate surprisingly that the difference between post- and pre-payment-anticipation covariance is insignificant. These results might lead to incorrect inference of stability of covariance around the payment-anticipation dates. This shows how the cross-sectional aggregations in the mean and median for comparing two sample 
distributions can generate misleading results. According to the covariance homogeneity tests, the covariance declines significantly in 42 out of those 72 deals while it rises in the rest. This opposite shifts cancels each other out and causes the mean and median of covariance remain stable around those dates.

The 2, 18 and 10 of those 30 rising shifts is observed in the Cash, Equity and Mixed subsamples, respectively. Those 2 increasing shifts in Cash subsample is not peculiar. They are in fact consistent with the payment-anticipation procedure since the covariance converges to the target level, i.e., shift from a negative value during the pre-anticipation segment to zero in the post-anticipation segment. Since the majority of shifts are declining in Cash subsample, the average (median) covariance declines after the payment-anticipation dates by a highly significant $-77.3 \%(-83.3 \%)$, from $2.2 \mathrm{bps}(1.2 \mathrm{bps})$ to $0.5 \mathrm{bps}(0.2 \mathrm{bps})$ from the pre- to post-anticipation segment. The average and median size of shifts in the covariance around the payment-anticipation breaks for Equity subsample (213\% and 233\%) is extremely larger than those around deal-anticipation dates (15\% and $-9.1 \%)$. The opposing shifts again lead the mean and median difference between Post- and Pre-anticipation covariance to be insignificant in the Mixed subsample. Overall, these sizable shifts in the covariance indicate that the market may receive strong signals about the likelihood of deal and its payment-form around the payment-anticipation break dates.

\title{
5.2.2.4. Acquirer-Target Correlation
}

The number of deals in which the correlation changes significantly due to the paymentform-anticipation breaks is 47 (out of 77 anticipated deals). The portion of significant shifts in the correlation $(61 \%)$ is significantly lower than that of the covariance $(93.5 \%)$. This may suggest that the correlation is more stable. However, a closer look at the number of consistent breaks across payment subsamples reveals that the correlation shifts less frequently compared to the covariance only in the Cash subsample. In fact, 22 out of 25 insignificant breaks in the correlation are observed in the Cash subsample. The payment-anticipation procedure identifies a break date as anticipated Cash offer if the correlation shifts significantly towards zero after that break date. An unreported indicates that 20 out of those 22 insignificant breaks are weakly correlated (with an absolute correlation less than $25 \%$ ) during the pre-anticipation segment. While declining shifts in the covariance anticipate those 20 Cash offers, correlation cannot shift significantly towards zero since it is already near to the zero level. Thus, correlation is more stable in the Cash subsample but it changes as intense and frequent as the covariance in the Equity and Mixed subsamples.

In contrast to insignificant results around deal-anticipation dates, the average and median difference between Post- vs. Pre-payment-anticipation correlations is significant in the whole sample and across payment subsamples. For example, the average (median) correlation increases after anticipating the Equity offers by a highly significant $144 \%(187 \%)$, from $25 \%(23 \%)$ to $61 \%(66 \%)$ from the pre- to post-anticipation segment. This average (median) size of shifts is substantially larger than those around deal-anticipation dates, i.e., $13.3 \%(10.3 \%)$.

\section{Anticipation Results Via Daily Average Bivariate Return Series}

\author{
Insert Figure 2 here
}

The results of performing Aue et al. (2009) test on the daily average acquirer and target return series for the total sample and payment subsample are reported in "Total Number of Break Dates" column of Table 6. Between one and two breaks are detected in their VCS. All 
breaks are significant at $1 \%$ level. Figure 2 illustrates how the variances, covariance and correlation change around those break dates. Although breaks can occur both in the pre- and post-announcement periods, all break dates are detected significantly prior to the bid announcement day. ${ }^{11}$ This suggests that on average the bid announcements are partly expected since part of the bid information has already revealed to the market via shifts in the risk profile of the target and acquirer firms.

\section{Insert Table 6 here}

There is one significant break in the VCS of acquirer and target average return series for the total sample at Day -231. Both target and acquirer variance decline significantly by $44 \%$ and $53 \%$ after this break date. Especially, a substantial drop in the risk of acquirer firm suggests that the market considers on average that the acquirer stock is a portfolio of acquirer and target stocks in the post-deal-anticipation segment. This is consistent with the diversification and synergy hypotheses that predict decline in the volatility of acquirer firms after the deal-anticipation date. There is also a marginally significant drop in covariance $(22 \%)$. All these consistent changes in the second-order moments imply that a deal is anticipated on average 231 days prior to the announcement day. This average anticipation date (i.e. Day -231), which is based on the daily average returns, is to some extent comparable with that average deal-anticipation date (Day -187), which is based on the subsample of individually anticipated deals (108 out of 125 deals). This result verifies that the anticipation is the key feature of this sample since it is detected even after the daily crosssectional aggregation.

Only one break is detected at Day -174 for the Equity subsample, indicating that this date is the only candidate date for both types of anticipations. All sample second-order moments significantly changes after that candidate date, so the market starts to anticipate the deal on average 174 days prior to the announcement day. Since both of the covariance and correlation upsurge significantly after that date, the market also anticipates that the paymentform is Equity. Thus, market starts to anticipate simultaneously both the deal and Equity offers on average 174 days prior to the announcement day.

Two significant breaks are detected at Day-282 and Day-208 in the Cash subsample. The first candidate date for the deal-anticipation date is Day-282, i.e., the farthest one relative to the announcement day. All moments (except the acquirer variance) change significantly after that date, implying that the market anticipates the deal on average 282 days prior to the announcement day in this subsample. This indicates that a deal is anticipated on average significantly earlier in Cash compared to Equity subsample (i.e. Day -282 compared to Day -174). However, both of the covariance and correlation diverges from zero (i.e., the hypothesized level of correlation in Cash deals) after that date. Thus, the market incorrectly predicts that the most likely payment-form is Equity offer. The market revises its paymentform prediction at the next significant break date, i.e. Day-208. Since both of the covariance and correlation declines and converges to zero after this date, the market anticipates correctly that the payment-form is Cash. These finding suggests that the Cash bids are anticipated on average earlier than the Equity bids (i.e. Day -208 compared to Day -174). Due to early anticipation of deal and payment-form in Cash subsample, one can conclude that the announcements of Cash offers are less surprising for the market investors.

Two significant breaks are detected at Day-164 and Day-9 in the Mixed subsample. Day-164 is the first candidate date for examining the deal anticipation. All moments (except

\footnotetext{
${ }^{11}$ At least 120 (54) out of 125 series are used to construct daily average return series during pre- (post-) announcement period for the total sample.
} 
the correlation) shift significantly after this date, indicating that the market anticipates the deal at Day -164. The sample covariance plunges and converges to zero, indicating that the market predicts that cash is the dominant portion in the payment-form of Mixed offers. However, the equity is the dominant payment-form in the Mixed subsample of this paper. Most of acquirers in this subsample pay more than $50 \%$ of the deal value by their own shares. If the market anticipates correctly the payment-form in the Mixed bids, the covariance and correlation should rise during the pre-announcement period. Since the sample covariance declines further after the next revised break date (i.e. at Day-9), the market cannot anticipate the payment-form in the Mixed offers using daily average return series. These results show that the market anticipates the deal and not the payment-form in Mixed subsample. Overall, the results of daily average bivariate return series indicate that the market anticipates on average the deal and payment-form long before the first bid announcement day.

\section{Robustness Checks}

\subsection{Benchmark Sample}

There might be non-M\&A mechanisms during the sample period of this paper that causes shifts in the variance-covariance structure (VCS) of the M\&A sample. In other words, there is some likelihood to detect similar consistent shifts in a random sample of non-M\&A firms. Thus, a random sample of non-M\&A firms is considered here as a benchmark sample in order to investigate whether those shifts are due to the proposed anticipation mechanism or something else. The results for this benchmark sample serve as the empirical identification strategy for the proposed mechanism.

A non-M\&A firm is a firm that has not been involved in any sort of takeover activities during the sample observation period of this paper. For each pair of M\&A firms in the M\&A sample, a pair of non-M\&A firms in the benchmark sample is selected randomly from the same industry as the pairs in the M\&A sample. This benchmark sampling is done without replacement. The industry-matching can generates a more conservative result compared to the case that any pair is selected randomly from the population of non-M\&A firms. The reason is that the M\&A deals happen in waves and the takeover transactions are more likely to cluster in some industries (e.g., the IT industry in this sample period). This argument means that the market can assign some positive likelihood of merging for those placebo pairs in this benchmark sample as well. The results for this benchmark sample hence provide an upper portion of anticipated deals compared to the case in which the placebo pairs are selected completely at random, i.e., without industry matching.

The comparison between the results of these two samples indicates the validity of the proposed anticipation mechanism. First, Aue et al. (2009) test detects shifts consistent with the deal-anticipation procedure in 52 out of 125 placebo pairs. However, only 38 out of those 52 shifts are detected at 5\% significant level while the rest are identified marginally at $10 \%$ significant level. This indicates that the market may indeed perceive some likelihood of merging only in those 38 pairs. This number for the benchmark sample (38) is significantly less than that for the M\&A sample (i.e., 105 deals are anticipated at 5\% level). There are consistent shifts with the offered payment-form only in 22 placebo pairs (only 15 of them are significant at 5\% level). This number is significantly smaller than the number of paymentform anticipated pairs in the main sample, i.e. 77. In other words, while the market anticipates both the deal and its payment-form in $62 \%$ of the M\&A sample, it may predicts that only $18 \%$ of the benchmark pairs can be involved in the M\&A deals. Second, more importantly, if any market-wide or industry-wide news (rather than the M\&A related information) causes those shifts in both the placebo and the main sample, one can expect that 
both anticipation dates should occur in comparable dates relative to the announcement days. However, this is not the case since only 4 (out of those 38 ) break dates of the benchmark sample lies within one-month distance from the anticipation dates of their matched pairs in the main sample. The rest (34) is located further away from the dates of their matched pairs. Third, another key difference between the M\&A and benchmark samples is that the levels of moments around those anticipation breaks differ significantly across these two samples. The returns of the placebo firms are on average much more volatile, less co-varying and weakly correlated at both pre- and post-break segments. For example, anticipating an Equity offer in the benchmark sample causes the covariance (correlation) to rise on average from $0.9 \mathrm{bps}$ $(9 \%)$ to 0.95 bps $(16 \%)$ from the pre- to post-break segments. However, the covariance (correlation) for the M\&A sample jumps on average from 1.5 bps $(25 \%)$ to $4.7 \mathrm{bps}(61 \%)$ from the pre- to post-break segments. It is hence difficult to relate those shifts in the benchmark sample to anticipation of Equity offers since the deviation from the hypothesized level of correlation (i.e. 100\%) is large. Thus, the market also distinguishes M\&A candidates from non-M\&A pairs based on the level of moments since the level of moments in the M\&A sample is more consistent with the hypothesized levels for the takeover anticipations. Finally, the VCS of the daily average return series (of the main and payment subsamples) for the benchmark sample are, however, stable. Aue et al. (2009) test cannot reject the null of stability at the conventional levels for those average series. This result indicates that the observed small portion of anticipated pairs at the individual level disappear when the data is aggregated at the cross-sections level for the benchmark sample. Overall, the results based on both of the aggregate and individual series support the idea that the observed more frequent anticipation shifts is a unique feature of the M\&A sample. ${ }^{12}$

\subsection{Univariate Vs. Multivariate Tests}

In addition to Aue et al. (2009) multivariate test, the univariate tests are performed separately in this paper for detecting multiple breaks in the variances, covariance and correlation. The Appendix (B) gives a detail presentation of these univariate tests. First, the univariate tests are performed to investigate what is the main source of non-stationarity in the VCS of the bivariate return series. Is instability in the target variance, for example, derives non-stationarity in the VCS? If this is the case, then non-stationarity in the VCS is nothing more than non-stationarity in the target variance and extending the analysis to investigate shifts in the VCS is useless. Second, detecting breaks in the moments of univariate series has its own interpretations. A decline (a shift) in the target (acquirer) variance during the preannouncement period suggests that the market anticipates the target (acquirer) firm. Moreover, existence of consistent shifts in the covariance and the correlation in the preannouncement period indicates that the market anticipates the payment form. These results also help to compare the performance of univariate tests vs. the multivariate test in anticipating the deal and payment-form.

The Appendix reports in detail the results of performing the univariate tests. The instability in the target and acquirer variances is the major sources of non-stationarity in the VCS of 125 bivariate return series. The results of univariate tests indicate that both acquirer and target firms are anticipatable in the pre-announcement period. However, the acquirer firms are more predictable than target firms, e.g., the acquirers are anticipated on average one month earlier than target firms. The fraction of anticipated deals via univariate tests is significantly smaller than that via the multivariate test. Furthermore, Aue et al. (2009) test is

\footnotetext{
${ }^{12}$ The results of analyzing the benchmark sample are not reported here for saving space but they are available upon request.
} 
more powerful than the univariate covariance and correlation tests in detecting PaymentForm-Anticipation dates. These results are expected since Aue et al. (2009) joint test uses efficiently variations in all second-order moments to detect breaks in the VCS of the joint bivariate return distribution.

\subsection{Raw vs. Winsorized Return Series}

The results of Hill test in the Appendix indicate that the number of return series with existent fourth-order moment increases significantly after the $99 \%$ winsorization. Since Aue et al. (2009) test requires existence of the fourth-order moment, the main results in this paper are based on the winsorized return series. One can however criticize that the winsorization may affect adversely the realized return distributions, and so the above results from Aue et al. test might be unreliable. Aue et al. (2009) test is hence repeated with Raw series to illustrate the effects of those potential outliers on the outcome of test.

The results in the Appendix report that the majority of results are consistent between winsorized and raw samples. However, existence of extreme observations in the Raw series cause Aue et al. (2009) test to lose its power in detecting extant breaks in the VCS of 26 deals. As expected, the $99 \%$ winsorization leads to obtain more robust results from Aue et al. (2009) test.

\subsection{Restricted vs. Full Sample Observation Period}

The above significant differences between the pre- and post-announcement moments (which is also observed in the merger arbitrage studies) suggest that the bivariate return distribution can change after the bid announcement. One can hence doubt whether the detected breaks during the pre-announcement period (and so the anticipation dates) is a consequence of mixing pre- with post-announcement returns in the Full sample observation period (i.e., Day-379 to Day C). Aue et al. (2009) test is hence repeated with the restricted sample observation period (only returns from the pre-announcement period, i.e., Day-379 to Day-1) using both raw and winsorized return series to reconcile the above comment.

The results in the Appendix indicate that shifts in the VCS can be detected in a significant portion of deals regardless of using the full or restricted periods. This leads to invalidate the claim that Aue et al. (2009) test detects arbitrarily breaks due to mixing preand post-announcement returns in the full sample observation period.

Those results also show that using restricted sample causes Aue et al. (2009) test to lose its power in detecting breaks close to the announcement day. This restriction hence pushes the distribution of break dates far away from the announcement day. Moreover, there is another concern of using restricted sample. The null hypothesis of this paper is existence of break(s) after the announcement day (i.e., absence of anticipations breaks). Restricted samples cannot be used to examine this null since the likelihood of detecting any break during the post-announcement period is zero by construction of the test. The test based on the full sample is hence more appropriate to investigate the hypotheses in this paper since it always assigns a positive likelihood of existence of breaks in both pre- and postannouncement periods. ${ }^{13}$

\footnotetext{
${ }^{13}$ Indeed, the main results in this paper reveals that at least one break exists during the post-announcement period in a significant portion of deals, $21.6 \%$.
} 


\section{Conclusion}

The results of both the multivariate and the univariate tests indicate that majority of M\&A deals and their payment-forms are anticipated long before the announcement day. A deal is anticipated on average 187 trading days prior to the announcement day. The portion of payment-form anticipated deals $(61.6 \%)$ is considerably lower than the anticipated deals (86.4\%). This is expected since the payment-form-anticipation procedure requires more precise changes in the second-order moments during the pre-announcement period. It takes on average three months for the market to receive more strong signals or to reinterpret available information to pinpoint the most likely payment-form of the anticipated deals. Cash offers are anticipated on average significantly earlier than Equity and Mixed offers. Studying the behavior of second-order moments reveals that the announcement of Cash (Equity and Mixed) offers contains the least (most) unexpected information for the market investors. The lowest portion of anticipated Mixed offers indicates that the market is less successful in anticipating the Mixed bids.

There might be non-M\&A mechanisms during the sample period of this paper that causes those consistent shifts in the variance-covariance structure (VCS) of the M\&A sample. The empirical identification strategy for the proposed anticipation mechanism is based on a benchmark sample. The same anticipation hypotheses are thus investigated for the benchmark sample (i.e. a random sample of non-M\&A firms). The consistent shifts occur much more frequent in the M\&A sample compared to the benchmark sample. This result hence confirms that the likely mechanism is related to the anticipation of takeover transactions.

The Appendix documents a detail presentation of data preparations, additional results and robustness checks. The results of robustness checks indicate that Aue et al. (2009) multivariate test outperforms the univariate tests in anticipating the deal and payment-form, and so reveals efficiency of using joint return distribution (vs. univariate return series) for the takeover anticipations. This paper use a modified version of Hill's test to document significant fatness in the tails of target and acquirer return series. Robustness tests document that using raw series with fatter tails lead to a significant underperformance of both multivariate and univariate tests in detecting breaks in the VCS. These checks also reveal that shifts in the VCS can be detected in majority of deals regardless of using full or restricted sample observation period. Overall, Aue et al. (2009) test based on the full sample and winsorized return series is more appropriate to investigate the anticipation hypotheses and to detect the takeover anticipation dates in this paper.

The findings of this paper have the following implications: First, the results of univariate tests indicate the acquirer firms are more predictable than target firms. This may have implications for the cross-sectional regressions employed in the M\&A studies since they usually assume that merging firms are unpredictable. (See, Cornett, Tanyeri, and Tehranian, 2011, for a detailed discussion.) Second, the majority of M\&A deals and their payment-form are anticipated in this paper due to shifts in the acquirer-target covariance. This result suggests that this moment might be relevant for using in other M\&A studies. Finally, the results of both univariate and multivariate tests indicate that breaks exist in the second-order moments during both pre- and post-announcement periods. The majority of those breaks are located far from the announcement day. These results have implications, e.g., for the merger arbitrage studies that impose a break in the sample second-order moments at the announcement day. 


\section{References}

- Amihud, Y., Lev, B. and Travlos, N. G., 1990, Corporate control and the choice of investment financing: the case of corporate acquisitions, Journal of Finance, 45, 2,603-616.

- Andrews, D.W.K., 1991, Heteroscedasticity and autocorrelation consistent covariance matrix estimation, Econometrica 59: 817-858.

- Andrews, D.W.K., Monahan, J.C., 1992, An improved heteroscedasticity and autocorrelation consistent covariance matrix estimator, Econometrica 60: 953-966.

- Aue, A., Hormann, S. Horvath, L., Reimherr, M., 2009, Break Detection in the Covariance Structure of Multivariate Time Series Models, Annals of Statistics 37, 4046-4087.

- Bai, J., Perron, P., 1998, Estimating and testing linear models with multiple structural changes, Econometrica 66, 47-78.

- Bai, J., Perron, P., 2003, Computation and analysis of multiple structural changes, Journal of Applied Econometrics 18, 1-22.

- Bai, J., Perron, P., 2006, Multiple Structural Change Models: A Simulation Analysis, in Econometric Theory and Practice: Frontiers of Analysis and Applied Research, D. Corbea, S. Durlauf and B. E. Hansen (eds.), Cambridge University Press, 2006, 212-237.

- Ben-Gal I., 2005, Outlier detection, in Data Mining and Knowledge Discovery Handbook: A Complete Guide for Practitioners and Researchers, Maimon O. and Rockach L. (Eds.), Kluwer Academic Publishers, 2005, 1-16.

- Beirlant, J., Vynckier, P. and Teugels, J.L., 1996, Tail Index Estimation, Pareto Quantile Plots, and Regression Diagnostics, Journal of the American Statistical Association, 91 (436), $1659-1667$.

- Berkes, I., Horváth, L., Kokoszka, P., and Shao, Q. -M, 2005, Almost sure convergence of the Bartlett estimator, Periodica Mathematica Hungarica, 51, 11-25.

- Bhagat, S., Brickley, J.A., Loewenstein, U., 1987, The pricing effects of interfirm cash tender offers, Journal of Finance 42, 965-986.

- Bhagwat, Vineet and Robert A. Dam, 2012, Legal Frameworks, Relatedness and the Method of Payment in Corporate Acquisitions. (December 9, 2012), http://leedsfaculty.colorado.edu/nilssom/BhagwatDam_MOPDraft_Boulder.pdf, (Accessed March 1, 2013)

- Bharath, S. T., and Wu, G., 2006, Long-run volatility and risk around mergers and acquisitions, University of Michigan, Working Paper, http://www.bauer.uh.edu/wu/Papers/Mergervol.pdf (Accessed March 1, 2013)

- Bradley, M., Desai, A. and Kim, E. H., 1988, Synergistic gains from corporate acquisitions and their division between the stockholders of target and acquiring firms, Journal of Financial Economics, Vol. 21, 3-40.

- Brown, Morton B., Forsythe, Alan B., 1974, Robust Tests for the Equality of Variances, Journal of the American Statistical Association, Vol. 69, No. 346 (Jun., 1974), 364-367.

- Chang, I.H., Tiao, G.C. and C. Chen, 1988, Estimation of Time Series Parameters in the Presence of Outliers, Technometrics, 30, 193-204.

- Chatterjee, Sayan and Lubatkin, Michael, 1990, Corporate Mergers, Stockholder Diversification, and Changes in Systematic Risk, Strategic Management Journal, Vol. 11, No. 4, 255-268.

- Chen, J. and Gupta, A.K., 1997, Testing and locating variance changepoints with application to stock prices, Journal of the American Statistical Association, 92, 739-747.

- Cornett, Marcia Millon, Başak Tanyeri, Hassan Tehranian, 2011, The effect of merger anticipation on bidder and target firm announcement period returns, Journal of Corporate Finance, Volume 17, Issue 3, 595-611

- Dlugosz, J., Fahlenbrach, R., Gompers, P., Metrick, A., 2006, Large blocks of stock: Prevalence, size, and measurement, Journal of Corporate Finance, 12 (3), pp. 594-618. 
- Eckbo, E., Giammarino, R., and Heinkel, R., 1990, Asymmetric information and the medium of exchange in takeovers: Theory and tests, Review of Financial Studies, 3, 651-675.

- Fama, E. F., 1963, Mandelbrot and the stable Paretian hypothesis, Journal of Business, $36: 420-429$.

- Galeano, P., Wied, D., 2013, Multiple break detection in the correlation structure of random variables, Computational Statistics and Data Analysis, 2013, forthcoming.

- Geppert, Gero, Kamerschen, David R., 2008, The effect of mergers on implied volatility of equity options, International Review of Financial Analysis, Volume 17, Issue 2, Pages 330344.

- Hadlock, C.J. and Pierce, J.R., 2010, New evidence on measuring financial constraints: moving beyond the KZ index, The Review of Financial Studies, 23, pp. 1909-1940.

- Hamada, R., 1972, The effect of the firm's capital structure on the systematic risk of common stocks, Journal of Finance, May 1972, pp. 435-45.

- Harford, Jarrad, 2005, What drives merger waves? Journal of Financial Economics, Volume 77, Issue 3, Pages 529-560.

- Haas, Markus and Christian Pigorsch, 2009, Financial Economics: Fat-tailed Distributions, in: Encyclopedia of Complexity and Systems Science, Vol. 4, Heidelberg: SpringerVerlag, 3404-3435.

- Hasbrouck, Joel, 1985, The characteristics of takeover targets q and other measures, Journal of Banking and Finance, Volume 9, Issue 3, 351-362.

- Hill, Bruce M., 1975, A Simple General Approach to Inference About the Tail of a Distribution, Annals of Statistics, Volume 3, Number 5, 1163-1174.

- Hutson, E., Kearney, C., 2001, Volatility in stocks subject to takeover bids: Australian evidence using daily data, Journal of Empirical Finance 8, 273-296.

- Hutson, E., Kearney, C., 2005, Stock price interaction between target and bidder stocks during takeover bids, Research in International Business and Finance 19, 1-26.

- Inclán, C., Tiao, G. C., 1994, Use of cumulative sums of squares for retrospective detection of changes of variance, Journal of the American Statistical Association 89:913-923.

- Ismail, A., and Krause, A., 2010, Determinants of the method of payment in mergers and acquisitions, The Quarterly Review of Economics and Finance, 50(4), 471-484.

- Jayaraman, Narayanan, Gershon Mandelker, and Kuldeep Shastri, 1991, Market anticipation of merger activities: An empirical test, Managerial and Decision Economics 12, 439-448.

- Jennrich, Robert I., 1970, An Asymptotic $\chi^{2}$ Test for the Equality of Two Correlation Matrices, Journal of the American Statistical Association, Vol. 65, No. 330, 904-912.

- Jensen, M.C. and R. Ruback, 1983, The Market for Corporate Control: The Scientific Evidence, Journal of Financial Economics (April), 5-50.

- Kokoszka, P. and Leipus, R., 2000, Change-point estimation in ARCH models, Bernoulli, Vol. 6, 513-539.

- Kothari, S.P., Warner, J., 2007, Econometrics of event studies, in: Eckbo, E. (Ed.), Handbook of Corporate Finance, vol. 1,Elsevier/North-Holland, Amsterdam, 1-36.

- Kumar, A., 2009, Who Gambles in the Stock Market? The Journal of Finance, 64: 18891933.

- Langetieg, T. C, R. S. Haugen and D. W. Wischern, 1980, Merger and stockholder risk, Journal of Financial and Quantitative Analysis, 15(3), 689-710.

- Laughran, T. and A.M. Vijh, 1997, Do Long-Term Shareholders Benefit from Corporate Acquisitions, Journal of Finance, Vol. 52, No. 5. , 1765-90.

- Levene, H., 1960, Robust Tests for Equality of Variances, in I. Olkin, ed., Contributions to Probability and Statistics, Palo Alto, Calif.: Stanford University Press, 1960, 278-92.

- Lim,T.-S., Loh, W.-Y., 1996, A comparison of tests of equality of variances, Computational Statistical and Data Analysis 22, 287-301.

- Loretan, M. And P. C. B. Phillips, 1994, Testing the covariance stationarity of heavy-tailed time series, Journal of Empirical Finance, 1(2): 211-248. 
- Mandelbrot, B., 1963, the variation of certain speculative prices, Journal of Business, 36:394419.

- Martin, Kenneth J., 1996, The method of payment in corporate acquisitions, investment opportunities, and management ownership, Journal of Finance 51, 1227-1246.

- Martynova, Marina and Renneboog, Luc, 2008, A century of corporate takeovers: What have we learned and where do we stand? Journal of Banking and Finance, 32, 2148-2177.

- Mitchell, M. L., and J. H. Mulherin, 1996, The Impact of Industry Shocks on Takeover and Restructuring Activity, Journal of Financial Economics 41, 193-229.

- Newey, Whitney K., West, Kenneth D., 1994, Automatic Lag Selection in Covariance Matrix Estimation, Review of Economic Studies, vol. 61(4), 631-53.

- Pitarakis, Jean-Yves, 2004, Least squares estimation and tests of breaks in mean and variance under misspecification, Econometrics Journal, volume 7, 32-54.

- Rodrigues, P. M. M.; Rubia, A., 2007, On the Finite Sample Size Distortions in Nonparametric Testing for Variance Constancy, Fundación de Cajas de Ahorros, Working Paper Series N247/2007

- Rodrigues, P. M. M.; Rubia, A., 2011, The Effects of Additive Outliers and Measurement Errors when Testing for Structural Breaks in Variance, Oxford Bulletin of Economics and Statistics, 73: 449-468.

- Sansó, A., Aragó, V. and Carrion-i-Silvestre, J. L1., 2004, Testing for Changes in the Unconditional Variance of Financial Time Series, Revista de Economía Financiera, 4, 32-53.

- Schwert, G. W., 1996, Markup pricing in mergers and acquisitions, Journal of Financial Economics, vol. 41(2), 153-192.

- Sharpe, William F, 1964, Capital Asset Prices: A Theory of Market Equilibrium under Conditions of Risk, Journal of Finance, 19:3, 425-42.

- Smith, R., Kim, J., 1994, The combined effects of free cash flow and financial slack on bidder and target stock returns, The Journal of Business, Vol. 67, No. 2, pp. 281310.

- Sul, D., Phillips, Peter C. B. and Choi, Chi.Y., 2005, Prewhitening Bias in HAC Estimation, Oxford Bulletin of Economics and Statistics, 67, 4, 517-546.

- Subramanian, A., 2004, Option pricing on stocks in mergers and acquisitions, Journal of Finance 59, 795-829.

- Travlos, N., 1987, Corporate takeover bids, methods of payment, and bidding firms' stock returns, Journal of Finance, 42, 943-963.

- Tukey, J.W., 1962, The future of data analysis, Annals of Mathematical Statistics 33(1), 1-67.

- Welch, B. L., 1947, The generalization of 'student's' problem when several different population variances are involved, Biometrika, 34, 28-35.

- Wilcoxon, F., 1945, Individual comparisons by ranking methods, Biometrics, 1, 80-83. 


\section{Appendix}

\section{A. Data Preparation}

After the seminal work of Mandelbrot (1963), confirmed by Fama (1963) and many others, there is a general consensus in finance that the return distribution of financial assets has fatter tails than the normal distribution. This type of distribution is called leptokurtic and is identified with an infinite fourth-order sample moment (i.e., a tail-index less than four). Both of multivariate and univariate CUSUM-type tests used in this paper requires explicitly existence of fourth-order moment for asymptotic convergence of their test statistics. This assumption might be violated when there is some extremely outlying returns at least in one of the target and acquirer return series. There are indeed studies that show significant size distortions and power loses in the CUSUM-type tests when the outliers cause a series to have an infinite fourth-order moment (see, for example, Rodrigues and Rubia, 2011). A modified version of Hill's (1975) statistic is used to test systematically whether the fourth sample moment exists in each target and acquirer return series. The result of Hill tests together with the effects of outliers on the sample moments are discussed in this Appendix.

Given the well-documented large positive (negative) significant Abnormal returns to the target (acquirer) firms around the announcement day, it is highly likely that those returns are outlying observations. The merger arbitrage literature excludes several observations surrounding the announcement day to reduce the influential impacts of potential outlying returns on the sample second-order moments and the related test statistics. For instance, Bhagat et al. (1987) exclude returns between Day-20 to Day1. This solution implicitly assumes that outlying returns are clustered around the announcement day. However, first, the outliers can be spread during the whole sample observation period. Second, exclusion of those returns can remove very important information about the takeover transactions, which might be necessary for the non-stationarity analysis.

A very simple rule is used in this paper to identify potential outliers in each target and acquirer return series. Then, the identified potential outliers are winsorized. Tukey (1962) explains that winsorising is better than trimming data in most cases since it can save important information and lead statistical procedures to generate more robust results. Winsorising reduces the contaminating effects of those extreme returns on the tests of this paper. ${ }^{14}$ It also retains important information necessary to figure out how the market anticipates the M\&A deals and the payment-forms.

\section{A.1. Identifying and Winsorising Outliers in the Return Series}

Let $Z_{A c q, n, t}$ denotes the $Z$-value of $n^{\text {th }}$ acquirer return at day $t$ and equals to $Z_{A c q, n, t}=\frac{r_{A c q, n, t}}{\sigma_{A c q, n}}$, where $\sigma_{A c q, n}=\sqrt{\frac{1}{(C+379)} \sum_{t=-379}^{T=C}\left(r_{A c q, n, t}-\bar{r}_{A c q, n}\right)^{2}}$ is the sample unconditional volatility over its sample observation period. Similarly, the Z-values are constructed for the target return series as well.

This $Z$ value corresponds to the $Z$-value of a standard normal distribution. The deviation of each realized return is computed from the sample median instead of the sample mean. The sample mean can be skewed due to the outliers. It is assumed for simplicity that the median is zero. According to Ben-Gal (2005), an observation can be identified as an

\footnotetext{
${ }^{14}$ Although winsorising might be used infrequently in the time series studies, it is common in the corporate finance literature to reduce the influential effects of outliers in the cross-sectional regressions. See, e.g., Dlugosz Fahlenbrach, Gompers, and Metrick (2006), Hadlock and Pierce (2010) and Kumar (2009).
} 
outlier if its absolute $\mathrm{Z}$-value is larger than 1.96 (corresponding to the $\mathrm{Z}$-value of 5\% significance level in the standard normal distribution). Since it is well documented that daily returns have fatter tails than normal distribution, a stricter rule is imposed in this paper to identify a daily log-return as an outlier. The absolute Z-value is increased to 3 (corresponding to the Z-value of $0.27 \%$ significance level in the standard normal distribution) to reduce the probability of incorrectly identifying a return as an outlier. The three absolute standard deviation (3ASTDV) rule is:

$$
\text { if }\left\{\begin{array}{ccc}
\left|Z_{i, n, t}\right| \geq 3 \quad & \Rightarrow & Z_{i, n, t} \text { is an outlier } \\
\text { Otherwise } & \Rightarrow & Z_{i, n, t} \text { is not an outlier }
\end{array}\right\}
$$

It should be notified that there are various parametric approaches for detecting outliers (e.g., Chang et al., 1988). The 3ASTDV rule is used in this paper since it is simple to apply and closely related to the winsorization idea.

The maximum number of observations that can be winsorized is equal to $1 \%$ of total number of returns in each series. Those identified outliers are then sorted decreasingly based on their $\left|Z_{i, n, t}\right|$. The largest outlying observations are selected based on the $1 \%$ rule and then winsorized (i.e., replaced) with the closest raw observation. This corresponds to a $99 \%$ winsorization. This winsorization is asymmetric since all (or majority) of extreme observations can be identified from one tail of return distribution. However, it is more suitable than the symmetric winsoriziation (e.g., winsorising both tails at $0.5 \%$ ). The reason is that it can also correct asymmetry in a distribution, if most of the outliers are clustered in one tail.

\section{A.2. Testing and Adjusting Structural Breaks in the mean of Return Series}

Pitarakis (2004), for instance, shows that inferences about shifts in the variance of a series may be biased when its mean is unstable. As required by Aue et al., mean stability of each series is tested before applying their test. If there are shifts in the mean of a series, that series is transformed to make its mean stable. Bai and Perron (1998, 2003 and 2006) test identifies the number of breaks (i.e., $m$ ), the break dates and corresponding shifts in the mean of return series by estimating the following regression:

$r_{i, n, t}=\bar{r}_{i, n, k}+\varepsilon_{t}$,

Where $t\left(=T_{k-1}+1, \ldots, T_{k}\right)$ is the daily subscript; $k(=1, \ldots, m+1)$ is the regime index; $\bar{r}_{A c q, n, k}(k=1, \ldots, m+1)$ is the mean of returns to the acquirer $n$ in the $k^{\text {th }}$ regime; $\varepsilon_{t}$ is the disturbance at day $\mathrm{t}$; the indices $T_{1}, \ldots, T_{m}$ are the estimates of unknown break dates that determines $m+1$ regimes and $T_{0}=-379$ and $T_{m+1}=C$. When the number of breaks in the mean of return series is statistically greater than zero (i.e. $m>0$ ), the transformed return series is computed from equation (1). It is simply equal to $\varepsilon_{t}$.

The practical recommendations of Bai and Perron $(2003,2006)$ are applied in this paper to improve the size and power of Bai and Perron test. First, the statistical significance of $U D \max F_{T}$ test is used to investigate the presence of at least one break $(m=1)$ in the mean of a return series. Second, Bai and Perron suggest that the $\operatorname{SupF}_{T}(\ell+1 \mid \ell)$ test is applied successively by using the sequential estimates of the break dates to assess whether there are 
more than one $(m>1)$ breaks. This sequential approach implies that the number of breaks is equal to $m$ when for the first time the $\operatorname{SupF}_{T}(m+1 \mid m)$ test statistics becomes insignificant at the conventional significance levels. A maximum of five breaks per series is allowed.

The trimming factor $(\varepsilon)$ determines the minimum distance between subsequent breaks and is measured as the percentage of the total number of observations of a series. Bai and Perron (2006) suggest to use a higher trimming factor (i.e., $\varepsilon \geq 15 \%$ ) for a typical sample with more than 100 observations and a smaller value when the sample size is large enough. The trimming factor is selected to be $10 \%$ in this paper because, first, the sample size is to some extent large. There are at least 400 observations in every return series. Second, Bai and Perron test is applied to examine whether the mean of a series is subject to shifts in the both of pre-and post-announcement periods. A trimming factor of $15 \%$ indicates that at least $15 \%$ of the observations of a return series should exist after the announcement day. Otherwise, Bai and Perron method pushes all breaks prior to the announcement day. This requires existence of around 80 observations during the post-announcement period. However, only half of deals in our sample can satisfy this requirement. Bai and Perron test is also repeated with trimming factor of $5 \%$ in deals with less than 50 observations during the post-announcement period to give a positive chance for detecting a break during that period. However, the results are the same regardless of the choice of $5 \%$ or $10 \%$ trimming factor.

Bai and Perron (2006) find in their simulations that correcting for heterogeneity in the data and in the errors across segments and the serial correlation can considerably improve the coverage ratio of confidence intervals for the structural break dates. Andrews's (1991) data dependent method (with the Quadratic Spectral kernel and an AR (1) approximation to select the bandwidth) is used to construct a covariance matrix robust to the heteroscedasticity and the serial correlation (the HAC estimator) in the residuals of regressions (1). Bai and Perron also provide an option to apply Andrews and Monahan (1992) pre-whitening prior to estimating the long run covariance matrix. This option is however not considered in this paper since Sul, Phillips, and Choi (2005) find that the pre-whitening can lead to biased HAC estimates, which in turn can reduce significantly the power of structural break tests. The HAC standard errors are constructed by allowing the distributions of the data and errors to differ across segments. These choices are relevant in this paper since the daily return series are mostly auto-correlated. It is also quite likely to observe heterogeneous distribution of returns and residuals across segments, especially around the announcement day. Moreover, accounting for the heterogeneity in the data and errors can control the adverse effects of outliers on Bai and Perron test.

\section{B. Detecting Breaks in the Second-Order Moments of Univariate Series}

There is a key difference between these univariate tests and the above tests for the equality of the sample-second order moments across two subsequent segments. Previous knowledge about timing of break dates is necessary before conducting the equality tests while break dates is unknown before applying the univariate structural break tests. The univariate tests are indeed performed to detect significant break date(s) in the sample second-order moments. However, the equality test is performed to examine whether the change in the sample second-order moment after a known break date is statistically significant or not.

\section{B.1. Detecting Breaks in the Variance of a Univariate Series}

In contrast to a very few tests for detecting breaks in the VCS of a multivariate series, the literature for detecting breaks in the variance of a univariate series is rich. Since CUSUM- 
type tests are simple and have robust statistical properties, they are applied in this paper. ${ }^{15}$ Inclan and Tiao (1994) propose a centered CUSUM of squares test for detecting breaks in the variance of a series. Their iterated CUSUM approach (ICSS) assumes an independent and identically distributed (i.i.d.) series in which observations follow the normal distribution. Chen and Gupta (1997) use same assumptions as Inclan and Tiao and suggest an alternative test based on the SIC. The simulated power of the proposed procedures is comparable to that of Inclan and Tiao test but with an advantage of less burdensome computation. However, the i.i.d. and normality assumptions are typically invalid for most of financial time series. Kokoszka and Leipus (2000) release the independence assumption and consider the parametric ARCH-type design to detect breaks in the variance of an individual series. Rodrigues and Rubia (2011) show that Inclan and Tiao, and Kokoszka and Leipus tests are sensitive to existence of outliers. Sansó, Aragó, and Carrion-i-Silvestre (2004) develop two tests by modifying (and extending) the ICSS test of Inclan and Tiao. They control fatness of tails (excess kurtosis) in their first test, $\kappa_{1}$, and capture more generalized dependence structure in the second test, $\kappa_{2}$. Sansó et al. (2004) show theoretically, empirically and by simulation that Inclan and Tiao, and Kokoszka and Leipus tests are severely biased in the presence of heavy tails and various type of serial dependence while their tests are robust in those cases. The nice feature of $\kappa_{1}$ and $\kappa_{2}$ tests is that both of them converge asymptotically to the ICSS test of Inclan and Tiao when outliers and serial correlation are absent in the data. The $\kappa_{2}$ test is a generalization of the $\kappa_{1}$ test, and so it is reduced to the $\kappa_{1}$ test in the absence of serial correlation. Although the $\kappa_{2}$ test is more conservative than $\kappa_{1}$ test, it is robust against both fatness of tails and the serial correlation, i.e., the two key features of financial time series. Thus, as suggested by Sansó et al. (2004), the $\kappa_{2}$ (henceforth, the ICSS test) is applied in this paper for detecting breaks in the variance of a univariate return series.

As in the multivariate test of Aue et al. (2009), the Bartlett estimator approximates the covariance matrix in testing procedure of the ICSS test and the lag truncation is based on the Newey and West (1994). The ICSS test examines the following hypotheses:

$$
\begin{array}{ll}
H_{0}: & \sigma_{T r g, 379}^{2}=\cdots=\sigma_{T r g, 0}^{2}=\cdots=\sigma_{T r g, C}^{2} \\
H_{A}: & \sigma_{T r g,-379}^{2}=\cdots=\sigma_{T r g, k_{1}}^{2} \neq \sigma_{T r g, k_{1}+1}^{2}=\cdots=\sigma_{T r g, k_{2}}^{2} \neq \cdots \neq \sigma_{T r g, k_{m}+1}^{2}=\cdots=\sigma_{T r g, C}^{2},
\end{array}
$$

Where $m$ is the unknown number of change-points, e.g., in the variance of target return series and $-379<k_{1}<\cdots<k_{m}<C$ are unknown positions of the change-points in the sample period. The ICSS test is performed separately across each of 125 target and acquirer return series to identify the number (i.e. $m)$ and the location of $\operatorname{shifts}\left(k_{1}\right.$ to $\left.k_{m}\right)$.

\section{B.2. Detecting Breaks in the Covariance Series}

To the best of my knowledge, there is not a specific test that is developed for detecting breaks in the covariance of a bivariate series. At first glance, the first alternative for detecting breaks in the covariance is modifying the CUSUM of squares approach of Sansó et al. (2004). However, this might be not applicable since the asymptotic distribution of $\kappa_{2}$ statistic and its critical values are particularly derived for the variance case. The key point is that variance of a series is always positive while the covariance can be either positive or negative. It is hence an agenda for further research to study the behavior of $\kappa_{2}$ statistic (or other

\footnotetext{
${ }^{15}$ See, e.g., Rodrigues and Rubia (2007) for a related discussion in detail.
} 
CUSUM-type tests) when it is modified and applied for detecting breaks in the covariance of a bivariate series.

However, Bai and Perron $(1998,2003)$ test can detect breaks in the mean of sample covariance since it does not require the covariance series to be positive. To do so, the realized covariance series is constructed:

$\sigma_{A c q-T r g, t}=\tilde{r}_{A c q, t} \cdot \tilde{r}_{T r g, t}$,

Where $\sigma_{A c q-T r g, t}$ is the daily-realized return covariance of acquirer-target firms at day $\mathrm{t}$. The aim of Bai and Perron test is to identify the number of breaks (i.e., $m$ ), the break dates and corresponding shifts in the mean of the realized covariance by estimating the following regression:

$\sigma_{A c q-T r g, t}=\bar{\sigma}_{A c q-T r g, k}+v_{t}$,

Where $t\left(=T_{k-1}+1, \ldots, T_{k}\right)$ is the daily subscript; $k(=1, \ldots, m+1)$ is the regime index; $\bar{\sigma}_{A c q-T r g, k}(k=1, \ldots, m+1)$ is the mean of realized covariance in the $k^{\text {th }}$ regime and $v_{t}$ is the disturbance at day $\mathrm{t}$; the indices $T_{1}, \ldots, T_{m}$ are the estimates of unknown break dates that determines $m+1$ regimes and $T_{0}=-379$ and $T_{m+1}=C$. The same options of Bai and Perron test as already discussed are used here as well.

\section{B.3. Detecting Breaks in the Correlation}

Tests for detecting structural breaks in the correlation of a bivariate series is very rare in the literature. Recently, Galeano and Wied (2013) propose a CUSUM-type test. Their test is applied in this paper to examine existence of multiple breaks in the sample correlation of acquirer-target return series during the sample observation period. Galeano and Wied test examines the following hypothesis:

$$
\begin{aligned}
& H_{0}: \quad \rho_{\text {Acq-Trg, }-379}=\cdots=\rho_{\text {Acq-Trg, } 0}=\cdots=\rho_{\text {Acq-Trg, }-379} \\
& H_{A}: \quad \rho_{\text {Acq-Trg, } 379}=\cdots=\rho_{\text {Acq-Trg, } k_{1}} \neq \rho_{\text {Acq-Trg, } k_{1}+1}=\cdots=\rho_{\text {Acq-Trg }, k_{2}} \neq \cdots \neq \rho_{\text {Acq-Trg, } k_{m}+1}=\cdots=\rho_{\text {Acq-Trg, },},
\end{aligned}
$$

Where $\rho_{A c q-T r g, k_{1}}=\frac{\sigma_{A c q-T r g, k_{1}}}{\sigma_{A c q, k_{1}} \cdot \sigma_{T r g, k_{1}}}$, for example, is the sample correlation in the first segment, $m$ is the unknown number of change-points and $-379<k_{1}<\cdots<k_{m}<C$ are unknown positions of the change-points in the observation period.

\section{Additional Data Analysis}

\section{C.1. Acquisitions and Pre-deal Target and Acquirer Characteristics}

The results in this subsection are computed via raw (non-winsorized) return series to compare with the previous M\&A studies. The descriptive statistics related to the acquisitions, pre-deal target and acquirer characteristics are summarized in Table C.1, providing insights into the nature of the sample data investigated in this paper. The number of acquisition between firms within similar industries $(S I C=1)$ is 72 deals. 
Only 5 out of 125 deals has less than 379 daily returns during the pre-announcement due to lacking returns of either target or acquirer firm. The total number of daily returns for the sample observation period of each deal is given by: $T_{n}=P_{n}+C_{n}$, where $T_{n}$ is the total number of daily returns, $P_{n}\left(C_{n}\right)$ is the number of daily returns during the pre- (post-) announcement period. Since $C_{n}$ varies among deals, $T_{n}$ is inconstant.

The average and median of $C$ (denoted by No-Obs-Aft $(\boldsymbol{C})$ in Table C.1) is respectively 83 and 73 trading days. The large F-value of ANOVA model (11.17) implies that the average consummation time (i.e., $C$ ) is significantly different across payment subsamples. The smaller average $C$ for Cash subsample (65 days) points out that the target of Cash offers is delisted earlier than Equity and Mixed offers. This is not surprising since Equity offers can be subject to different regulatory frameworks like the approval of shareholders.

The largest wealth effect of takeovers is usually observed at the first bid announcement day (i.e., Day 0) when acquirers offer a bid premium to gain control of the target firms. The average return to the target shareholders at Day 0 (i.e., TARG-Announce-Return) is significantly positive (11.9\%) while $\boldsymbol{A C Q}$-Announce-Return is statistically negative (-1.5\%). The mean and median tests also confirm that these averages are significantly different. This indicates that the target shareholders receive the most benefits of takeovers transactions, as observed in other studies (e.g., Schwert, 1996).

The ANOVA analysis points out that the average announcement return to either of target and acquirer shareholders is statistically different across payment subsamples (the Fvalue is 4.04 and 4.35, respectively). The acquirers on average offer a higher bid premium in Cash offers (15.4\%) than Equity and Mixed offers (7\%, 11.3\%). The market reacts to Equity and Mixed offers with lowering the acquirer's share price at the announcement day $(-3.3 \%$ and $-2.6 \%)$.

The markup premium to the target shareholders (TARG-Mark-up) is the cumulative $\log$ returns to the target's stock from the announcement day through delisting day. The markup premium measures the final bid premium per share that the acquirer pays to gain the control of target firm. The average markup premium to the target shareholders is significant and equals to $20 \%$ while it is slightly positive $(2.7 \%)$ but statistically insignificant for the acquirer. The mean and median tests also show that the difference between these averages is significant. This result is comparable to some extent to Schwert (1996)'s findings in which target's markup premium for completed tender offers is $20.1 \%$ and insignificant for the acquirers $(2.5 \%)$. However, he uses a different post-announcement period and a different measure for price performance (i.e., CAARs), while the raw returns are used here.

Any public information about a forthcoming bid offer that is released prior to the announcement day can enhance the takeover anticipations. That information is captured by News dummy variable. Since rumors are released for a small fraction of deals $(16.8 \%)$, it is difficult to conclude that news causes the anticipations.

The average (median) acquisition in the sample has a deal value of 2655 (428) million U.S. dollars. The Deal-Value $(\$ \mathrm{~m})$ ranges from 52 to 67000 million U.S. dollars, indicating that the sample deals is not restricted to only very big or very small deals. The average deal value for Equity subsample ( $\$ 5340$ million) is much larger than Cash subsample (\$469 million), which is also confirmed by the significant F-value of the ANOVA model (7.34). This suggests that the relative size of target to acquirer can be important in the choice of method of payment if the acquirer is financially constraint. Relative-Size is computed as market capitalization of target firm divided by market capitalization of acquirer firm at the year-end prior to the bid announcement. Large F-value of ANOVA analysis (11.17) shows that the average Relative-Size among payment subsamples is indeed statistically different. The fraction of acquirer's shares that the bidders use to finance the acquisitions increases 
with the average Relative-Size. The payment-form to the target shareholders is on average Equity-exchange when the target is about the same size as the acquirer.

\section{C.2. Outliers and Existence of Fourth-Order Moment}

The current knowledge in finance accepts that the Gaussian is inappropriate to model the heavy tails of financial return distributions. The literature agrees on the Pareto-type distributions as more appropriate model for those fatter tails. This distribution is characterized by a tail index (tail exponent), which measures the fatness of tails. The tail index is also a measure of the largest sample moment of a distribution. ${ }^{16} \mathrm{~A}$ tail index less than four implies a non-existent fourth-order sample moment that in turn may lead to inconsistent results obtained from Aue et al. (2009) and univariate tests.

Existence of the forth-order moment of each tail of a series is rejected if its estimate of tail index is statistically less than four at the conventional levels $(1 \%$ to $10 \%)$. This is examined by a left-tailed test whose null hypothesis is that a tail estimate is larger than four against the alternative of smaller than four. ${ }^{17}$

Hill's (1975) estimator is used to estimate the Left and Right Tail Index of each return series. This estimate depends on the choice of the number of observations in each tail (i.e., $\boldsymbol{K}$ ) that is used to fit the Pareto distribution. Modifications of Hill test are considered here. The optimal $\boldsymbol{K}$ is determined by a procedure proposed by Beirlant, Vynckier, and Teugels (1996), which minimize the asymptotic mean squared error (AMSE). The suggestion of Loretan and Phillips (1994) is used, i.e., the max of $\boldsymbol{K}$ should not be larger than $10 \%$ of sample size.

\section{Insert Table C. 2 here}

Panel A of Table C.2 summarizes the sample second-order moments, skewness and kurtosis and the modified Hill statistics for the left and right tail index of 125 target and acquirer series. Both target and acquirer Raw return series has heavily leptokurtic distributions since their average and median kurtoses are significantly larger than of a normal distribution (i.e., 3). The target returns series are significantly skewed to the right while the acquirer return series resemble a symmetric distribution. These results suggest that both of the acquirer and target return distributions are non-normal.

Unreported mean and median tests indicate that average and median kurtosis of the target raw return series (21.87 and 12.97) are significantly larger than those of acquirer return series (10.62 and 6.4). Similar mean and median tests suggest that the target return series are more positively skewed compared to the acquirer return series. Part of the positive skewness and fatter tails of the target return distributions can be explained by the observed larger abnormal returns to the target shareholders around the bid announcements.

Unreported mean and median tests show that the average and median estimates of left and right tail index of both target and acquirer raw return series are significantly less than four (except the average left tail index of acquirer series). This suggests that the Pareto-type distributions fits better with the acquirer and target raw return distributions than the $\alpha$-stable distribution, which is recommended by Mandelbrot (1963) and Fama (1963). This result is consistent with previous findings, e.g., Loretan et al. (1994). The results of left-sided test indicate that existence of fourth-order moment can be rejected in $68.8 \%(58.4 \%)$ of 125 target return series since their estimate of right (left) tail index is statistically lower than four. The Fraction of Non-Existent $4^{\text {th }}$ Moment for the acquirer series is significantly lower and equal to $40 \%(39.2 \%)$ for the right (left) tail. These significant fractions of infinite fourth

\footnotetext{
${ }^{16}$ See, e.g., Haas and Pigorsch (2009) for further details about the properties of financial return distributions (in particular, the Pareto-type tails).

${ }^{17}$ See, e.g., Loretan et al. (1994) for more details about the test and its asymptotic distribution.
} 
moment in those Raw Series warns substantially that the multivariate and univariate structural break tests can lose significantly their power in detecting existent shifts in the second-order moments. These tests (i.e., Aue et al., and ICSS) use a measure of sample fourth-order moments in their denominators. Thus, inflated fourth moments can result in a smaller test statistic and so a less powerful test compared to the cases when those moments are finite. This is the reason why those tests require existence of sample fourth-order moment.

One may ask whether few outlying observations in each return series cause this nonnormality and Pareto-type tails. If so, how controlling the influential effect of those outliers, e.g., by the proposed $99 \%$ winsorization, can improve the fraction of deals with existent fourth moment.

The 3ASTDV rule identifies approximately $1 \%$ of sample returns in each series as potential outliers. There are almost 5 outliers in each of target and acquirer return series. The announcement day return is outlier in 73 (23) of 125 target (acquirer) series, from which only 46 (21) are the largest outlier. As expected, the announcement day is the most likely time to observe extreme returns since the bulk of outliers are located at that day ( $8.3 \%$ of total). In contrast to implicit assumption in the M\&A studies, the announcement day is not the largest and the unique outlying return. The rest of outliers (91.7\% of total) are distributed during the sample observation period. This result suggests that more robust methods for existence of outliers should be considered when they are applied to study M\&A deals.

Panel B of Table C.2 summarizes the above statistics after winsorising the outliers of each return series at 99\% level. The average and median differences between Raw and Winsorized Series in Table C. 2 show that the outliers inflate significantly all second-order moments of target and acquirer return series. Both mean and median difference test (RawWinsorized) indicates that the winsorization mitigates significantly the excess kurtoses problem in both target and acquirer return series. For example, the average kurtosis of the target return series is reduced significantly from 21.87 in the Raw Series to 5.46 in the Winsorized Series. Both tests also indicate that the winsoriaztion makes the target return series more symmetric and retains the symmetry of the acquirer series. Overall, this winsorization reduces the fatness of tails and make the distribution more symmetric.

As expected, the winsorization reduces significantly the number of target and acquirer return series with infinite fourth-order moment. The Fraction of Non-Existent Fourth Moment in 125 target (acquirer) return series is declined significantly from $60 \%(40 \%)$ to almost $30 \%$ (20\%) after the winsorization. One may comment from this result that the $99 \%$ winsorization is incapable in ensuring the existence of fourth moment across all return series. A higher level of winsorization (like 95\% level) might be recommended. However, a higher level can lead to winsorize non-outlying returns as well and may discard relevant information necessary for identifying anticipation breaks and for studying the behavior of the secondorder moments. The unreported results also indicate the main differences in the sample second-order moments across payment subsamples are retained after this winsorization. This indicates that the $99 \%$ winsorization restores meaningful variations in those moments across subsamples that are necessary for the payment anticipations. Moreover, unreported results indicate that the number of target (acquirer) return series with non-existent fourth moment in both tails is reduced from 55 (23) to 13(11) after the winsorization. This suggests the number of target and acquirer series either with one fat tail or with two thin tails is increased significantly in the winsorized series, proposing that a higher level of winsorization might be unnecessary. Overall, it is concluded that those outliers identified by the 3ASTDV rule inflate the second-order moments and kurtosis and generate a significant portion of series with nonexistent fourth-order moment. The 99\% winsorization can cause Aue et al. (2009) and 
univariate test to generate more consistent results with their asymptotic distributions. This will be systematically investigated in the robustness checks.

\section{C.3. Structural Breaks in the Mean of Return Series}

Bai and Perron test is separately performed on each of 125 target and acquirer return series. Unreported results indicate that the mean of target (acquirer) return series is shifted in 16 (15) series. There is only 4 deals that Bai and Perron test detects shifts in the mean of both target and acquirer return series. All of those breaks are located during the pre-announcement period. Bai and Perron test cannot reject the stability of means in 98 deals. This suggests that the mean of target and acquirer return series is rather stable. Those return series are adjusted for their shifts in order to maintain the mean stability assumption required by the CUSUMtype tests.

\section{Robustness Checks in Detail}

\section{D.1. Univariate Vs. Multivariate Tests}

Results of detecting multiple breaks in the second-order moments of univariate series are summarized in Table D.1. The major goal of this section is to compare these results with those of Aue et al. (2009) multivariate test. It is of particular interest to investigate whether there is any relationship between these two methods in term of frequency and timing of the breaks and which one outperforms in anticipating the deal and payment-form.

\section{Insert Table D.1 here}

The total number of significant breaks in the unconditional second-order moments of 125 deals is detected downwardly in: the target variance (122), acquirer variance (112), the covariance (58), and the correlation (35). The same sequence follows for the fraction of deals with significant breaks. Unreported results indicate that the average number of breaks per deal and the fraction of deals with significant breaks are similar for the target and acquirer variances. However, those statistics are significantly larger than those detected for the covariance and correlations. These results suggests that instability in the target and acquirer variances are the major sources of non-stationarity in the VCS of 125 bivariate return series, which is detected by Aue et al. (2009) test.

Unreported results indicate that none of the univariate tests can detect any structural breaks in the second-order moments of 12 deals during the pre-announcement period. This result is comparable to the multivariate results for that period since Aue et al. (2009) test cannot reject the null of stable VCS in 16 out of 125 deals. Moreover, the results of univariate tests indicates that only one of those unconditional second-order moments shifts significantly in 49 out of 125 deals: 16, 25, 2 and 6 deals have only break(s) in the target variance, acquirer variance, the covariance and the correlation, respectively. Thus, at least two of those moments change significantly in the rest of deals, 64 out of 125 deals. Shifts in the comovement moments during the pre-announcement period can anticipate the forthcoming deals and its payment-form. However, consistent shifts in the target (acquirer) variance during the pre-announcement period can only anticipate the target (acquirer), and so inadequate for anticipating the deal and its payment-form. This discussion indicates that 53 out of 125 deals $(42.4 \%$ of total) are not anticipated by the univariate tests. Those 53 deals are the sum of 12,16 and 25, deals with stable moments, with break(s) only in the target and acquirer variance, respectively. Therefore, the portion of anticipated deals via the univariate tests $(57.6 \%)$ is significantly lower than the portion of anticipated deals via Aue et al. (2009) multivariate test $(86.4 \%)$. 
When Aue et al.'s multivariate test detects multiple breaks in the VCS, it assumes implicitly that at least some of the second-order moments shifts jointly after the detected break dates. This indicates that the joint test imposes a restriction on the location of those break dates, i.e. a uniform set of hypothetical break dates in the individual second-order moments. However, each of univariate tests (here, the ICSS, Bai and Perron, and Galeano and Wied tests) is performed separately to detect break dates in each of those second-order moments. These tests are hence free from any restriction about coincidence of break dates for those moments, and so preferable to the multivariate test to detect break dates of each moment. Relaxing of the joint date assumption generates some differences between the distribution of break dates of univariate and the multivariate tests though they are on average insubstantial. The explanation is as follows: The univariate tests find that at least two of those second-order moments shift consistently during the pre-announcement period in the majority of deals. This implies that the average pre-announcement break dates of those moments can be a proxy for the average deal-anticipation date. To make this approximation plausible the Target, Acquirer and payment-form anticipation dates is considered. These anticipation dates are comparable with deal-anticipation dates of Aue et al. (2009) since both of them are mostly based on the first break date during the pre-announcement period when there are multiple breaks. The unreported mean tests indicate separately that the average TargetAnticipation date (Day-181), average Acquirer-Anticipation date (Day-206) and covariance based average Payment-Form-Anticipation date (Day -179) is indifferent from the average Aue et al.'s Deal-Anticipation Date (Day -187). This leads to conclude that the market anticipates on average M\&A deals almost 9 months prior to the announcement day regardless of using the univariate tests or the multivariate test.

However, it should be notified that Aue et al.'s multivariate test is more appropriate to investigate the proposed anticipation mechanism. When the market starts to anticipate the forthcoming bid and payment-form, some of the second-order moments of the joint return distribution should shift simultaneously during the pre-announcement period. Thus, the joint break date assumption of the multivariate test is not only reasonable (as illustrated in the above results) but is also necessary for detecting a deal and payment-form anticipation date. In contrast, existence of different (against joint) break dates across second-order moments of a deal can indeed complicate noticeably selecting a date as an anticipation date. For example, segments of one moment can easily overlap with the segments of the other moments. This in turn confounds identifying consistent breaks in one segment in order to detect a deal and payment anticipation date. Overall, these arguments suggest identifying anticipation dates based on the univariate tests is inferior to that of the multivariate test.

Similar to the results of Aue et al.'s multivariate test, the majority of breaks for each second-order moment are significantly located distant from the announcement day. For example, Table D.1 illustrates that 107 out of 112 shifts (94 out of 122 shifts) in the acquirer (target) variance are located during the pre-announcement period. The unreported interquartile range for the acquirer (target) variance break date is between Day-359 (Day367) and Day-103 (Day-11). Moreover, the univariate tests reject the stability of secondorder moments in a significant portion of deals. The stability of target, acquirer variance, the covariance and correlation over the sample observation period is rejected in $71.2 \%, 65.6 \%$, $36 \%$ and $25.6 \%$ of total deals.

Since the merger arbitrage literature mainly use either the cross-sections of target or acquirer firms, the results of univariate tests have direct implications for validity of their assumptions, and so for their results. The merger arbitrage literature assumes that the secondorder moments shift at the announcement day. In on hand, there are some instances in which this assumption is marginally verified by the univariate tests. The ICSS test finds that variance of 21 out of 125 target firms shifts significantly close to the announcement day (i.e., 
between Day 0 and Day 3). On the other hand, the majority of above results show severe violations from these assumptions. First, a significant portion of target and acquirer return series has instable variances $(71.2 \%$ and $65.6 \%)$. Second, the majority of shifts in all of the second-order moments are skewed significantly towards the pre-announcement period instead of locating around the announcement day.

The following example shows how that assumption might lead to invalid inferences: The cross-sectional average (median) of sample correlations during the post-announcement period is significantly different from that during the pre-announcement period for the current sample of 125 deals (see Table 1). The largest (smallest) average significant change is observed in Equity (Cash) subsample. These results might lead a risk arbitrage study to conclude that the bid announcements shift significantly the correlations and the direction of shifts are also consistent with the offered medium of payment. However, these conclusions might be misleading due to the results of Galeano and Wied test: first, the correlation is stable over the sample observation period in a very significant portion of deals, $74.4 \%$. In other words, there is no break in the correlations at the announcement day in 93 out of 125 deals. Second, there is a break around the announcement day only in $10.4 \%$ out of total deals.

\section{D.1.1. Target and Acquirer Anticipation Breaks}

Table D.1 illustrates that the number of anticipated acquirer (target) firms due to consistent shifts in their variance is 81 (70) out of 125 firms. This result is comparable with the number of consistent shifts in the acquirer and target variances around the DealAnticipation dates, i.e., 80 and 68. This suggests that the number of deals with consistent shifts in their variances is independent of using the univariate or the multivariate approach.

Unreported portion equality test indicates that the fraction of anticipated acquirers $(64.8 \%)$ is marginally larger than that of targets $(56 \%)$. However, the fraction of target firms whose variance shifts during the post-announcement period $(22.4 \%)$ is significantly larger than that of the acquirer firms (4\%). The results suggest a skewed division of shifts in the target and acquirer variance between pre- and post-announcement periods. Indeed, 18 unanticipated target firms only have Reaction-Breaks in their variance while almost all of significant breaks in the acquirer variance are located during the pre-announcement period. The skewed division is hence responsible for the difference between degree of predictability between target and acquirer firms. Moreover, the most frequent reactions to the bid announcement among the second-order moments are observed in the target variance. All of those 28 Reaction-shifts in the target risk are declining. This suggests that the bidannouncement resolve some important uncertainties about those 28 target firms, like the magnitude of bid-premium, the portion of cash in the bid payment and etc. An unreported mean test (with P-value of 6.3\%) indicates that the average Target-Anticipation date (Day181) is statistically different from the average Acquirer-Anticipation date (Day-206). Using the ICSS test illustrates that the acquirer firms are anticipated on average one month earlier than the target firms. This result together with the above-mentioned skewed division lead to conclude that the acquirer firms are more predictable than target firms. Using a different approach (a cross-sectional two-stage multinomial model), Cornett et al. (2011) conclude a similar result: " investors can predict acquirer firms more successfully than target firms." Moreover, they find that this difference in the degree of predictability can explain the documented disparity between the Abnormal returns to the target and acquirer shareholders around the announcement day.

Overall, these results indicate that a large portion of target and acquirer firms is anticipated long before the announcement day. 


\section{D.1.2. Payment-Form Anticipation via shifts in the Covariance and Correlation}

Table D.1 illustrates that the payment-form of 23 deals are anticipated due consistent shifts in their covariance series. This number is slightly lower (i.e., 15) when consistent shifts in correlations are considered though the difference is insignificant. Total number of payment-form anticipated deals due to the consistent shifts in either the covariance, correlation or both of them is only 30 . This number however is strictly lower than the 77 payment-form anticipated deals via Aue et al. (2009) multivariate approach. This leads to conclude that those univariate tests (Bai and Perron, and Galeano and Wied) underperform their multivariate counterpart (Aue et al. test) in anticipating the payment-form in this sample of M\&A deals.

An unreported mean test indicates that the average Payment-Anticipation date based on consistent shifts in the covariance series (Day-179) is statistically different from that in the correlation series (Day-83). The covariance series incorporates on average earlier than the correlation series relevant anticipation signals. This might be due to the fact that the covariance is free from the standardizations used in computing the correlations. Overall, univariate results like the multivariate ones confirm the relative efficiency of covariance for anticipating payment forms in M\&A deals.

The very small F-values of ANOVA tests for the univariate tests (i.e., 0.28 and 0.8 ) indicate that average payment-anticipation dates are similar across payment subsamples. This is in contrast to the significant ANOVA result of the multivariate test (6.11), which documents that the Cash offers are anticipated on average 3 months earlier than Equity and Mixed offers.

\section{D.2. Raw vs. Winsorized Return Series}

The Full $(F)$ sample contains all returns during the sample observation period (i.e., both pre- and post-announcement periods) while the Restricted $(R)$ sample considers only returns during the pre-announcement period of each return series. Each of 125 daily acquirer and target realized return series is adjusted for any breaks in the mean and non-zero mean in the Raw (R) sample. An extra adjustment is applied in the Winsorized $(W)$ samples, i.e., winsorising outliers of each return series. These classifications lead to construct four different samples of 125 bivariate returns series used in the diagnostic tests: Full Raw (FR), Full Winsorized (FW), Restricted Raw (RR) and Restricted Winsorized (RW). Table D.2 summarizes the results of performing Aue et al. (2009) test separately across those four samples to detect the number and location of significant shifts in the VCS of each sample. The results for $F W$ sample are considered here as the benchmark results.

The anticipation dates are directly originated from Aue et al. (2009) detected break dates. The anticipation dates across those four samples are not discussed here for the sake of brevity. However, one can expect similar differences across anticipation dates as well.

\section{Insert Table D.2 here}

The mean difference tests in Table D.2 indicate that the average break dates of $F R$ sample (i.e., Total sample, Pre- and Post-Announcement period subsamples) are similar to those of $F W$ sample. This may indicate that the winsorising does not change significantly the distribution of break dates, and in turn predicts that the distribution of anticipation dates of the $F R$ and $F W$ samples to be similar.

The total number of breaks detected in the $F R$ sample is 166 , which is significantly lower than 235 breaks detected in the $F W$ sample. Both mean and median tests in Table D.2 show that average and median number of breaks per deal in $F R$ is significantly smaller than $F W$. Moreover, the two-sample proportion test with Z-value of 3.9 implies that the fraction of 
deals with breaks in the $F R$ sample $(66.4 \%)$ is significantly smaller than that of the $F W$ sample $(87.2 \%)$. There are 83 (16) out of 125 deals with (without) significant breaks regardless of using winsorized or raw return series. This result implies that the majority of Aue et al. results are consistent between $F R$ and $F W$ samples and not solely due to the winsorization. However, the winsorization leads Aue et al. (2009) test to reject the stability of VCS in 26 deals whose moments are stable in the $F R$ sample. As expected, these results indicate that existence of extreme observations in the Raw series cause Aue et al. (2009) test to lose its power in detecting existent breaks in the VCS. Overall, the $99 \%$ winsorization leads to obtain more robust results from Aue et al. (2009) test.

\section{D.3. Restricted vs. Full Sample Observation Period}

Aue et al. (2009) results across full and restricted samples are not directly comparable due to mismatch of their periods. Either $R W$ or $R R$ results should be compared with those of $F W$ (Pre) (i.e., the Pre-Announcement subsample of $F W$ sample) to resolve this issue.

The unreported results indicate: first, the average and median number of breaks per deal in $R R$ sample is significantly smaller than $R W$ sample. Second, the fraction of deals with breaks in the $R R$ sample (58.4\%) is significantly smaller than that of the $R W$ sample $(70.4 \%)$. Third, the average break date is indifferent between $R R$ and $R W$ samples. Similar to the comparison between $F R$ and $F W$ results, these results indicate that the controlling outlier is essential to improve the power of Aue et al. test. Aue et al. (2009) results are therefore compared across winsorized samples, i.e., $R W$ and $F W$ (Pre). Use of winsorized samples also helps to attribute easily any difference in the results solely due to restricting the sample observation period to the pre-announcement period. Moreover, one can expect that similar differences between $R W$ and $F W$ (Pre) samples can be also identifiable when the $R R$ results are compared with those of $F W$ (Pre). The reason is that $R W$ has more break than $R R$, thus the observed difference between $R W$ and $F W$ (Pre) can indeed enlarge when $R R$ used instead of $R W$ in comparison.

Table D.2 reports significant difference between average (median) number of breaks per deal across $R W$ and $F W$ (Pre) samples. The total number of breaks and the fraction of deals with breaks in the $R W$ sample are 133 and 70.4\%, which are significantly smaller than those of $F W$ (Pre), i.e. 196 and 86.4\%. Apart from these differences, the results indicate that shifts in the VCS can be detected in a significant portion of deals regardless of using full or restricted samples. This leads to invalidate the claim that Aue et al. (2009) test detects arbitrarily breaks due to mixing pre- and post-announcement returns in the full sample.

Moreover, the average break date of $R W$ sample (Day -207) is significantly smaller than that of $F W$ (Pre) sample (Day -142). This suggests that restricting the sample observation period to the pre-announcement period pushes improperly the distribution of break dates far away from the announcement day. However, there is a chance of detecting break dates either close or distant from the announcement day when the full sample observation period is used in Aue et al. (2009) test. This indicates that using restricted sample can lead Aue et al. (2009) test to lose its power in detecting breaks close to the announcement day.

Two alternative approaches are also discussed: using the daily average return series in Aue et al. (2009) test and those univariate tests. Similar types of robustness tests are also performed to assess the sensitivity of those tests when the raw and restricted samples are used. The results across four samples are qualitatively similar to those derived here and indicate that the uses of full winsorized sample in those tests generate more robust results. However, they are not reported here for the sake of brevity. ${ }^{18}$

\footnotetext{
18 Those results are available upon the request.
} 


\section{Table 1}

Summary of Sample Second-Order Moments of the Return Series in the Pre- and Post- Announcement Periods

This table summarizes the sample second-order moments of the acquirer and target daily-log-returns series during the Pre- and Post-Announcement Period. The sample consists of 125 completed acquisitions and splits to 54 Cash, 33 Equity and 38 Mixed payment bids. The pre-announcement period is from Day-379 to Day-1 relative to the first bid announcement. The post-announcement period is from the day of first bid announcement through delisting of target shares. The largest absolute daily-log-returns of each return series are winsorized at 99\%. Bai and Perron (1998 and 2003) test detects break(s), if any; in the mean of each return series. The return series are adjusted for the detected breaks in the mean of series. The return series is then demeaned. The sample unconditional moments include: Target Variance, Acquirer Variance, Acquirer-Target Covariance and Acquirer-Target Correlation and computed in the usual way. Variances and covariance are reported in the basis points (bps). The Relative Change quantifies the change in a post-announcement sample moment of a series relative to its preannouncement value. Significance of Mean and Median is only tested for the bold statistics. The difference between cross-sectional average (median) of sample moments (i.e., Post-Pre) are tested using the matched-pairs $t$-test (the Wilcoxon (1945) matched-pairs signed-ranks test). The modified Levene test of Brown and Forsythe (1974) and the common F-test examines the equality of post- vs. pre-announcement variances and the equality of post- vs. pre-announcement covariance, respectively. Jennrich 's test (1970) examines the equality of post- vs. pre-announcement correlation. These equality tests are performed for moments of each target, acquirer and the pair firm in the sample. The fraction of total equality tests that the post-announcement moment is statistically differ from its preannouncement value at conventional levels is reported in the Portion of Significant Changes column. The one-way ANOVA model tests the equality-of-means across payment subsamples. All above tests are two-tailed tests. $* * *, * *$ and $*$ denotes statistical significant at the $1 \%, 5 \%$ and $10 \%$ level, respectively.

\begin{tabular}{|c|c|c|c|c|c|c|c|c|c|c|c|c|}
\hline \multirow[b]{2}{*}{ Variables } & \multirow[b]{2}{*}{ Mean } & \multirow[b]{2}{*}{ Median } & \multirow[b]{2}{*}{ Std. Dev. } & \multirow[b]{2}{*}{ Min } & \multirow[b]{2}{*}{ Max } & \multicolumn{2}{|c|}{ Difference (Post - Pre) } & \multirow{2}{*}{$\begin{array}{c}\text { Portion of } \\
\text { Significant } \\
\text { Change (\%) } \\
\end{array}$} & \multicolumn{3}{|c|}{ Mean value of } & \multirow{2}{*}{$\begin{array}{c}\text { F-Value of } \\
\text { One-way } \\
\text { ANOVA }\end{array}$} \\
\hline & & & & & & $t$-Stat. & Sign-Rank Z-Stat. & & Cash & Mixed & Equity & \\
\hline \multicolumn{13}{|l|}{ Target Variance (bps) } \\
\hline Pre-Announcement & 10.7 & 8.5 & 8.0 & 0.5 & 35.5 & & & & 9.7 & 10.8 & 12.2 & 0.99 \\
\hline Post-Announcement & 3.6 & 2.4 & 3.5 & 0.0 & 20.4 & $-13.16 * * *$ & $-9.67 * * *$ & & 2.2 & 3.4 & 6.0 & $14.33 * * *$ \\
\hline Relative Change (Post vs. Pre) & $-62 \% * * *$ & $-71 \% * * *$ & $26 \%$ & $-100 \%$ & $42 \%$ & & & $88.8 \%$ & $-77 \% * * *$ & $-62 \% * * *$ & $-39 \% * * *$ & $32.92 * * *$ \\
\hline \multicolumn{13}{|l|}{ Acquirer Variance (bps) } \\
\hline Pre-Announcement & 7.2 & 4.3 & 7.5 & 0.6 & 42.6 & & & & 5.1 & 7.7 & 10.0 & $4.66 * *$ \\
\hline Post-Announcement & 4.8 & 3.5 & 4.8 & 0.4 & 29.9 & $-5.66 * * *$ & $-6.61 * * *$ & & 3.7 & 4.9 & 6.2 & $3.03 * *$ \\
\hline Relative Change (Post vs. Pre) & $-21 \% * * *$ & $-25 \% * * *$ & $35 \%$ & $-90 \%$ & $108 \%$ & & & $55.2 \%$ & $-20 \% * * *$ & $-23 \% * * *$ & $-23 \% * * *$ & 0.14 \\
\hline \multicolumn{13}{|l|}{ Acquirer-Target Covariance (bps) } \\
\hline Pre-Announcement & 1.9 & 1.2 & 2.2 & -0.4 & 12.8 & & & & 1.1 & 2.2 & 2.6 & $5.73 * * *$ \\
\hline Post-Announcement & 1.8 & 0.6 & 3.4 & -2.4 & 18.9 & -0.23 & $-2.31 * *$ & & 0.002 & 2.1 & 4.3 & $23.03 * * *$ \\
\hline Relative Change (Post vs. Pre) & $144 \% *$ & $-34 \%$ & $854 \%$ & $-850 \%$ & $7608 \%$ & & & $88.0 \%$ & $-70 \%$ & $216 \%$ & $410 \%$ & $3.56 * *$ \\
\hline \multicolumn{13}{|l|}{ Acquirer-Target Correlation } \\
\hline Pre-Announcement & $25 \%$ & $21 \%$ & $19 \%$ & $-9 \%$ & $80 \%$ & & & & $17 \%$ & $30 \%$ & $31 \%$ & $8.28 * * *$ \\
\hline Post-Announcement & $34 \%$ & $25 \%$ & $40 \%$ & $-48 \%$ & $97 \%$ & $3.08 * * *$ & $2.85^{* * *}$ & & $3 \%$ & $49 \%$ & $69 \%$ & $62.69 * * *$ \\
\hline Relative Change (Post vs. Pre) & $310 \% * *$ & $40 \% * *$ & $1565 \%$ & $-1806 \%$ & $14194 \%$ & & & $62.4 \%$ & $-63 \%$ & $477 \%$ & $727 \%$ & $3.02 * *$ \\
\hline
\end{tabular}


Table 2

Frequency Distribution of Number of Breaks Per Deal and Location of Break Dates Relative to the Announcement Day

This table summarizes the frequency distribution of number of breaks in the variance-covariance structure (VCS) of each 125 deals and number of deals with break(s) located only during the pre-announcement period, only during the post-announcement period and in the both periods. The total sample consists of 125 completed acquisitions from 1 July 2003 to 30 June 2006. The pre-announcement period is from Day-379 to Day-1 relative to the first bid announcement. The post-announcement period is from the day of first bid announcement through delisting of target shares. The largest absolute daily-log-returns of each acquirer and target return series are winsorized at 99\%. Bai and Perron $(1998,2003)$ test detects break(s), if any; in the mean of each return series. The return series are adjusted for the detected breaks in the mean of series. The mean of return series is then deducted from the series. Aue et al. (2009) test detects the number and location of significant shifts in the VCS of each 125 bivariate return series.

\begin{tabular}{ccccc}
\hline & Number of Deals & \multicolumn{2}{c}{ Number of Deals with Break(s) During } \\
\cline { 2 - 4 } Number of Breaks Per Deal & Without Break & Pre-Announcement & Post-Announcement & Both Periods \\
\hline 0 & 16 & 33 & 1 & 7 \\
1 & & 29 & 15 \\
2 & & 17 & 2 \\
3 & & 2 & 3 \\
\hline & 16 & 81 & 1 \\
\hline Frequency & $12.8 \%$ & $64.8 \%$ & 27 \\
\hline \% of Total & & & $21.6 \%$ \\
\hline
\end{tabular}




\section{Figure 1}

Distribution of Total Break Dates in the Variance-Covariance Structure and Box Plot of Anticipation Break Dates

Panel A : Distribution of Break Dates

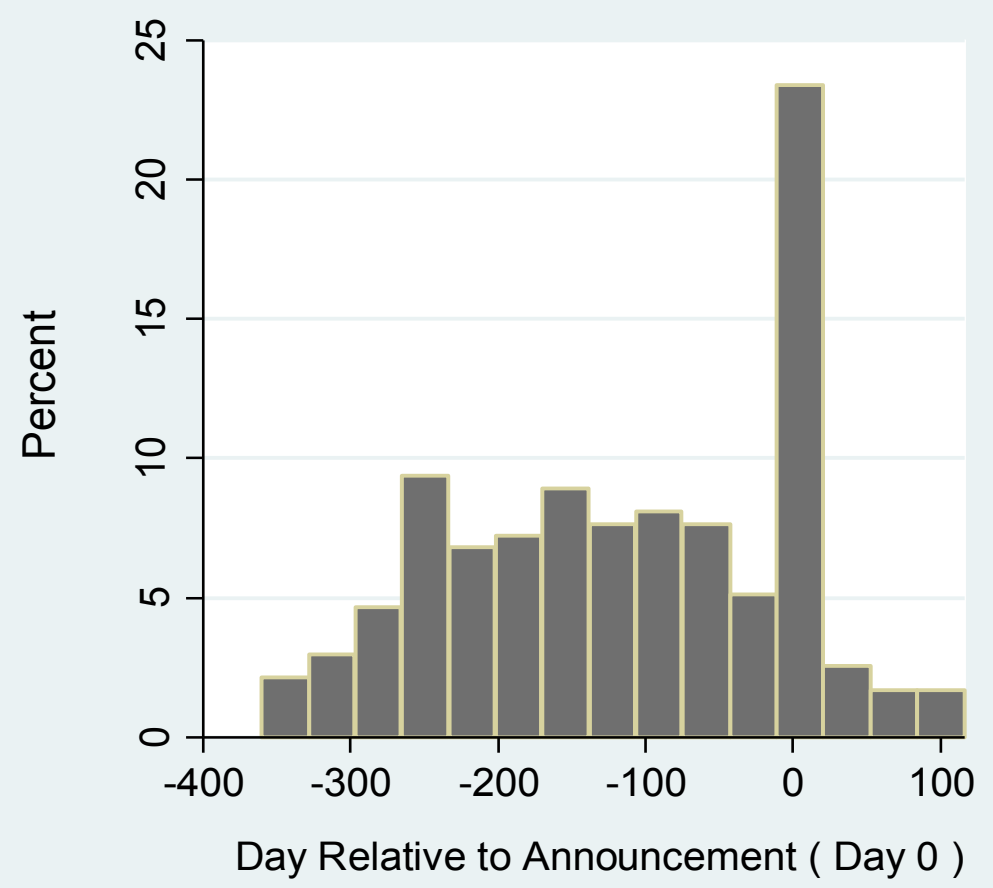

\section{Panel B: Box Plot of Anticipation Break Dates}

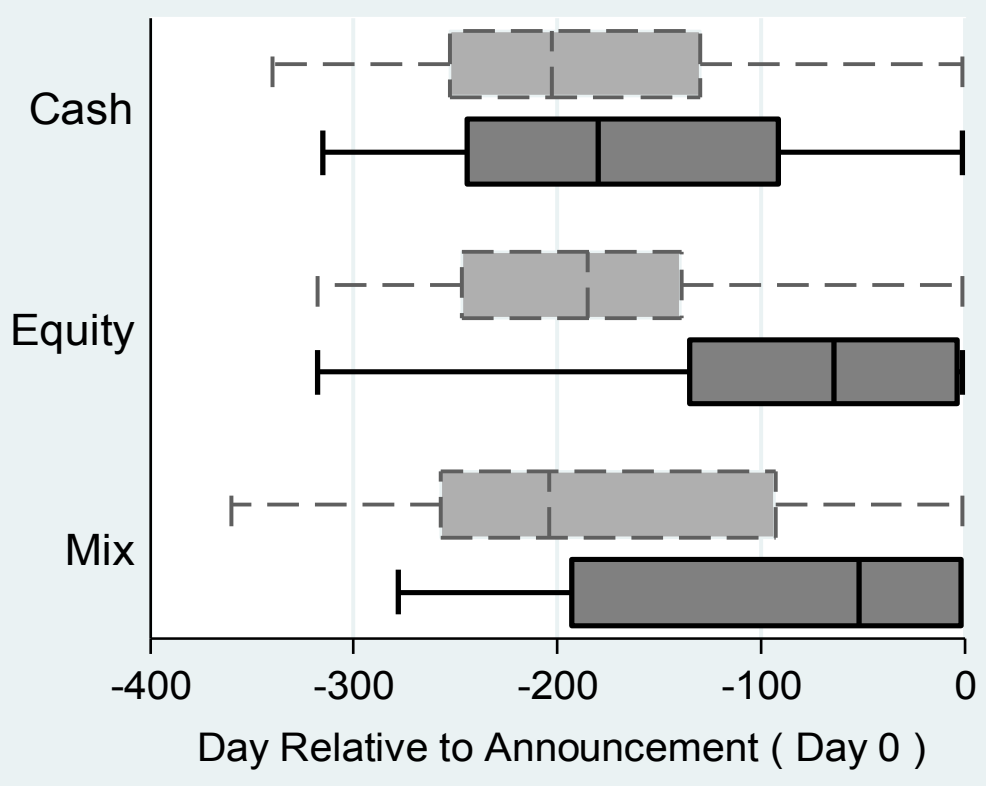

Deal-Anticipation $\square$ Payment-Anticipation

Panel A of this Figure illustrates the distribution of total break dates in the variance-covariance structure (VCS) of daily acquirer and target return series relative to the announcement day (Day 0). Panel B shows the box plot of the distribution of Deal and Payment-Form anticipation break dates across payment subsamples relative to Day 0. The sample consists of 125 completed acquisitions and splits to 54 Cash, 33 Equity and 38 Mixed payment bids. The pre-announcement period is from Day-379 to Day-1 relative to the first bid announcement. The post-announcement period is from the day of first bid announcement through delisting of target shares. Each of 125 daily acquirer and target return series is sequentially adjusted for outliers, breaks in the mean, and non-zero mean (see explanation in the ( of Table 2). Aue et al. (2009) test detects the number and location of significant shifts in the VCS of each 125 bivariate return series. See the Anticipation Hypotheses (Section 3) how a break in the VCS of a deal during the pre-announcement period is recognized as Deal-Anticipation and Payment-Form-Anticipation dates. The distant and close hinges of the box plot relative to Day 0 corresponds to the $1^{\text {st }}$ and $3^{\text {rd }}$ quartile of anticipation dates, respectively. Moreover, the line inside the box plot presents the median of anticipation dates. 
Table 3

Summarized Results of Aue et al. Test for Detecting Multiple Breaks in the Variance-Covariance Structure of Bivariate Return Series

This table summarizes the result of performing Aue et al. (2009) test for detecting multiple breaks in the variance-covariance structure (VCS) of total sample and across payment subsamples. The total sample consists of 125 completed acquisitions and splits to 54 Cash, 33 Equity and 38 Mixed payment bids. The preannouncement period is from Day-379 to Day-1 relative to the first bid announcement. The post-announcement period is from the day of first bid announcement through delisting of target shares. Each of 125 daily acquirer and target return series is sequentially adjusted for outliers, breaks in the mean, and non-zero mean (see explanation in the caption of Table 2). Aue et al. (2009) test detects the number and location of significant shifts in the VCS of each 125 bivariate return series. The first break date during the post-announcement period is identified as the Reaction-Break date of a deal. See the Anticipation Hypotheses (Section 3) how a break in the VCS of a deal during the pre-announcement period is recognized as Deal-Anticipation and Payment-Form-Anticipation dates. The difference between average Deal-Anticipation and Payment-Form-Anticipation dates (Deal-Payment) is examined by the unpaired and the Welch's (1947) unequal variance option of $t$-test. The fraction of total deals that the breaks are either significant at conventional levels or identified as Reaction, Deal-Anticipation and PaymentForm-Anticipation breaks is reported in the Fraction of Total Deal column. The Fraction of Total Deals across Cash, Equity and Mixed subsamples is computed based on the total number of deals in each of those subsamples. The one-way ANOVA model tests the equality-of-average break dates across payment subsamples. All above tests are two-tailed tests. ${ }^{* * *}, * *$ and $*$ denotes statistical significant at the $1 \%, 5 \%$ and $10 \%$ level, respectively.

\begin{tabular}{|c|c|c|c|c|c|c|c|c|c|c|c|}
\hline \multirow[b]{2}{*}{ Variables } & \multirow{2}{*}{$\begin{array}{l}\text { Number } \\
\text { of Breaks }\end{array}$} & \multirow{2}{*}{$\begin{array}{l}\text { Fraction of } \\
\text { Total Deals } \\
\end{array}$} & \multicolumn{7}{|c|}{ Distribution of Break Dates Relative to the Announcement Day (=0) } & \multirow{2}{*}{$\frac{\text { Difference (Deal - Payment) }}{t \text {-Stat. }}$} & \multirow{2}{*}{$\begin{array}{c}\text { F-Value of } \\
\text { One-way } \\
\text { ANOVA }\end{array}$} \\
\hline & & & Mean & Median & Std. Dev. & Min & 1st Quartile & 3rd Quartile & $\operatorname{Max}$ & & \\
\hline Total Sample & 235 & $87.2 \%$ & -114.4 & -106 & 111.0 & -360 & -208 & -1 & 116 & & \\
\hline Pre-Announcement & 196 & $86.4 \%$ & -141.9 & -139 & 99.9 & -360 & -227 & -60 & -1 & & \\
\hline Post-Announcement & 39 & $22.4 \%$ & 23.9 & 4 & 33.2 & 0 & 0 & 44 & 116 & & \\
\hline \multicolumn{12}{|l|}{ Reaction-Breaks } \\
\hline Total & 28 & $22.4 \%$ & 9.8 & 1 & 22.2 & 0 & 0 & 7 & 95 & & 1.71 \\
\hline Cash & 7 & $13.0 \%$ & 1.7 & 0 & 2.8 & 0 & 0 & 4 & 7 & & \\
\hline Equity & 13 & $39.4 \%$ & 17.8 & 2 & 30.9 & 0 & 0 & 9 & 95 & & \\
\hline Mixed & 8 & $21.1 \%$ & 3.6 & 1 & 6.1 & 0 & 0 & 6 & 17 & & \\
\hline \multicolumn{12}{|l|}{ Deal-Anticipation } \\
\hline Total & 108 & $86.4 \%$ & -186.6 & -190 & 87.3 & -360 & -253 & -133 & -1 & $-4.49 * * *$ & 0.05 \\
\hline Cash & 46 & $85.2 \%$ & -189.2 & -198 & 84.0 & -340 & -253 & -130 & -1 & -1.41 & \\
\hline Equity & 30 & $90.9 \%$ & -186.2 & -186 & 78.4 & -318 & -249 & -139 & -1 & $-4.29 * * *$ & \\
\hline Mixed & 32 & $84.2 \%$ & -183.2 & -204 & 101.4 & -360 & -257 & -93 & -1 & $-3.07 * *$ & \\
\hline \multicolumn{12}{|c|}{ Payment-Form-Anticipation } \\
\hline Total & 77 & $61.6 \%$ & -123.1 & -106 & 99.8 & -318 & -210 & -25 & -1 & & $6.11 * * *$ \\
\hline Cash & 37 & $68.5 \%$ & -161.8 & -171 & 91.4 & -315 & -240 & -92 & -1 & & \\
\hline Equity & 21 & $63.6 \%$ & -83.1 & -64 & 88.7 & -318 & -135 & -3 & -1 & & \\
\hline Mixed & 19 & $50.0 \%$ & -91.8 & -52 & 103.3 & -278 & -193 & -1 & -1 & & \\
\hline
\end{tabular}




\section{Table 4}

Summary Statistics for the Size of Shifts in the Sample Second-Order Moments around the Deal-Anticipation Break Dates

This table summarizes the magnitude of shifts in the sample second-order moments of the acquirer and target daily-log-returns series around the Deal Anticipation Date. The sample consists of 125 completed acquisitions and splits to 54 Cash, 33 Equity and 38 Mixed payment bids. The pre-announcement period is from Day379 to Day-1 relative to the first bid announcement. Each of 125 daily acquirer and target return series is sequentially adjusted for outliers, breaks in the mean, and non-zero mean (see explanation in the caption of Table 2). Aue et al. (2009) test detects the number and location of significant shifts in the variance-covariance structure (VCS) of each 125 bivariate return series. See the Anticipation Hypotheses (Section 3) how a break in the VCS of a deal during the pre-announcement period is recognized as Deal-Anticipation and Payment-Form-Anticipation dates. Each Deal-Anticipation break date is associated with two segments, i.e., Preand Post-Deal-Anticipation segments. The sample unconditional Target Variance, Acquirer Variance, Acquirer-Target Covariance and Acquirer-Target Correlation are computed across segments in the usual way. The difference between cross-sectional average (median) of Post- vs. Pre-anticipation sample moments (i.e., Post-Pre) are tested using the matched-pairs $t$-test (the Wilcoxon (1945) matched-pairs signed-ranks test). The Relative Change (Post vs. Pre) quantifies shift in a post-break sample moment relative to its pre-break value and the equality tests examines the significance of those relative changes (see the caption of Table 1). The total number of deals that the post-anticipation moment is statistically different from its pre-anticipation value at conventional levels is reported in the Number of Significant Changes column. The one-way ANOVA model tests the equality-of-means across payment subsamples. All above tests are two-tailed tests. Variances and covariance are reported in the basis points (bps). ${ }^{* *},{ }^{* *}$ and ${ }^{*}$ denotes statistical significant at the $1 \%, 5 \%$ and $10 \%$ level, respectively.

\begin{tabular}{|c|c|c|c|c|c|c|c|c|c|c|}
\hline & & \multirow[b]{2}{*}{ Mean } & \multirow[b]{2}{*}{ Median } & \multirow[b]{2}{*}{ Std. Dev. } & \multirow[b]{2}{*}{ Min } & \multirow[b]{2}{*}{ Max } & \multicolumn{2}{|c|}{ Difference (Post - Pre) } & \multirow{2}{*}{$\begin{array}{c}\text { Number of } \\
\text { Significant } \\
\text { Changes }\end{array}$} & \multirow{2}{*}{$\begin{array}{c}\text { F-Value of } \\
\text { One-way } \\
\text { ANOVA }\end{array}$} \\
\hline & & & & & & & $t$-Stat. & Sign-Rank Z-Stat. & & \\
\hline \multicolumn{11}{|c|}{ Target Variance (bps) } \\
\hline \multirow[t]{3}{*}{ Total } & Pre-Anticipation & 14.3 & 10.3 & 12.5 & 0.5 & 73.1 & & & & 0.12 \\
\hline & Post-Anticipation & 9.8 & 6.5 & 11.4 & 0.4 & 74.8 & $-4.04 * * *$ & $-6.46 * * *$ & & $2.61 *$ \\
\hline & Relative Change (Post vs. Pre) & $-26 \%$ & $-41 \%$ & $55 \%$ & $-84 \%$ & $295 \%$ & & & 78 & $6.73 * * *$ \\
\hline \multirow[t]{3}{*}{ Cash } & Pre-Anticipation & 13.8 & 11.1 & 12.7 & 0.8 & 73.1 & & & & \\
\hline & Post-Anticipation & 8.2 & 6.6 & 6.3 & 0.4 & 22.6 & $-4.15 * * *$ & $-4.9 * * *$ & & \\
\hline & Relative Change (Post vs. Pre) & $-33 \%$ & $-40 \%$ & $39 \%$ & $-84 \%$ & $129 \%$ & & & 32 & \\
\hline \multirow[t]{3}{*}{ Equity } & Pre-Anticipation & 14.1 & 10.3 & 11.5 & 0.5 & 50.5 & & & & \\
\hline & Post-Anticipation & 13.8 & 7.0 & 18.4 & 0.8 & 74.8 & -0.12 & -1.57 & & \\
\hline & Relative Change (Post vs. Pre) & $3 \%$ & $-32 \%$ & $81 \%$ & $-68 \%$ & $295 \%$ & & & 22 & \\
\hline \multirow[t]{3}{*}{ Mixed } & Pre-Anticipation & 15.2 & 10.0 & 13.3 & 2.8 & 55.8 & & & & \\
\hline & Post-Anticipation & 8.4 & 5.1 & 7.5 & 0.9 & 26.6 & $-4.64 * * *$ & $-4.65 * * *$ & & \\
\hline & Relative Change (Post vs. Pre) & $-43 \%$ & $-49 \%$ & $29 \%$ & $-79 \%$ & $36 \%$ & & & 24 & \\
\hline
\end{tabular}




\begin{tabular}{|c|c|c|c|c|c|c|c|c|c|c|}
\hline & & \multirow[b]{2}{*}{ Mean } & \multirow[b]{2}{*}{ Median } & \multirow[b]{2}{*}{ Std. Dev. } & \multirow[b]{2}{*}{ Min } & \multirow[b]{2}{*}{ Max } & \multicolumn{2}{|c|}{ Difference (Post - Pre) } & \multirow{2}{*}{$\begin{array}{c}\text { Number of } \\
\text { Significant } \\
\text { Changes }\end{array}$} & \multirow{2}{*}{$\begin{array}{c}\text { F-Value of } \\
\text { One-way } \\
\text { ANOVA }\end{array}$} \\
\hline & & & & & & & $t$-Stat. & Sign-Rank Z-Stat. & & \\
\hline \multicolumn{11}{|c|}{ Acquirer Variance (bps) } \\
\hline \multirow[t]{3}{*}{ Total } & Pre-Anticipation & 9.9 & 5.4 & 11.1 & 0.5 & 62.7 & & & & $3.0 * *$ \\
\hline & Post-Anticipation & 7.7 & 4.5 & 13.8 & 0.6 & 114.0 & $-2.48 * *$ & $-5.52 * * *$ & & $2.97 * *$ \\
\hline & Relative Change (Post vs. Pre) & $-18 \%$ & $-38 \%$ & $52 \%$ & $-74 \%$ & $179 \%$ & & & 80 & $2.99 * *$ \\
\hline \multirow{3}{*}{ Cash } & Pre-Anticipation & 7.0 & 4.7 & 6.5 & 0.5 & 32.6 & & & & \\
\hline & Post-Anticipation & 5.7 & 3.5 & 8.6 & 0.6 & 57.1 & -1.4 & $-3.1 * * *$ & & \\
\hline & Relative Change (Post vs. Pre) & $-13 \%$ & $-34 \%$ & $56 \%$ & $-66 \%$ & $139 \%$ & & & 33 & \\
\hline \multirow[t]{3}{*}{ Equity } & Pre-Anticipation & 12.7 & 7.6 & 14.6 & 0.5 & 62.7 & & & & \\
\hline & Post-Anticipation & 12.8 & 5.3 & 22.8 & 0.8 & 114.0 & 0.02 & $-2.05 * *$ & & \\
\hline & Relative Change (Post vs. Pre) & $-6 \%$ & $-33 \%$ & $58 \%$ & $-71 \%$ & $179 \%$ & & & 22 & \\
\hline \multirow[t]{3}{*}{ Mixed } & Pre-Anticipation & 11.5 & 7.3 & 12.0 & 1.7 & 45.8 & & & & \\
\hline & Post-Anticipation & 5.8 & 4.3 & 4.8 & 1.3 & 19.3 & $-4.15 * * *$ & $-4.38 * * *$ & & \\
\hline & Relative Change (Post vs. Pre) & $-35 \%$ & $-47 \%$ & $33 \%$ & $-74 \%$ & $60 \%$ & & & 25 & \\
\hline \multicolumn{11}{|c|}{ Acquirer-Target Covariance (bps) } \\
\hline \multirow[t]{3}{*}{ Total } & Pre-Anticipation & 2.5 & 1.3 & 3.3 & -2.9 & 16.7 & -1.34 & $-3.39 * * *$ & & 1.59 \\
\hline & Post-Anticipation & 2.0 & 1.0 & 4.0 & -1.1 & 33.8 & & & & $4.56^{* * *}$ \\
\hline & Relative Change (Post vs. Pre) & $-51 \%$ & $-47 \%$ & $946 \%$ & $-9382 \%$ & $1216 \%$ & & & 91 & 0.90 \\
\hline \multirow[t]{3}{*}{ Cash } & Pre-Anticipation & 1.9 & 1.1 & 2.5 & -0.3 & 10.8 & & & & \\
\hline & Post-Anticipation & 1.0 & 0.5 & 1.5 & -1.1 & 8.1 & $-2.81 * * *$ & $-2.94 * * *$ & & \\
\hline & Relative Change (Post vs. Pre) & $28 \%$ & $-58 \%$ & $323 \%$ & $-669 \%$ & $1216 \%$ & & & 39 & \\
\hline \multirow[t]{3}{*}{ Equity } & Pre-Anticipation & 3.2 & 2.2 & 3.7 & -2.6 & 13.2 & & & & \\
\hline & Post-Anticipation & 3.7 & 2.0 & 6.9 & -0.5 & 33.8 & 0.47 & -0.73 & & \\
\hline & Relative Change (Post vs. Pre) & $-249 \%$ & $-23 \%$ & $1746 \%$ & $-9382 \%$ & $1126 \%$ & & & 23 & \\
\hline \multirow[t]{3}{*}{ Mixed } & Pre-Anticipation & 2.8 & 1.9 & 3.9 & -2.9 & 16.7 & & & & \\
\hline & Post-Anticipation & 1.9 & 1.4 & 1.9 & -0.5 & 7.2 & $-1.86^{*}$ & $-1.98 * *$ & & \\
\hline & Relative Change (Post vs. Pre) & $20 \%$ & $-46 \%$ & $194 \%$ & $-124 \%$ & $871 \%$ & & & 29 & \\
\hline \multicolumn{11}{|c|}{ Acquirer-Target Correlation } \\
\hline \multirow[t]{3}{*}{ Total } & Pre-Anticipation & $25 \%$ & $23 \%$ & $21 \%$ & $-17 \%$ & $84 \%$ & & & & $2.84 *$ \\
\hline & Post-Anticipation & $25 \%$ & $21 \%$ & $24 \%$ & $-15 \%$ & $89 \%$ & 0.23 & -0.12 & & $8.31 * * *$ \\
\hline & Relative Change (Post vs. Pre) & $-44 \%$ & $-3 \%$ & $1314 \%$ & $-12946 \%$ & $1977 \%$ & & & 40 & 1.11 \\
\hline \multirow[t]{3}{*}{ Cash } & Pre-Anticipation & $19 \%$ & $17 \%$ & $15 \%$ & $-4 \%$ & $54 \%$ & & & & \\
\hline & Post-Anticipation & $15 \%$ & $15 \%$ & $16 \%$ & $-15 \%$ & $61 \%$ & -1.58 & -1.28 & & \\
\hline & Relative Change (Post vs. Pre) & $69 \%$ & $-31 \%$ & $485 \%$ & $-1301 \%$ & $1977 \%$ & & & 13 & \\
\hline \multirow[t]{3}{*}{ Equity } & Pre-Anticipation & $30 \%$ & $29 \%$ & $26 \%$ & $-16 \%$ & $84 \%$ & & & & \\
\hline & Post-Anticipation & $34 \%$ & $32 \%$ & $27 \%$ & $-12 \%$ & $89 \%$ & 0.8 & 0.13 & & \\
\hline & Relative Change (Post vs. Pre) & $-347 \%$ & $-5 \%$ & $2406 \%$ & $-12946 \%$ & $1685 \%$ & & & 14 & \\
\hline \multirow[t]{3}{*}{ Mixed } & Pre-Anticipation & $27 \%$ & $26 \%$ & $22 \%$ & $-17 \%$ & $73 \%$ & & & & \\
\hline & Post-Anticipation & $32 \%$ & $29 \%$ & $25 \%$ & $-9 \%$ & $89 \%$ & 1.16 & 0.99 & & \\
\hline & Relative Change (Post vs. Pre) & $80 \%$ & $19 \%$ & $279 \%$ & $-144 \%$ & $1432 \%$ & & & 13 & \\
\hline
\end{tabular}




\section{Table 5}

Summary Statistics for the Size of Shifts in the Sample Second-Order Moments around the Payment-Form-Anticipation Break Dates

This table summarizes the magnitude of shifts in the sample second-order moments of the acquirer and target daily-log-returns series around the Payment-Form Anticipation Date. The sample consists of 125 completed acquisitions and splits to 54 Cash, 33 Equity and 38 Mixed payment bids. The pre-announcement period is from Day-379 to Day-1 relative to the first bid announcement. Each of 125 daily acquirer and target return series is sequentially adjusted for outliers, breaks in the mean, and non-zero mean (see explanation in the caption of Table 2). Aue et al. (2009) test detects the number and location of significant shifts in the variancecovariance structure (VCS) of each 125 bivariate return series. See the Anticipation Hypotheses (Section 3) how a break in the VCS of a deal during the preannouncement period is recognized as Deal-Anticipation and Payment-Form-Anticipation dates. Each Payment-Anticipation break date is associated with two segments, i.e., Pre- and Post-Payment-Anticipation segments. The sample unconditional Target Variance, Acquirer Variance, Acquirer-Target Covariance and Acquirer-Target Correlation are computed across segments in the usual way. The difference between cross-sectional average (median) of Post- vs. Preanticipation sample moments (i.e., Post-Pre) are tested using the matched-pairs $t$-test (the Wilcoxon (1945) matched-pairs signed-ranks test). The Relative Change (Post vs. Pre) quantifies shift in a post-break sample moment relative to its pre-break value and the equality tests examines the significance of those relative changes (see the caption of Table 1). The total number of deals that the post-anticipation moment is statistically different from its pre-anticipation value at conventional levels is reported in the Number of Significant Changes column. The one-way ANOVA model tests the equality-of-means across payment subsamples. All above tests are two-tailed tests. Variances and covariance are reported in the basis points (bps). ${ }^{* * *}, * *$ and $*$ denotes statistical significant at the $1 \%, 5 \%$ and $10 \%$ level, respectively.

\begin{tabular}{|c|c|c|c|c|c|c|c|c|c|c|}
\hline & & \multirow[b]{2}{*}{ Mean } & \multirow[b]{2}{*}{ Median } & \multirow[b]{2}{*}{ Std. Dev. } & \multirow[b]{2}{*}{ Min } & \multirow[b]{2}{*}{ Max } & \multicolumn{2}{|c|}{ Difference (Post - Pre) } & \multirow{2}{*}{$\begin{array}{c}\text { Number of } \\
\text { Significant } \\
\text { Changes }\end{array}$} & \multirow{2}{*}{$\begin{array}{c}\text { F-Value of } \\
\text { One-way } \\
\text { ANOVA }\end{array}$} \\
\hline & & & & & & & $t$-Stat. & Sign-Rank Z-Stat. & & \\
\hline \multicolumn{11}{|c|}{ Target Variance (bps) } \\
\hline \multirow[t]{3}{*}{ Total } & Pre-Anticipation & 11.8 & 8.0 & 13.1 & 0.4 & 73.1 & & & & 0.90 \\
\hline & Post-Anticipation & 6.6 & 4.7 & 6.8 & 0.2 & 45.4 & $-4.55^{* * *}$ & $-6.06 * * *$ & & 1.55 \\
\hline & Relative Change (Post vs. Pre) & $-31 \%$ & $-42 \%$ & $47 \%$ & $-89 \%$ & $135 \%$ & & & 60 & $4.45^{* *}$ \\
\hline \multirow[t]{3}{*}{ Cash } & Pre-Anticipation & 13.1 & 10.8 & 13.1 & 0.4 & 73.1 & & & & \\
\hline & Post-Anticipation & 6.8 & 6.0 & 5.1 & 0.2 & 21.3 & $-3.92 * * *$ & $-4.44 * * *$ & & \\
\hline & Relative Change (Post vs. Pre) & $-39 \%$ & $-51 \%$ & $44 \%$ & $-89 \%$ & $129 \%$ & & & 31 & \\
\hline \multirow[t]{3}{*}{ Equity } & Pre-Anticipation & 12.8 & 7.0 & 15.8 & 0.5 & 71.4 & & & & \\
\hline & Post-Anticipation & 8.3 & 6.0 & 9.7 & 0.8 & 45.4 & -1.49 & $-2.03 * *$ & & \\
\hline & Relative Change (Post vs. Pre) & $-6 \%$ & $-14 \%$ & $58 \%$ & $-75 \%$ & $135 \%$ & & & 14 & \\
\hline \multirow[t]{3}{*}{ Mixed } & Pre-Anticipation & 8.3 & 5.8 & 9.4 & 0.9 & 44.1 & & & & \\
\hline & Post-Anticipation & 4.5 & 2.9 & 5.7 & 0.9 & 26.6 & $-4.1 * * *$ & $-3.74 * * *$ & & \\
\hline & Relative Change (Post vs. Pre) & $-43 \%$ & $-41 \%$ & $28 \%$ & $-79 \%$ & $38 \%$ & & & 15 & \\
\hline
\end{tabular}




\begin{tabular}{|c|c|c|c|c|c|c|c|c|c|c|}
\hline & & \multirow[b]{2}{*}{ Mean } & \multirow[b]{2}{*}{ Median } & \multirow[b]{2}{*}{ Std. Dev. } & \multirow[b]{2}{*}{ Min } & \multirow[b]{2}{*}{ Max } & \multicolumn{2}{|c|}{ Difference (Post - Pre) } & \multirow{2}{*}{$\begin{array}{c}\text { Number of } \\
\text { Significant } \\
\text { Changes } \\
\end{array}$} & \multirow{2}{*}{$\begin{array}{c}\text { F-Value of } \\
\text { One-way } \\
\text { ANOVA }\end{array}$} \\
\hline & & & & & & & $t$-Stat. & Sign-Rank Z-Stat. & & \\
\hline \multicolumn{11}{|c|}{ Acquirer Variance (bps) } \\
\hline \multirow[t]{3}{*}{ Total } & Pre-Anticipation & 7.1 & 4.8 & 7.4 & 0.5 & 42.6 & & & & 1.80 \\
\hline & Post-Anticipation & 5.7 & 4.1 & 7.8 & 0.8 & 58.7 & $-2.04 * *$ & $-3.47 * * *$ & & $3.27 * *$ \\
\hline & Relative Change (Post vs. Pre) & $-5 \%$ & $-26 \%$ & $53 \%$ & $-71 \%$ & $179 \%$ & & & 47 & 1.98 \\
\hline \multirow[t]{3}{*}{ Cash } & Pre-Anticipation & 6.2 & 4.9 & 4.9 & 0.6 & 21.2 & & & & \\
\hline & Post-Anticipation & 4.2 & 3.4 & 3.3 & 0.8 & 14.8 & $-3.18 * * *$ & $-3.14 * * *$ & & \\
\hline & Relative Change (Post vs. Pre) & $-18 \%$ & $-34 \%$ & $49 \%$ & $-71 \%$ & $137 \%$ & & & 23 & \\
\hline \multirow[t]{3}{*}{ Equity } & Pre-Anticipation & 9.7 & 4.8 & 11.2 & 0.5 & 42.6 & & & & \\
\hline & Post-Anticipation & 9.3 & 4.4 & 13.7 & 1.0 & 58.7 & -0.178 & -1.37 & & \\
\hline & Relative Change (Post vs. Pre) & $7 \%$ & $-17 \%$ & $60 \%$ & $-56 \%$ & $179 \%$ & & & 11 & \\
\hline \multirow[t]{3}{*}{ Mixed } & Pre-Anticipation & 6.0 & 3.2 & 5.7 & 1.3 & 23.5 & & & & \\
\hline & Post-Anticipation & 4.7 & 4.7 & 2.9 & 1.5 & 11.9 & -1.51 & -0.76 & & \\
\hline & Relative Change (Post vs. Pre) & $5 \%$ & $-4 \%$ & $51 \%$ & $-56 \%$ & $127 \%$ & & & 13 & \\
\hline \multicolumn{11}{|c|}{ Acquirer-Target Covariance (bps) } \\
\hline \multirow[t]{3}{*}{ Total } & Pre-Anticipation & 1.9 & 1.2 & 2.4 & -2.9 & 10.8 & & & & 0.54 \\
\hline & Post-Anticipation & 1.9 & 0.8 & 4.1 & -1.1 & 33.8 & 0.09 & -1.03 & & $8.67 * * *$ \\
\hline & Relative Change (Post vs. Pre) & $62 \%$ & $-37 \%$ & $307 \%$ & $-669 \%$ & $1665 \%$ & & & 72 & $11.59 * * *$ \\
\hline \multirow[t]{3}{*}{ Cash } & Pre-Anticipation & 2.2 & 1.2 & 2.5 & -0.6 & 10.8 & & & & \\
\hline & Post-Anticipation & 0.5 & 0.2 & 1.0 & -1.1 & 3.7 & $-5.4 * * *$ & $-5.05 * * *$ & & \\
\hline & Relative Change (Post vs. Pre) & $-89 \%$ & $-79 \%$ & $116 \%$ & $-669 \%$ & $166 \%$ & & & 36 & \\
\hline \multirow[t]{3}{*}{ Equity } & Pre-Anticipation & 1.5 & 0.9 & 2.4 & -2.6 & 9.1 & & & & \\
\hline & Post-Anticipation & 4.7 & 3.0 & 7.1 & 0.3 & 33.8 & $2.39 * *$ & $4.02 * * *$ & & \\
\hline & Relative Change (Post vs. Pre) & $246 \%$ & $179 \%$ & $284 \%$ & $10 \%$ & $1126 \%$ & & & 18 & \\
\hline \multirow[t]{3}{*}{ Mixed } & Pre-Anticipation & 1.6 & 1.0 & 2.3 & -2.9 & 7.2 & & & & \\
\hline & Post-Anticipation & 1.5 & 1.2 & 1.2 & -0.1 & 4.0 & -0.21 & 0.2 & & \\
\hline & Relative Change (Post vs. Pre) & $152 \%$ & $81 \%$ & $432 \%$ & $-110 \%$ & $1665 \%$ & & & 18 & \\
\hline \multicolumn{11}{|c|}{ Acquirer-Target Correlation } \\
\hline \multirow[t]{3}{*}{ Total } & Pre-Anticipation & $25 \%$ & $24 \%$ & $20 \%$ & $-17 \%$ & $74 \%$ & & & & 0.63 \\
\hline & Post-Anticipation & $32 \%$ & $20 \%$ & $32 \%$ & $-17 \%$ & $97 \%$ & $1.91 *$ & $1.62 *$ & & $39.56^{* * *}$ \\
\hline & Relative Change (Post vs. Pre) & $76 \%$ & $6 \%$ & $337 \%$ & $-1301 \%$ & $1685 \%$ & & & 47 & $12.49 * * *$ \\
\hline \multirow[t]{3}{*}{ Cash } & Pre-Anticipation & $23 \%$ & $23 \%$ & $16 \%$ & $-17 \%$ & $54 \%$ & & & & \\
\hline & Post-Anticipation & $9 \%$ & $7 \%$ & $13 \%$ & $-17 \%$ & $41 \%$ & $-5.21 * * *$ & $-4.32 * * *$ & & \\
\hline & Relative Change (Post vs. Pre) & $-89 \%$ & $-57 \%$ & $219 \%$ & $-1301 \%$ & $222 \%$ & & & 14 & \\
\hline \multirow[t]{3}{*}{ Equity } & Pre-Anticipation & $25 \%$ & $23 \%$ & $24 \%$ & $-16 \%$ & $74 \%$ & & & & \\
\hline & Post-Anticipation & $61 \%$ & $66 \%$ & $27 \%$ & $8 \%$ & $97 \%$ & $9.18^{* * *}$ & $4.02 * * *$ & & \\
\hline & Relative Change (Post vs. Pre) & $302 \%$ & $205 \%$ & $375 \%$ & $16 \%$ & $1685 \%$ & & & 18 & \\
\hline \multirow[t]{3}{*}{ Mixed } & Pre-Anticipation & $30 \%$ & $25 \%$ & $22 \%$ & $-9 \%$ & $69 \%$ & & & & \\
\hline & Post-Anticipation & $46 \%$ & $54 \%$ & $31 \%$ & $-2 \%$ & $89 \%$ & $2.16^{* *}$ & $2.01 * *$ & & \\
\hline & Relative Change (Post vs. Pre) & $146 \%$ & $72 \%$ & $325 \%$ & $-116 \%$ & $1221 \%$ & & & 15 & \\
\hline
\end{tabular}


Figure 2

Multiple Structural Breaks in the Variance-Covariance Structure of Daily Acquirer and Target Average Return Series

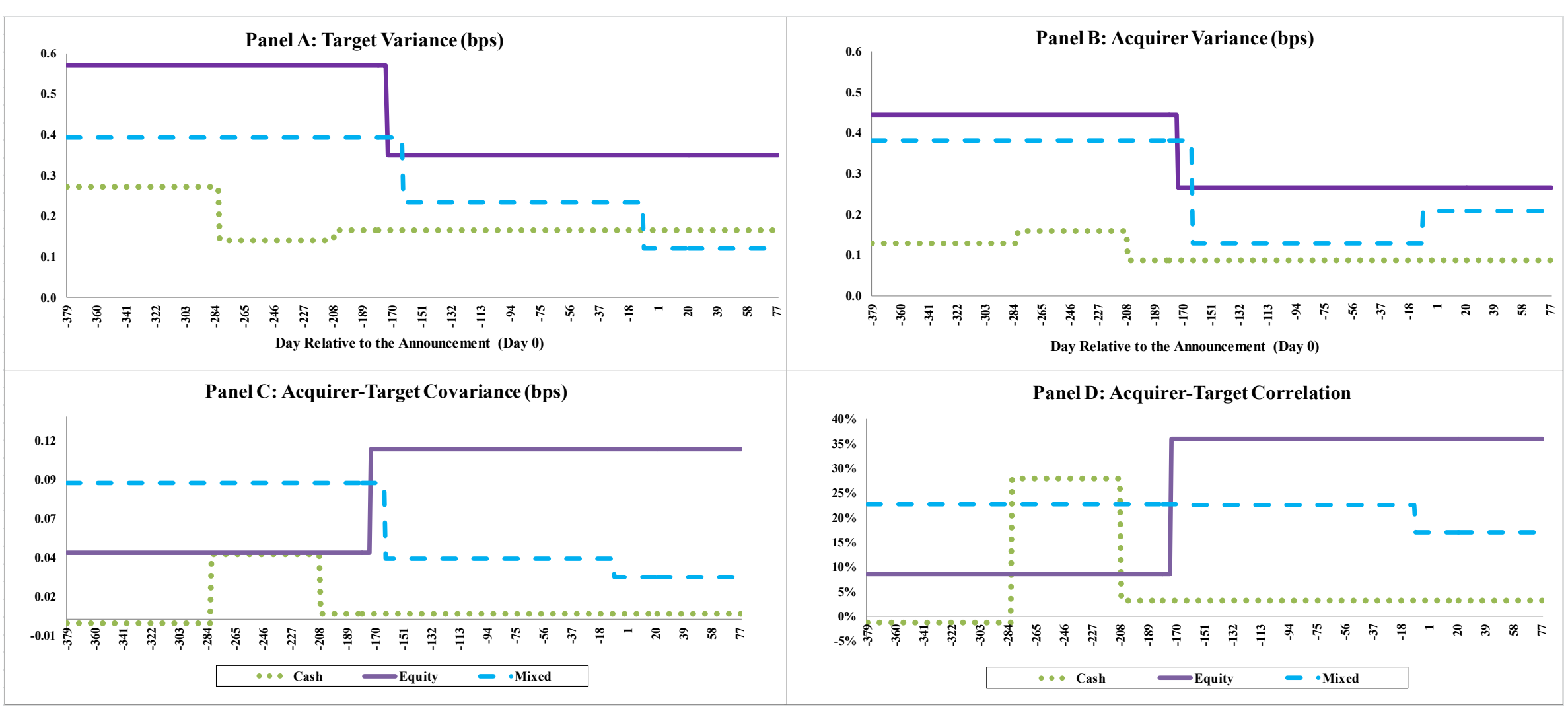

This figure illustrates multiple shifts in the second-order moments of daily acquirer and target average return series across payment subsamples. Panel A (B) depicts how the Target (Acquirer) Variance changes during the sample observation period. Panel C (D) illustrates shifts in the Acquirer -Target covariance (correlation). The sample consists of 125 completed acquisitions and splits to 54 Cash, 33 Equity and 38 Mixed payment bids. The daily average return series runs from trading day -379 to +78 relative to the first bid announcement (Day 0). See section 3 how the daily target and acquirer average return series is constructed. The largest absolute daily average returns of each series are winsorized at 99\%. Bai and Perron (1998 and 2003) test detects break(s), if any, in the mean of each average series. The average return series is then adjusted for the detected breaks. The average return series is finally demeaned. Aue et al. (2009) test is applied to each payment subsample to detect multiple breaks in the variance-covariance structure of the daily acquirer and target average return series. Each break date splits the sample period into two segments. The sample unconditional second-order moments are computed across detected segments in the usual way and reported in the basis points (bps), except the correlation, which is presented in the percentage. 


\section{Table 6}

Deal and Payment-Form Anticipation Dates via the Daily Average Return Series

This table shows deal and payment-form anticipation dates of total sample and payment subsamples when the daily acquirer and target average return series is used and summaries the size of sample second-order moments around those dates. The total sample consists of 125 completed acquisitions and splits to 54 Cash, 33 Equity and 38 Mixed payment bids. See explanation in the caption of Figure 2 about computation of the daily average return series (i.e., winsorized, break-in-mean and mean adjusted series). Aue et al. (2009) test is applied to the total sample and each payment subsample to detect significant shifts in the variance-covariance structure of the daily acquirer and target average return series. Each break date is associated with two segments, i.e., Pre- and Post-Anticipation segments. The sample unconditional Target Variance, Acquirer Variance, Acquirer-Target Covariance and Acquirer-Target Correlation are computed across segments in the usual way. The Relative Change (Post vs. Pre) quantifies the change in a post-break sample moment relative to its pre-break value and the equality tests examines the significance of those relative changes (see the caption of Table 1). See the Anticipation Hypotheses (Section 3) how a break in the VCS of a deal during the pre-announcement period is recognized as Deal-Anticipation and Payment-Form-Anticipation dates. Variances and covariance are reported in the basis points (bps). $* * *, * *$ and $*$ denotes statistical significant at the $1 \%, 5 \%$ and $10 \%$ level, respectively.

\begin{tabular}{|c|c|c|c|c|c|c|c|c|c|c|c|}
\hline & \multirow{2}{*}{$\begin{array}{c}\text { Total } \\
\text { Number } \\
\text { of Break } \\
\text { Dates }\end{array}$} & \multicolumn{5}{|c|}{ Deal-Anticipation } & \multicolumn{5}{|c|}{ Payment-Form-Anticipation } \\
\hline & & $\begin{array}{l}\text { Anticipation } \\
\text { Date }\end{array}$ & $\begin{array}{c}\text { Order of } \\
\text { Break } \\
\text { Date }\end{array}$ & $\begin{array}{c}\text { Pre- } \\
\text { Anticipation } \\
\text { Segment }\end{array}$ & $\begin{array}{c}\text { Post- } \\
\text { Anticipation } \\
\text { Segment }\end{array}$ & $\begin{array}{c}\text { Relative } \\
\text { Change } \\
\text { (Post vs. Pre) }\end{array}$ & $\begin{array}{c}\text { Anticipation } \\
\text { Date }\end{array}$ & $\begin{array}{c}\text { Order of } \\
\text { Break } \\
\text { Date }\end{array}$ & $\begin{array}{c}\text { Pre- } \\
\text { Anticipation } \\
\text { Segment }\end{array}$ & $\begin{array}{c}\text { Post- } \\
\text { Anticipation } \\
\text { Segment }\end{array}$ & $\begin{array}{c}\text { Relative } \\
\text { Change } \\
\text { (Post vs. Pre) }\end{array}$ \\
\hline Total Sample & 1 & -231 & First & & & & Not Applicable & & & & \\
\hline Target Variance (bps) & & & & 0.15 & 0.08 & $-44 \% * * *$ & & & & & \\
\hline Acquirer Variance (bps) & & & & 0.11 & 0.05 & $-53 \% * * *$ & & & & & \\
\hline Acquirer-Target Covariance (bps) & & & & 0.010 & 0.008 & $-22 \% *$ & & & & & \\
\hline Acquirer-Target Correlation & & & & $8.2 \%$ & $12.6 \%$ & $53 \%$ & & & & & \\
\hline Cash Subsample & 2 & -282 & First & & & & -208 & Second & & & \\
\hline Target Variance (bps) & & & & 0.27 & 0.14 & $-48 \% * *$ & & & 0.14 & 0.17 & $18 \%$ \\
\hline Acquirer Variance (bps) & & & & 0.13 & 0.16 & $24 \%$ & & & 0.16 & 0.09 & $-45 \% * * *$ \\
\hline Acquirer-Target Covariance (bps) & & & & -0.002 & 0.04 & $1835 \% * * *$ & & & 0.04 & 0.004 & $-91 \% * * *$ \\
\hline Acquirer-Target Correlation & & & & $-1.3 \%$ & $27.9 \%$ & $2266 \% *$ & & & $27.9 \%$ & $3 \%$ & $-89 \% * *$ \\
\hline Equity Subsample & 1 & -174 & First & & & & -174 & First & & & \\
\hline Target Variance (bps) & & & & 0.57 & 0.35 & $-40 \% * * *$ & & & 0.57 & 0.35 & $-40 \% * * *$ \\
\hline Acquirer Variance (bps) & & & & 0.44 & 0.27 & $-39 \% * * *$ & & & 0.44 & 0.27 & $-39 \% * * *$ \\
\hline Acquirer-Target Covariance (bps) & & & & 0.04 & 0.11 & $156 \% * * *$ & & & 0.04 & 0.11 & $156 \% * * *$ \\
\hline Acquirer-Target Correlation & & & & $8.5 \%$ & $35.9 \%$ & $323 \% * * *$ & & & $8.5 \%$ & $35.9 \%$ & $323 \% * * *$ \\
\hline Mixed Subsample & 2 & -164 & First & & & & The Payment-f & orm is not & anticipated. & & \\
\hline Target Variance (bps) & & & & 0.39 & 0.23 & $-40 \% * * *$ & & & & & \\
\hline Acquirer Variance (bps) & & & & 0.38 & 0.13 & $-66 \% * * *$ & & & & & \\
\hline Acquirer-Target Covariance (bps) & & & & 0.09 & 0.04 & $-55 \% * * *$ & & & & & \\
\hline Acquirer-Target Correlation & & & & $22.6 \%$ & $22.6 \%$ & $0 \%$ & & & & & \\
\hline
\end{tabular}




\section{Appendix Table C.1}

\section{Descriptive Statistics of Acquisitions and Pre-deal Target and Acquirer Characteristics}

This table summarizes the descriptive statistics for the 125 completed acquisitions and for their pre-deal characteristics. The sample period runs from 1 July 2003 to 30 June 2006. No-Obs-Aft (C) is the number of daily returns available from the day after the first bid announcement through delisting day of target shares. $\boldsymbol{A C \boldsymbol { C }}$ Announce-Return (TARG-Announce-Return) is daily log return to the acquirer (target) shareholders at the announcement day. ACQ-Mark-up (TARG-Mark-up) is the cumulative (buy-and-hold) log returns to the acquirer (target) 's stock from the announcement day through delisting day. Deal-Value ( $\$ m$ ) is the total value of acquisition in Million U.S. Dollars. Relative-Size is equal to market capitalization of target firm divided by market capitalization of acquirer firm at year-end prior to the bid announcement. News is 1 if the deal is rumored in the press prior to the bid announcement day. SIC is 1 if at least 3 out of the 4 digits of the U.S. Standard Industrial Classification (SIC) code of target and acquirer firm are the same. Cash (Equity) is 1 if the payment to the target shareholders is all-Cash (allEquity). Mixed is 1 if the payment to the target shareholders is a combination of cash and equity. The significance of mean is only tested for the bold variables. Mean and Median difference between variables related to the Acquirer and Target (ACQ - TARG) is tested by means of the matched-pairs $t$-test and the Wilcoxon matched-pairs signed-ranks test (Wilcoxon, 1945), respectively. The one-way ANOVA model tests the equality-of-means across payment subsamples, i.e., Cash, Equity and Mixed. All above tests are two-tailed tests. ***, ** and * denotes statistical significant at the $1 \%, 5 \%$ and $10 \%$ level, respectively.

\begin{tabular}{|c|c|c|c|c|c|c|c|c|c|c|c|c|}
\hline \multirow[b]{2}{*}{ Variables } & \multirow[b]{2}{*}{ Mean } & \multirow[b]{2}{*}{ Median } & \multirow[b]{2}{*}{ Std. Dev. } & \multirow[b]{2}{*}{ Min } & \multirow[b]{2}{*}{ Max } & \multirow[b]{2}{*}{ Obs. } & \multicolumn{2}{|c|}{ Difference (ACQ-TARG) } & \multicolumn{3}{|c|}{ Mean value of } & \multirow{2}{*}{$\begin{array}{l}\text { F-value of } \\
\text { One-way } \\
\text { ANOVA }\end{array}$} \\
\hline & & & & & & & $t$-test & sign-rank test & Cash & Mixed & Equity & \\
\hline No-Obs-Aft (C) & 83 & 73 & 42.6 & 28 & 235 & 125 & & & 65 & 91 & 104 & $11.17 * * *$ \\
\hline ACQ-Announce-Return (\%) & $-1.5 * * *$ & -0.8 & 6.2 & -24.5 & 23.2 & 125 & $-9.76 * * *$ & $-8.08 * * *$ & 0.3 & $-2.6 * *$ & $-3.3 * * *$ & $4.35 * *$ \\
\hline TARG-Announce-Return (\%) & $11.9 * * *$ & 9.3 & 13.8 & -11.6 & 66.1 & 125 & & & $15.4 * * *$ & $11.3 * * *$ & $7 * * *$ & $4.04 * *$ \\
\hline ACQ-Mark-up (\%) & 2.7 & 3.0 & 22.1 & -62.0 & 131.2 & 125 & $-8.35 * * *$ & $-8.37 * * *$ & 2.5 & 1.3 & 4.4 & 0.18 \\
\hline TARG-Mark-up (\%) & $20 * * *$ & 20.0 & 17.9 & -25.5 & 67.0 & 125 & & & $21 * * *$ & $19.5 * * *$ & $18.9 * * *$ & 0.16 \\
\hline Deal-Value $(\$ m)^{l}$ & 2655 & 428 & 8763.4 & 52 & 67000 & 125 & & & 469 & 3430 & 5340 & $7.34 * * *$ \\
\hline \multirow[t]{2}{*}{ Relative-Size } & 0.52 & 0.21 & 1.17 & 0.0002 & 9.38 & 102 & & & 0.20 & 0.44 & 1.08 & $5.37 * * *$ \\
\hline & $\begin{array}{l}\text { Number } \\
\text { of Deals }\end{array}$ & & & & & & $\begin{array}{l}\text { By year of } \\
\text { the first bid }\end{array}$ & $\begin{array}{c}\text { Number of } \\
\text { Deals }\end{array}$ & & & & \\
\hline News & 21 & & & & & & 2003 & 27 & & & & \\
\hline$S I C$ & 72 & & & & & & 2004 & 42 & & & & \\
\hline Cash & 54 & & & & & & 2005 & 39 & & & & \\
\hline Equity & 33 & & & & & & 2006 & 17 & & & & \\
\hline Mixed & 38 & & & & & & & & & & & \\
\hline
\end{tabular}




\section{Appendix Table C.2}

\section{Summary of Sample Moments and Results of Hill Test Before (Raw) and After Winsorising Return Series}

This table summarizes the sample second-order moments, skewness and kurtosis and the modified Hill statistics for the left and right tail index of 125 target and acquirer daily return series before and after winsorising outliers of each series. The Raw Series (Panel A) is the realized daily log-return series of target and acquirer stocks from Day-379 to Day C (the consummation date of deal) relative to the bid announcement date (Day 0). If an absolute daily log-return is larger than three standard deviations of that return series, it is recognized as a potential outlier. A $99 \%$ winsorization is applied to those potential outliers to build a Winsozried Series (Panel B). A modified Hill's (1975) estimator estimates the Left and Right Tail Index of each return series (see, Beirlant et al. 1996). Existence of the forth-order moment of each tail of a series is rejected if its estimate of tail index is statistically less than four at the conventional levels (1\% to $10 \%)$. See, e.g., Loretan et al., (1994) for the details of this test. The fraction of total 125 series with Tail Index less than four is reported in the Fraction of Non-Existent 4th Moment column. The difference between cross-sectional average (median) of raw vs. winsorized sample moments and Hill statistics (i.e., Raw-Winsorized) are tested using the matched-pairs $t$-test (the Wilcoxon (1945) matched-pairs signed-ranks test). Mean and median tests are two-tailed tests. Variances and covariance are reported in the basis points (bps). $* * * * *$ and $*$ denotes statistical significant at the $1 \%, 5 \%$ and $10 \%$ level, respectively.

\begin{tabular}{|c|c|c|c|c|c|c|c|c|}
\hline \multirow[b]{2}{*}{ Variables } & \multirow[b]{2}{*}{ Mean } & \multirow[b]{2}{*}{ Median } & \multirow[b]{2}{*}{ Std. Dev. } & \multirow[b]{2}{*}{ Min } & \multirow[b]{2}{*}{ Max } & \multicolumn{2}{|c|}{ Difference (Raw-Winsorized) } & \multirow{2}{*}{$\begin{array}{c}\text { Fraction of Non- } \\
\text { Existent 4th Moment }\end{array}$} \\
\hline & & & & & & $t$-Stat. & Sign-Rank Z-Stat. & \\
\hline & \multicolumn{7}{|c|}{ Panel A: Raw Return Series } & \\
\hline \multicolumn{9}{|l|}{ Target } \\
\hline Variance (bps) & 12.3 & 9.0 & 9.0 & 0.5 & 42.5 & $10.50 * * *$ & $9.70 * * *$ & \\
\hline Skewness & 0.80 & 0.48 & 1.92 & -5.33 & 7.59 & $3.60 * * *$ & $3.49 * * *$ & \\
\hline Kurtosis & 21.87 & 12.97 & 22.48 & 3.96 & 108.36 & $8.35^{* * *}$ & $9.70 * * *$ & \\
\hline Left Tail Index-Hill 's Statistic & 3.17 & 3.01 & 1.30 & 1.52 & 10.58 & $-5.95 * * *$ & $-7.03 * * *$ & $58.4 \%$ \\
\hline Right Tail Index -Hill 's Statistic & 2.80 & 2.64 & 0.91 & 1.42 & 6.30 & $-7.62 * * *$ & $-8.25 * * *$ & $68.8 \%$ \\
\hline \multicolumn{9}{|l|}{ Acquirer } \\
\hline Variance (bps) & 8.0 & 5.5 & 8.4 & 0.6 & 45.6 & $5.46^{* * *}$ & $9.66 * * *$ & \\
\hline Skewness & -0.02 & 0.12 & 1.35 & -4.74 & 9.94 & -1.17 & -0.61 & \\
\hline Kurtosis & 10.62 & 6.40 & 16.07 & 3.35 & 158.28 & $4.54 * * *$ & $9.70 * * *$ & \\
\hline Left Tail Index-Hill 's Statistic & 3.69 & 3.47 & 1.39 & 1.57 & 9.93 & $-4.91 * * *$ & $-6.98 * * *$ & $39.2 \%$ \\
\hline Right Tail Index-Hill 's Statistic & 3.55 & 3.33 & 1.10 & 1.64 & 8.09 & $-5.74 * * *$ & $-8.07 * * *$ & $40.0 \%$ \\
\hline Acquirer-Target Covariance (bps) & 2.0 & 1.2 & 2.3 & -0.5 & 14.5 & $2.14 * *$ & $3.26 * * *$ & \\
\hline Acquirer-Target Correlation & $23 \%$ & $18 \%$ & $20 \%$ & $-6 \%$ & $81 \%$ & $-7.54 * * *$ & $-7.25 * * *$ & \\
\hline \multicolumn{9}{|c|}{ Panel B : Winsorized Return Series } \\
\hline Target & & & & & & & & \\
\hline Variance (bps) & 9.5 & 7.6 & 7.2 & 0.5 & 31.4 & & & \\
\hline Skewness & 0.20 & 0.18 & 0.29 & -0.55 & 1.05 & & & \\
\hline Kurtosis & 5.46 & 5.31 & 1.42 & 3.09 & 11.92 & & & \\
\hline Left Tail Index-Hill 's Statistic & 3.90 & 3.50 & 1.56 & 1.83 & 10.07 & & & $31.2 \%$ \\
\hline Right Tail Index-Hill 's Statistic & 4.14 & 3.48 & 2.09 & 1.87 & 16.53 & & & $32 \%$ \\
\hline \multicolumn{9}{|l|}{ Acquirer } \\
\hline Variance (bps) & 6.8 & 4.4 & 6.9 & 0.6 & 38.4 & & & \\
\hline Skewness & 0.12 & 0.11 & 0.24 & -0.66 & 1.16 & & & \\
\hline Kurtosis & 4.16 & 4.01 & 0.79 & 2.81 & 6.47 & & & \\
\hline Left Tail Index-Hill 's Statistic & 4.52 & 4.16 & 2.12 & 1.87 & 19.32 & & & $24 \%$ \\
\hline Right Tail Index-Hill 's Statistic & 4.92 & 4.25 & 2.87 & 2.23 & 26.56 & & & $23.2 \%$ \\
\hline Acquirer-Target Covariance (bps) & 1.9 & 1.1 & 2.2 & -0.2 & 13.9 & & & \\
\hline Acquirer-Target Correlation & $26 \%$ & $21 \%$ & $20 \%$ & $-7 \%$ & $85 \%$ & & & \\
\hline
\end{tabular}




\section{Appendix Table D.1}

Summarized Results of Tests for Detecting Multiple Breaks in the Second-Order Moments of Daily Acquirer and Target Return Series

This table summarizes the result of performing various structural break tests for detecting multiple breaks in the second-order moments of daily acquirer and target return series. The total sample consists of 125 completed acquisitions and splits to 54 Cash, 33 Equity and 38 Mixed payment bids. The pre-announcement period is from Day-379 to Day-1 relative to the first bid announcement. The post-announcement period is from the day of first bid announcement through delisting of target shares. Each of 125 daily acquirer and target return series is sequentially adjusted for outliers, breaks in the mean, and non-zero mean (see explanation in the caption of Table 2). The ICSS test detects separately the number and location of significant shifts in the unconditional variance of each 125 daily target and acquirer return series. Bai and Perron (BP) (Galeano and Wied, GW) test detects the number and location of significant shifts in the unconditional daily-realized covariance (the unconditional correlation) of acquirer and target return series. The first break date during the post-announcement period is identified as the Reaction-Break date. The first break date during the pre-announcement period, which is the closest to the start of the sample observation period (Day -379), is identified as the first candidate date for the anticipation date. If the target (acquirer) variance declines (shifts) significantly after the candidate date, that date is considered as Target (Acquirer)-Anticipation Date. See the Payment-Form Anticipation procedure (Section 3) how an anticipation date is identified as a Payment-Form-Anticipation Date if at least one of the sample covariance and correlation shifts consistently after that date. The fraction of total deals that the breaks are either significant at conventional levels or identified as Reaction, Target-Anticipation, Acquirer-Anticipation and Payment-Form-Anticipation breaks is reported in the Fraction of Total Deal column. Note that the Fraction of Total Deals across Cash, Equity and Mixed subsamples is computed based on the total number of deals in each of those subsamples. The one-way ANOVA model tests the equality-of-average break dates across payment subsamples. All above tests are two-tailed tests. $* * * * *$ and $*$ denotes statistical significant at the $1 \%, 5 \%$ and $10 \%$ level, respectively.

\begin{tabular}{|c|c|c|c|c|c|}
\hline \multirow[b]{2}{*}{ Variables } & \multirow{2}{*}{$\begin{array}{l}\text { Fraction of } \\
\text { Total Deals }\end{array}$} & \multicolumn{3}{|c|}{$\begin{array}{c}\text { Distribution of Break Dates Relative to } \\
\text { the Announcement Day }(=0)\end{array}$} & \multirow{2}{*}{$\begin{array}{c}\text { F-Value of } \\
\text { One-way } \\
\text { ANOVA }\end{array}$} \\
\hline & & Mean Median Std. Dev. & Min & Max & \\
\hline
\end{tabular}

\begin{tabular}{|c|c|c|c|c|c|c|c|c|}
\hline \multicolumn{9}{|c|}{ ICSS Test } \\
\hline \multicolumn{9}{|l|}{ Target Variance } \\
\hline Total & 122 & $71.2 \%$ & -125.8 & -119 & 106.8 & -367 & 46 & \\
\hline Pre-Announcement & 94 & $56.8 \%$ & -165 & -168 & 90 & -367 & -2 & \\
\hline Post-Announcement & 28 & $22.4 \%$ & 5.6 & 0 & 12.2 & 0 & 46 & \\
\hline \multicolumn{9}{|l|}{ Reaction-Breaks } \\
\hline Total & 28 & $22.4 \%$ & 5.6 & 0 & 12.2 & 0 & 46 & 1.83 \\
\hline Cash & 14 & $25.9 \%$ & 6.1 & 0 & 12.4 & 0 & 41 & \\
\hline Equity & 3 & $9.1 \%$ & 16.7 & 3 & 25.4 & 1 & 46 & \\
\hline Mixed & 11 & $28.9 \%$ & 2.0 & 0 & 4.8 & 0 & 16 & \\
\hline \multicolumn{9}{|l|}{ Target-Anticipation } \\
\hline Total & 70 & $56.0 \%$ & -180.9 & -193 & 89.5 & -367 & -2 & 0.46 \\
\hline Cash & 26 & $48.1 \%$ & -168.8 & -181 & 94.8 & -367 & -2 & \\
\hline Equity & 21 & $63.6 \%$ & -194.0 & -222 & 90.5 & -349 & -26 & \\
\hline Mixed & 23 & $60.5 \%$ & -182.8 & -181 & 84.5 & -318 & -22 & \\
\hline
\end{tabular}




\begin{tabular}{|c|c|c|c|c|c|c|c|c|}
\hline \multirow[b]{2}{*}{ Variables } & \multirow{2}{*}{$\begin{array}{l}\text { Number } \\
\text { of Breaks }\end{array}$} & \multirow{2}{*}{$\begin{array}{l}\text { Fraction of } \\
\text { Total Deals }\end{array}$} & \multicolumn{5}{|c|}{$\begin{array}{c}\text { Distribution of Break Dates Relative to } \\
\text { the Announcement Day }(=0)\end{array}$} & \multirow{2}{*}{$\begin{array}{c}\text { F-Value of } \\
\text { One-way } \\
\text { ANOVA }\end{array}$} \\
\hline & & & Mean & Median & Std. Dev. & Min & Max & \\
\hline \multicolumn{9}{|c|}{ ICSS Test } \\
\hline \multicolumn{9}{|l|}{ Acquirer Variance } \\
\hline Total & 112 & $65.6 \%$ & -177.7 & -189 & 95.7 & -359 & 62 & \\
\hline Pre-Announcement & 107 & $64.8 \%$ & -188.1 & -193 & 84.4 & -359 & -1 & \\
\hline Post-Announcement & 5 & $4.0 \%$ & 45.2 & 51 & 16.3 & 25 & 62 & \\
\hline \multicolumn{9}{|l|}{ Reaction-Breaks } \\
\hline Total & 5 & $4 \%$ & 45 & 51 & 16 & 25 & 62 & $\mathrm{NA} \dagger$ \\
\hline Cash & 2 & $3.7 \%$ & 28 & 28 & 4 & 25 & 31 & \\
\hline Equity & 3 & $9.1 \%$ & 57 & 57 & 6 & 51 & 62 & \\
\hline Mixed & 0 & $0 \%$ & & & & & & \\
\hline \multicolumn{9}{|l|}{ Acquirer-Anticipation } \\
\hline Total & 81 & $64.8 \%$ & -206.2 & -206 & 76.5 & -359 & -32 & 1.40 \\
\hline Cash & 34 & $63.0 \%$ & -218.0 & -216 & 71.0 & -357 & -85 & \\
\hline Equity & 25 & $75.6 \%$ & -185.4 & -183 & 89.8 & -359 & -32 & \\
\hline Mixed & 22 & $57.9 \%$ & -211.6 & -218 & 66.1 & -334 & -78 & \\
\hline \multicolumn{9}{|c|}{ BP Test } \\
\hline \multicolumn{9}{|c|}{ Acquirer-Target Covariance } \\
\hline Total & 58 & $36 \%$ & -128.9 & -96 & 127.7 & -341 & 101 & \\
\hline Pre-Announcement & 45 & $28.8 \%$ & -171.8 & -169 & 111.5 & -341 & -1 & \\
\hline Post-Announcement & 13 & $10.4 \%$ & 19.6 & 2 & 33.5 & 0 & 101 & \\
\hline \multicolumn{9}{|l|}{ Reaction-Breaks } \\
\hline Total & 13 & $10.4 \%$ & 19.6 & 2 & 33.5 & 0 & 101 & 1.71 \\
\hline Cash & 4 & $7.4 \%$ & 0.3 & 0 & 0.5 & 0 & 1 & \\
\hline Equity & 7 & $21.2 \%$ & 34.6 & 22 & 40.9 & 0 & 101 & \\
\hline Mixed & 2 & $5.3 \%$ & 6.0 & 6 & 5.7 & 2 & 10 & \\
\hline \multicolumn{9}{|c|}{ Payment-Form-Anticipation } \\
\hline Total & 23 & $18.4 \%$ & -178.6 & -169 & 116.5 & -341 & -1 & 0.28 \\
\hline Cash & 14 & $25.9 \%$ & -192.3 & -211 & 112.3 & -341 & -36 & \\
\hline Equity & 4 & $12.1 \%$ & -144.0 & -130 & 160.7 & -315 & -1 & \\
\hline Mixed & 5 & $13.2 \%$ & -167.8 & -99 & 110.9 & -314 & -73 & \\
\hline \multicolumn{9}{|c|}{ GW Test } \\
\hline \multicolumn{9}{|c|}{ Acquirer-Target Correlation } \\
\hline Total & 35 & $25.6 \%$ & -77.2 & -54 & 93.8 & -314 & 58 & \\
\hline Pre-Announcement & 22 & $16 \%$ & -126.0 & -116 & 85.9 & -314 & -7 & \\
\hline Post-Announcement & 13 & $10.4 \%$ & 5.5 & 0 & 16.0 & 0 & 58 & \\
\hline \multicolumn{9}{|l|}{ Reaction-Breaks } \\
\hline Total & 13 & $10.4 \%$ & 5.5 & 0 & 16.0 & 0 & 58 & 0.26 \\
\hline Cash & 0 & $0.0 \%$ & & & & & & \\
\hline Equity & 8 & $24.2 \%$ & 7.4 & 0 & 20.5 & 0 & 58 & \\
\hline Mixed & 5 & $13.2 \%$ & 2.6 & 1 & 4.2 & 0 & 10 & \\
\hline \multicolumn{9}{|c|}{ Payment-Form-Anticipation } \\
\hline Total & 15 & $12.0 \%$ & -83.2 & -90 & 55.9 & -212 & -7 & 0.80 \\
\hline Cash & 2 & $3.7 \%$ & -108.5 & -109 & 26.2 & -127 & -90 & \\
\hline Equity & 7 & $21.2 \%$ & -81.6 & -86 & 69.3 & -212 & -7 & \\
\hline Mixed & 6 & $15.8 \%$ & -76.7 & -81 & 50.3 & -134 & -16 & \\
\hline
\end{tabular}




\section{Appendix Table D.2}

\section{Summarized Results of Aue et al. Test applied across Various Samples of Bivariate Return Series}

This table summarizes the results of performing Aue et al. (2009) test for detecting multiple breaks in the variance-covariance structure (VCS) of bivariate return series across various samples: Full Raw (FR), Full Winsorized (FW), Restricted Raw (RR) and Restricted Winsorized (RW). The total sample consists of 125 completed acquisitions. The Pre-Announcement period is from Day-379 to Day-1 relative to the first bid announcement. The Post-Announcement period is from the day of first bid announcement through delisting of target shares. Each of 125 daily acquirer and target realized return series is adjusted for any breaks in the mean and non-zero mean in the $\boldsymbol{R a w}(\boldsymbol{R})$ sample. A $99 \%$ winsorization is applied for Winsorized (W) sample (see the caption of Table 2). The Full sample contains all returns during the sample observation period (i.e., both pre- and post-announcement periods) of each return series. The Restricted (R) sample considers only returns during the pre-announcement period of each return series. The Full sample (Total) splits to two subsamples: Pre-Announcement and PostAnnouncement periods. FW (Pre) represents the Pre-Announcement subsample of FW sample. Aue et al. (2009) test is applied separately across those four samples to detect the number and location of significant shifts in the VCS of each sample's 125 bivariate return series. The fraction of total 125 deals that has significant breaks at the conventional levels (1\% to 10\%) is reported in the Fraction of Total Deal column. The unpaired and the Welch's (1947) unequal variance options of $t$-test examine the difference in Average Break Date across samples (FR-FW and RW-FW (Pre)). Mean and Median difference between Number of Breaks per Deal across samples (FR-FW and RW-FW (Pre)) is tested via matched-pairs $t$-test and the Wilcoxon (1945) matched-pairs signed-ranked test, respectively. Two-sample proportion test, i.e., Z-test examines the equality of Fraction of Total Deals across samples (FR-FW and RW-FW (Pre)). All above tests are two-tailed tests. $* * *, * *$ and $*$ denotes statistical significant at the $1 \%, 5 \%$ and $10 \%$ level, respectively.

\begin{tabular}{|c|c|c|c|c|c|c|c|c|c|c|c|c|c|c|c|}
\hline \multirow[b]{3}{*}{ Samples } & \multirow{3}{*}{$\begin{array}{c}\text { Number } \\
\text { of } \\
\text { Breaks }\end{array}$} & \multirow{3}{*}{$\begin{array}{c}\text { Fraction } \\
\text { of Total } \\
\text { Deals } \\
\end{array}$} & \multirow{2}{*}{\multicolumn{5}{|c|}{$\begin{array}{l}\text { Distribution of Break Dates Relative } \\
\text { to the Announcement Day }(=0) \\
\end{array}$}} & \multicolumn{2}{|c|}{ Average Break Date } & \multicolumn{4}{|c|}{ Mean and Median Number of Breaks per Deal } & \multicolumn{2}{|c|}{ Fraction of Total Deals } \\
\hline & & & & & & & & \multirow{2}{*}{$\frac{\mathbf{F R}-\mathbf{F W}}{c t \text {-Stat. }}$} & \multirow{2}{*}{ 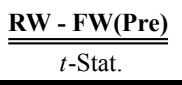 } & \multicolumn{2}{|r|}{ FR - FW } & \multicolumn{2}{|c|}{ RW - FW(Pre) } & \multirow{2}{*}{$\frac{\mathbf{F R}=\mathbf{F W}}{\underline{Z \text {-Stat. }}}$} & \multirow{2}{*}{$\underline{\mathbf{R W}=\mathbf{F W}(\mathbf{P r e})}$} \\
\hline & & & Mean & Median & Std. Dev. & Min & Max & & & $t$-Stat. & Sign-Rank Z-Stat. & $t$-Stat. & Sign-Rank Z-Stat. & & \\
\hline \multicolumn{16}{|l|}{ Full Raw (FR) } \\
\hline Total & 166 & $66.4 \%$ & -125.2 & -118 & 113.2 & -370 & 116 & -0.95 & & $-6.58 * * *$ & $-5.76 * * *$ & & & $-3.9 * * *$ & \\
\hline Pre-Announcement & 139 & $64.8 \%$ & -154.8 & -153 & 98.2 & -370 & -1 & -1.18 & & $-6.23 * * *$ & $-5.63 * * *$ & & & $-3.98 * * *$ & \\
\hline Post-Announcement & 27 & $15.2 \%$ & 27.6 & 10 & 34.5 & 0 & 116 & 0.43 & & $-2.23 * *$ & $-2.35 * *$ & & & -1.46 & \\
\hline \multicolumn{16}{|l|}{ Full Winsorized (FW) } \\
\hline Total & 235 & $87.2 \%$ & -114.4 & -106 & 111.0 & -360 & 116 & & & & & & & & \\
\hline Pre-Announcement & 196 & $86.4 \%$ & -141.9 & -139 & 99.9 & -360 & -1 & & & & & & & & \\
\hline Post-Announcement & 39 & $22.4 \%$ & 23.9 & 4 & 33.2 & 0 & 116 & & & & & & & & \\
\hline \multicolumn{16}{|l|}{ Restricted Raw (RR) } \\
\hline Total & 110 & $58.4 \%$ & -212.3 & -218 & 77.1 & -363 & -39 & & & & & & & & \\
\hline \multicolumn{16}{|l|}{ Restricted Winsorized (RW) } \\
\hline Total & 133 & $70.4 \%$ & -206.6 & -215 & 77.4 & -360 & -24 & & $-6.6 * * *$ & & & $-6.12 * * *$ & $-5.54 * * *$ & & $-3.07 * * *$ \\
\hline
\end{tabular}

